Portland State University

PDXScholar

\title{
An Exploration of Effective Community College Instructors' Use of Culturally Competent Pedagogies
}

Aylin Bunk

Portland State University

Follow this and additional works at: https://pdxscholar.library.pdx.edu/open_access_etds

Part of the Bilingual, Multilingual, and Multicultural Education Commons, and the Community College Leadership Commons

Let us know how access to this document benefits you.

\section{Recommended Citation}

Bunk, Aylin, "An Exploration of Effective Community College Instructors' Use of Culturally Competent Pedagogies" (2017). Dissertations and Theses. Paper 3481.

https://doi.org/10.15760/etd.5365

This Dissertation is brought to you for free and open access. It has been accepted for inclusion in Dissertations and Theses by an authorized administrator of PDXScholar. Please contact us if we can make this document more accessible: pdxscholar@pdx.edu. 
An Exploration of Effective Community College Instructors' Use of Culturally

Competent Pedagogies

by

Aylin Bunk

A dissertation submitted in partial fulfillment of the requirements for the degree of

Doctor of Education

in

Educational Leadership: Postsecondary Education

\author{
Dissertation Committee: \\ Becky Boesch, Chair \\ Cheryl Livneh \\ Andrew Job \\ Martha Hickey
}

Portland State University

2017 
(C) 2016 Aylin Bunk 


\begin{abstract}
Increasing diversity among community college students and the rising demand for a culturally competent workforce necessitate community college faculty across all disciplines to adjust their pedagogical choices to effectively serve diverse students while preparing all students for the new global era. The purpose of this narrative study was to explore what culturally competent pedagogies effective community college instructors use and reasons behind their choices. The study was conducted at a large community college in the Pacific Northwest. Data was collected through in-depth interviews with ten instructors teaching in different disciplines. In addition, the Intercultural Development Inventory (IDI) was used to measure participants' intercultural competency. The findings revealed that the participants were cognizant of the growing diversity in their classes and made a number of pedagogical choices to accommodate their students' needs. The findings also revealed that the participants' teaching in the Humanities and the Adult Basic Skills departments had more latitude in engaging diversity and choosing materials to fit the needs of their students compared to science and vocational field instructors.
\end{abstract}




\section{Dedication}

To my husband David and my daughter Soley. 


\section{Acknowledgements}

I would like to thank my husband, David, for being such a caring and supporting husband. Throughout our marriage, he has always supported me in my educational endeavors both in Turkey and in the U.S. Without him, never in my life would I think of immigrating the U.S. and see what opportunities this country offers. He never doubted my abilities to be successful and chose to be by my side in this long doctoral journey.

I also want to thank my seven-year old daughter Soley for coming to my life halfway through the program and giving me a new perspective of life. She still thinks that I will be able to fix her leg if she breaks it when I become a doctor.

I would like to thank my wonderful advisor Dr. Becky Boesch for accepting me as her advisee in a later stage of this dissertation and guiding me to the finish line. During this long process, she always motivated me and helped me to stay on course. I found myself confused by the data many times, and each and every time she provided incredible insights that I would never have thought of by myself. I truly appreciated her support, encouragement, and enthusiasm every time I walked into her office. I would also like to thank my committee members Dr. Cheryl Livneh, Dr. Andy Job, and Dr. Martha Hickey for their support. I would like to extend special thanks to my former advisor Cheyl Livneh for her continuous support, feedback and attention to detail.

I am indebted to Dr. Micki Caskey for her invaluable support during my years at PSU. I was very lucky to be her graduate assistant, which provided me with valuable office and life skills and introduced me to American culture in many ways that I would not have experienced otherwise. Dr. Caskey gracefully accepted me as her assistant even 
though I lacked skills in doing office-related work. She patiently guided me in learning the work and sent me to workshops to improve my skills. Without her constant support, guidance and mentorship, I would not be able to get through the most difficult years of the program. In addition to her support in the program, she also wrote wonderful recommendation letters for my job applications, which I am confident that helped secure my current full-time dream job.

I would like to thank my cohort member and friend Yoko Sakurauchi for being such a positive, supportive, and kind friend. Yoko is the reason why I have become interested in intercultural communication, which opened my horizon to whole another field.

Last but not least, I would like to thank my editor Jennifer Wells, Ed.D. for making it possible to complete this work. Without her help, I would not be able to find the motivation to keep going. 


\section{Table of Contents}

ABSTRACT

CHAPTER I INTRODUCTION .......................................................................................... 1

INCREASING DIVERSITY AMONG COMMUNITY COLLEGE STUDENT POPULATIONS............. 3

INTERCULTURALLY COMPETENT COLLEGE INSTRUCTORS .............................................. 4

The NeEd to AdaPt Programs for the Changing NeEdS of Students ................... 5

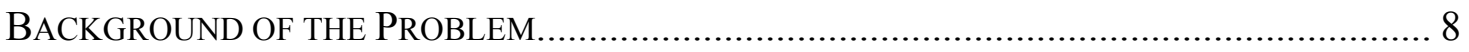

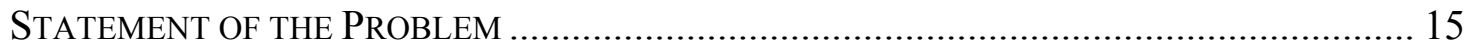

REASONS FOR ADAPTING InSTRUCTION To MEEt StUdENT NEEDS ……………............ 16

PURPOSE OF THE STUDY ………………………………........................................ 19

SUMMARY AND THE OUTLINE OF THE DISSERTATION ................................................... 20

CHAPTER II REVIEW OF THE LITERATURE.................................................... 22

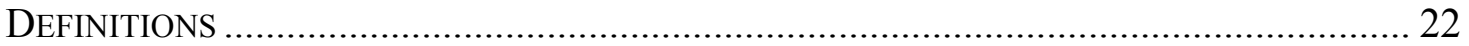

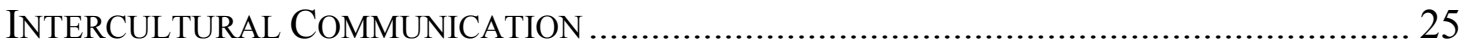

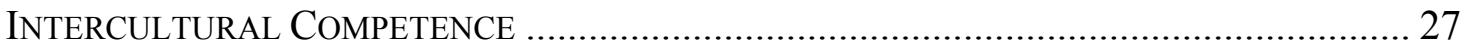

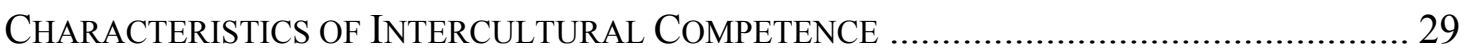

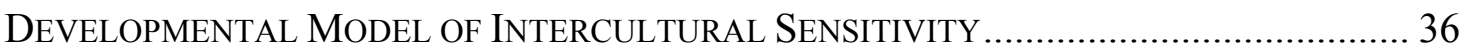

THE BENEFITS OF DIVERSITY TO STUDENT LEARNING.................................................. 46

THE NEED FOR INTERCULTURALLY COMPETENT FACULTY …………............................ 49

RESEARCH ON INTERCULTURAL COMPETENCE AND HIGHER EDUCATION FACULTY....... 51

BeSt Practice Teaching StRategies.................................................................. 57

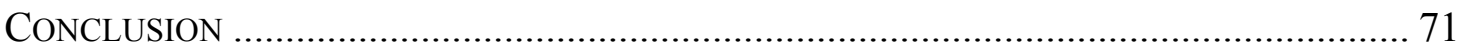

CHAPTER III METHODS .............................................................................................. 73

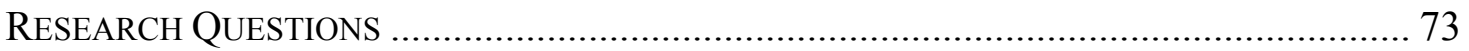

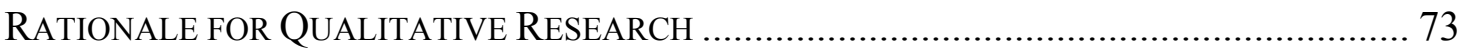

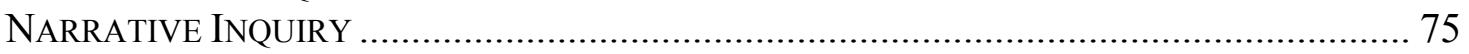

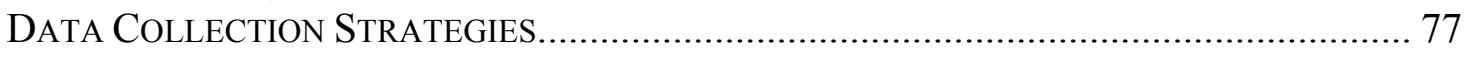

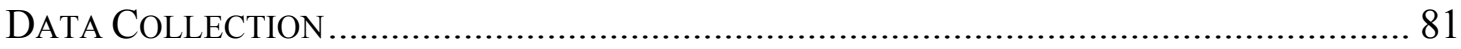

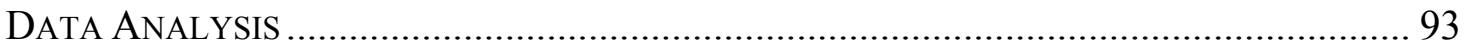

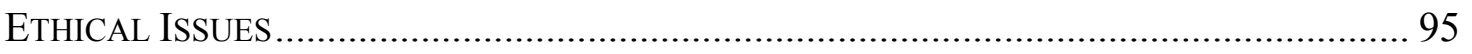

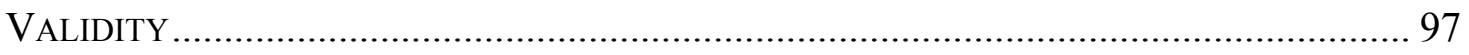

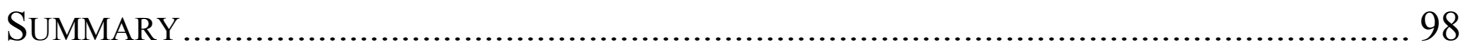

CHAPTER IV FINDINGS .............................................................100

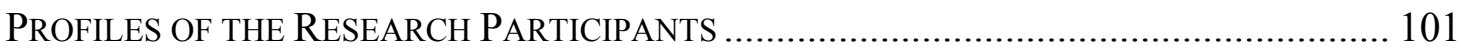

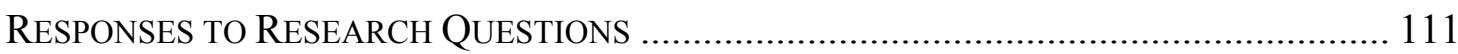

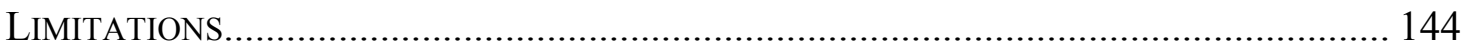

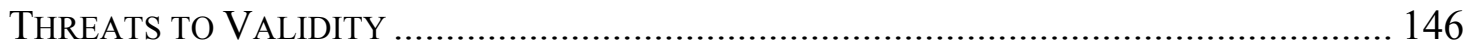




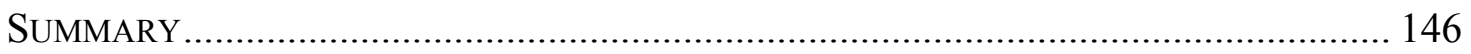

CHAPTER V DISCUSSION............................................................................. 151

MATERIAL SELECTION THAT REFLECTS DiVERSE WAYS OF KNOWING ...................... 151

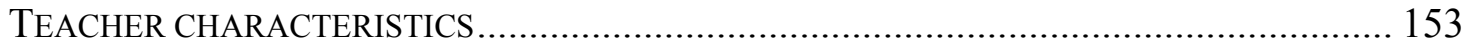

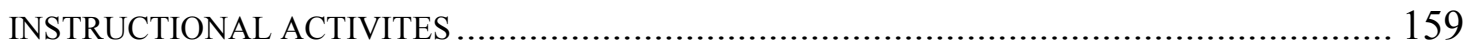

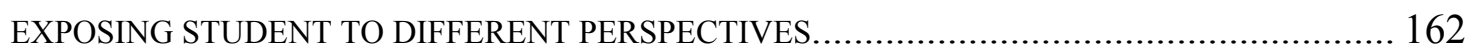

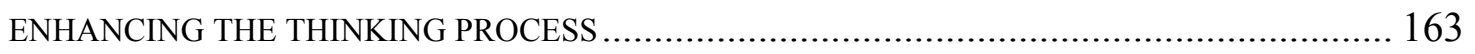

FACILITATING THE LEARNING PROCESS THROUGH BUILDING SELF CONFIDENCE........... 164

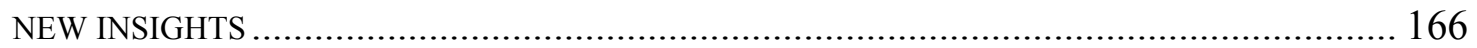

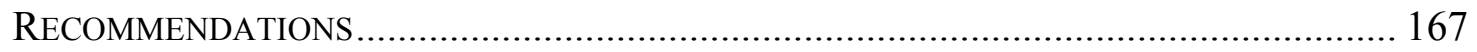

SUGGESTIONS FOR FUTURE RESEARCH ............................................................ 174

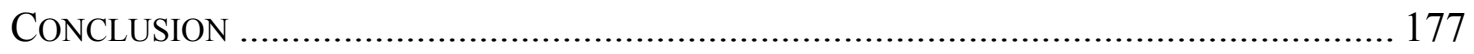

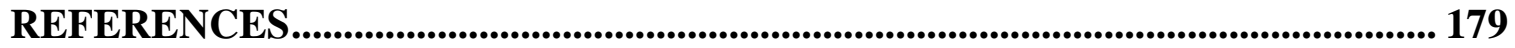

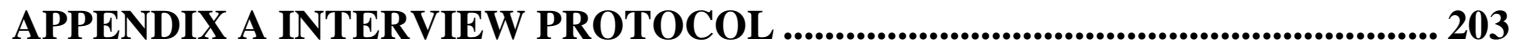

APPENDIX B STATEMENT OF INFORMED CONSENT ................................. 205 


\section{List of Tables}

Table

Page

1. Table 1. Population by Race and Hispanic Origin..............................2

2. Table 2. Participants' Demographic Information and the IDI Scores..................102

3. Table 3. Themes That Emerged in Response to the First Research Question........149

4. Table 4. Themes That Emerged in Response to the Second Research Question....150 


\section{List of Figures}

Figure $\quad$ Page

1. Figure 1. Deardorff's Process Model of Intercultural Competence...................34

2. Figure 2. Developmental Model of Intercultural Sensitivity.....................38 


\section{CHAPTER I}

\section{INTRODUCTION}

The world has become increasingly interdependent and interconnected as a result of communication technologies, migration of people both internationally and nationally, and emerging global economies (Association of American Colleges and Universities, 2007; Gacel-Avila, 2005). There is no doubt that the boundaries between peoples, cultures and countries are becoming less and less visible (Cohn \& Mullennix, 2007).

Domestically, increasing diversity in the U.S. population has led to a more multicultural and multilingual population. According to Gollnick and Chinn (2002), the U.S. currently consists of at least 276 ethnic groups; data from the 2010 U.S. census shows a dramatic growth in non-White populations in the past ten years while the white population has a relatively slow rate of growth (United States Census, 2010). The 2010 census showed that while the largest minority group in the nation remains AfricanAmericans, there is approximately a $43 \%$ growth in the Asian and Hispanic populations. Based on the 2010 census report and official estimates through 2013, the Census Bureau published a report in 2015 that projected a more diverse nation a half century from now. According to this report (Colby and Ortman, 2015), more than half of all Americans are projected to belong to a minority group by 2044 . They also projected that almost one in five of the nation's population would be foreign born. Meanwhile, the Hispanic population is projected to more than double, from 55.4 million in 2014 to 119 million in 2060. The black population is projected to increase from 42 million to 59.6 million over the same period. The Asian population is expected to be the second fastest growing 
group with an increase of 128 percent. American Indians and Alaska Natives are expected to increase from 6.9 million in 2014 to 10.1 million in 2060 . The same report indicates that the number of people who identify themselves as being of two or more races is projected to more than triple, from eight million to 26 million over the same period. Figure 1 compares percentages of population by race and Hispanic origin between 2014 and 2060 .

Population by Race and Hispanic Origin: 2014 and 2060 (Population in thousands)

\begin{tabular}{|c|c|c|c|c|c|c|}
\hline \multirow{2}{*}{ Race and Hispanic origin' } & \multicolumn{2}{|c|}{2014} & \multicolumn{2}{|c|}{2060} & \multicolumn{2}{|c|}{ Change, 2014 to 2060} \\
\hline & Number & Percent & Number & Percent & Number & Percent \\
\hline Total population...................... & 318,748 & 100.0 & 416,795 & 100.0 & 98,047 & 30.8 \\
\hline 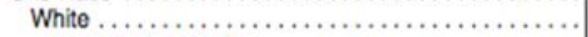 & 246,940 & 77.5 & 285,314 & 68.5 & 38,374 & 15.5 \\
\hline 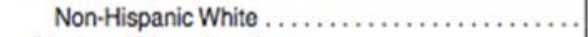 & 198,103 & 62.2 & 181,930 & 43.6 & $-16,174$ & -8.2 \\
\hline 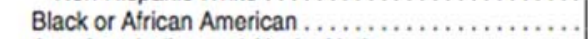 & 42,039 & 13.2 & 59,693 & 14.3 & 17,654 & 42.0 \\
\hline Native Hawaiian and Other Pacific Islander. ........ & 734 & 0.2 & 1,194 & 0.3 & 460 & 62.6 \\
\hline Two or More Races $\ldots \ldots \ldots \ldots \ldots \ldots \ldots \ldots \ldots \ldots \ldots \ldots \ldots \ldots$ & 7,995 & 2.5 & 26,022 & 6.2 & 18,027 & 225.5 \\
\hline \multicolumn{7}{|l|}{ Race Alone or in Combination ${ }^{2}$} \\
\hline 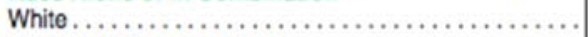 & 254,009 & 79.7 & 309,567 & 74.3 & 55,558 & 21.9 \\
\hline 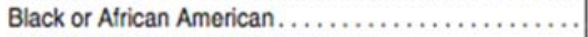 & 45,562 & 14.3 & 74,530 & 17.9 & 28,968 & 63.6 \\
\hline \multicolumn{7}{|l|}{ Hispanic or Latino Origin } \\
\hline Hispanic. .............. & 55,410 & 17.4 & 119,044 & 28.6 & 63,635 & 114.8 \\
\hline Not Hispanic . . . . . . . . . . . . . . . . . . . . . . & 263,338 & 82.6 & 297,750 & 71.4 & 34,412 & 13.1 \\
\hline
\end{tabular}

Table 1. Population by Race and Hispanic Origin: 2014 and 2060

The U.S. is projected to become a plurality nation by 2044, with no race or ethnic group representing more than a 50 percent share of the nation's total (Colby and Ortman, 2015). This rapidly increasing diversity of cultural and ethnic groups is also reflected on higher education campuses.

Indeed, the U.S. student demographics today are more diverse than ever before (Pascerella \& Terenzini, 2005). In addition to changes in the national population, the 
increasing number of immigrants and growing number of international students add to the increase of diversity on college campuses (Ignash, 2000; Rhoads \& Valadez, 1997).

These aforementioned globalization and population trends require that today's college graduates be aware of diversity and be culturally competent both in the workplace and the community (Cohn \& Mullennix, 2007). The ability to interact successfully with diverse others, whether they are from another country or another ethnic, religious, or cultural group, is a necessary skill in this new global marketplace (Levin, 2002).

Similarly Fantini (2000) stated "from the arena of international business to the intimacy of family life, there is an increasing need to be able to deal effectively and appropriately with diversity, whether ethnic, racial, religious or cultural" (p. 26). Accordingly, intercultural skills, which are some of the mostly desired $21^{\text {st }}$ century skills, are the sine qua non for being successful at navigating the complex life and work environment in the globally competitive and culturally diverse market (Cohn \& Mullennix, 2007; Emert \& Pearson, 2007; Gacel-Avila, 2005; Guerin, 2009; Levin, 2002; Martin \& Nakayama, 2009; Sanderson, 2011).

\section{Increasing Diversity among Community College Student Populations}

Open access policies and the affordability of community colleges make postsecondary education accessible to all students, which often makes them the first choice of diverse populations. As a result, low-income citizens, minorities from different ethnic and cultural backgrounds, and immigrants make up a considerable portion of community college student demographics (Harbour \& Ebie, 2011; Koltai, 1993; Moore, 2006; Nevarez \& Wood, 2010). 
According to the American Association of Community Colleges (AACC) 2012 report, the diversity of student enrollment has increased dramatically in the past two decades. Students from diverse backgrounds minorities comprise $45 \%$ of the student population in community colleges nationwide. In urban community colleges, minority student enrollment is often more than 50\% (Coley, 2000). According to AACC (2012), community college enrollment has exceeded that of four-year institutions. Moreover, in community colleges overall, minority enrollment grew by $48 \%$ between 1990 and 2000 . Lavin (2000) stated that the lack of affirmative action policies in four-year public institutions have decreased enrollment numbers of historically underrepresented groups, causing the enrollment numbers of these groups to dramatically increase in community colleges. Indeed, the National Center for Education Statistics (2008) reported that in 2005 ethnic minority percentages in community colleges were $37 \%$, which were greater than that of in four year public institutions (28\%) and private four-year institutions $(27 \%)$. As a result, a large number of cultural groups and sub-groups make up a large portion of the student body in community colleges today.

\section{Interculturally Competent College Instructors}

Increasing diversity among students and the rising demand for an interculturally competent workforce is impacting the requirement that college instructors themselves be interculturally competent. College faculty today must possess new skills and qualities that will help them to effectively prepare a growing number of diverse students for the new global era. 
More culturally competent higher education faculty means more supportive and successful learning environments for all students. Therefore, it is necessary for faculty to examine their own assumptions and roles in multicultural classrooms and carefully reflect on how they convey the importance of intercultural competence to their students (Scisney-Matlock \& Matlock, 2001). Higher education faculty must know and model culturally appropriate knowledge, behaviors and attitudes when they interact both in and outside of the classroom.

Stoll (1995) stated that community colleges philosophically strive to meet diverse student needs; "history demonstrates their ability to change faster than any other type of collegiate institution; and student diversity is greater at community colleges than at all other types of higher education institutions" (p.13). In short, because of the composition of the community college student body, community college faculty and students find themselves in contact with people from different backgrounds. These changes in student demographics make possessing intercultural competence skills essential to manage differences among students in the classroom "flexibly and mindfully" (Ting-Toomey, 1999, p. 3).

\section{The Need to Adapt Programs for the Changing Needs of Students}

In response to the changes brought by increasing diversity on community college campuses, the American Council of Education (1995) called for action to change the way colleges and universities educate students and include intercultural competence in students' educational experience. Given the rich diversity on campuses and community colleges' "adaptability, cutting edge innovations, and responsiveness to community 
needs" (Mendoza, Basham, Campbell, O’Daniels, Malcom, \& Felton, 2009, p. 867), community colleges are well suited for the development of intercultural competence skills.

However, according to a study conducted by Bikson and Law (1994), corporations are skeptical about higher education institutions' ability to foster intercultural competence skills in their students only through their foreign language or study abroad programs. The same study revealed that college students in the U.S. tend to be more culturally insulated as compared to students elsewhere, therefore, it is difficult for them to develop intercultural skills.

Indeed, while community colleges strive to best serve their student body, in many cases, faculty members may not possess the diversity, new skills and qualities necessary to teach an ever-increasing diverse student population. According to Quaye and Harper (2007), many faculty fail to include multicultural perspectives in their classroom materials and discussions. Consequently, minority students often find it difficult to relate to classroom materials and topics.

To make matters worse, faculty are not held accountable for not teaching in culturally inclusive ways creating classroom experiences that will enhance students' learning experiences about cultural differences. One of the reasons for this may be because many instructors do not necessarily begin their careers with a specific goal to teach, but rather they choose later in life to teach within community college settings (Twombly \& Townsend, 2008). Even though most faculty members hold master's degrees, with the exception of occupational program faculty who typically possess only 
baccalaureate degrees and job-related experience, community college instructors are often hired with no or minimum academic preparation in terms of teaching and learning (Twombly \& Townsend, 2008).

Quaye and Harper (2007) stated that many faculty members teach in culturally neutral ways because often times they have not received training to search for and "infuse diverse readings and pedagogical methods into their courses. Most of the professors they had as graduate students did not model an appreciation for multiculturalism, emphasize cultural inclusiveness in their socialization efforts, or engage in culturally empowering pedagogical practices" (p. 36).

Another reason why faculty avoid capitalizing on classroom diversity to enhance student learning is that it is easier to ignore diversity than acknowledge it (Quaye \& Harper, 2007). According to Quaye and Harper (2007), most professors prefer to ignore the culturally rooted contributions that students from diverse backgrounds have to offer and expect all students to understand and operate within the boundaries of mainstream culture. They suggested that it may be precisely because many faculty believe that changing instructional practices to reflect diverse viewpoints in class will eventually result in conflict between students, instructors frequently chose to restrict their choices to mainstream, "heteronormative content and knowledge that is already dominant" (Quaye \& Harper, 2007, p. 36).

Instructors across all subjects must respond to the new realities of teaching in the twenty-first century and diverse classrooms and adjust their curricula and teaching practices to respect and include cultural differences (Armstrong, 2011; Lee, Poch, Shaw, 
\& Williams, 2012; Quaye and Harper, 2007; Townsend, 2000). Unfortunately, research on intercultural competence of community college instructors and how they demonstrate their competence in pedagogical practices in serving their culturally diverse students and fostering intercultural competence is scarce. This study contributes towards work to address this significant gap in the literature through an examination of the level of intercultural competence found among effective community college faculty in a community college and how they perceive that competence is reflected in their instructional practices.

\section{Background of the Problem}

In his New York Times best seller, The World is Flat, Thomas Friedman (2007) described the world as a place where people are more interdependent and interconnected than ever before on a global scale. This new reality has significantly affected people's activities, including their educational experiences. Friedman described the new era of globalization as Globalization 3.0, a period in human history, which is different from the previous eras not only in terms of how globalization essentially shrinks the world, but also in how it empowers individuals and businesses in every part of the world to interact more fully across traditional boundaries than was possible in the past.

Friedman (2007) argued that the individuals operating within this new context of globalization are going to be "a much more diverse — non-Western, non-White — group of individuals... Globalization 3.0 makes it possible for so many people to plug in and play and you are going to see every color of the human rainbow take part" (p. 11). In the same vein, Legrain (2004) stated, "our lives are becoming increasingly intertwined with 
those of distant people and places around the world - economically, politically, and culturally" (p. 4).

As a result, in addition to being competent in their chosen academic disciplines, college graduates today have to be globally competent citizens who are life-long learners and who are aware of cultural diversity so that they can "recognize global interdependence, be capable of working in various environments, and accept responsibility for world citizenship" (Spaulding, Mauch, \& Lin, 2001, p. 190). Echoing Spaulding and colleagues, Stewart (2007) added that globally and culturally competent citizens need more skills than just being competent in basic subjects such as math, science, and technologies. Rather they need to know about the world beyond their own particular disciplines and culture and learn to speak a language other than their native language.

In this new century, it will be increasingly important to be able to recognize and accommodate cultural differences, and it will be equally important to leverage these differences creatively to produce ideas and solutions to problems (Thrilling \& Fadel, 2009). When twenty of the best-known American companies in the Fortune 500 filed a legal brief supporting University of Michigan in a lawsuit about its admission policies (University of Michigan, 2000), they argued that:

...managers and employees who graduated from institutions with diverse student bodies are better prepared to understand, learn from and collaborate with others from a variety of racial, ethnic and cultural backgrounds; demonstrate creative problem solving by integrating differing perspectives; exhibit the skills required 
for good teamwork; and demonstrate more effective responsiveness to the needs of all types of consumers (p.7).

In response to these national and international changes, higher education institutions, including community colleges, must provide an education that fosters intercultural competence as a student outcome and provide instruction that supports diverse students' learning (Knight, 2007; Schuerholz-Lehr, 2007). In recognition of this societal imperative, many U.S. institutions of higher education, including community colleges, are striving to diversify their student body and celebrate the ideals of multiculturalism. These institutions recognize the importance of preparing their graduates for an increasingly interdependent, diverse world where individuals will have to work and live with others from different cultural backgrounds (Helms, 2003).

In fact, the Association of American Colleges and Universities (2007) recommended intercultural knowledge and competence as essential learning outcomes that are "important for all students and should be fostered and developed across the entire educational experience, and in the context of students' major fields" (p. 2). According to Anderson (2008), "the readiness of a college or university to confront its $21^{\text {st }}$ century responsibilities is directly correlated with the degree to which it has embedded diversity and globalism concerns into the basic philosophy and infrastructure of the institutions" (p. 1).

Based on this stance, many community colleges have already begun to modify their mission statements to emphasize inclusiveness of different cultures and awareness of global movements and economies (Levin, 2002; Zeszotarski, 2001). Acknowledging 
the need to produce interculturally competent graduates, colleges have begun including intercultural competence as an explicit programmatic learning outcome. Although institutions are unsure as to exactly how to successfully develop intercultural competence in students (Bok, 2006; Cohen \& Brawer, 2008), many colleges have been employing various strategies to achieve this goal.

For example, some of the ways that colleges are approaching this goal is to make efforts to internationalize their campuses by developing programs explicitly aimed at recruiting international students and faculty. Colleges are increasingly designing study abroad programs and providing extracurricular activities to promote greater global competency (Boggs \& Irwin, 2007; Raby, 2007). According to Laird, Engberg, and Hurtado (2005), such programs create contexts for students where they can interact with and learn about diverse peoples and worldviews. They argue that this exposure helps students to "learn the knowledge and skills necessary to function effectively in our increasingly diverse and complex society" (p. 448).

For many students, community college may be the only places where they will experience formal post-secondary level education. They may also be the only places where students will be exposed to multicultural perspectives. Therefore, it is important that community colleges prepare all students, whether they will work in their local environment or in an international setting, to manage the complexities of a multicultural society and globalized market (Green, 2007; Sanderson, 2011; Stearns, 2009).

Intercultural competence is also important in terms of responding to the needs of culturally diverse classrooms in order to promote successful and effective learning for 
students. Given the fact that classrooms today are more diverse than ever, faculty will be interacting with more students from diverse backgrounds (Marin, 2000); therefore, instructors who possess intercultural competence are crucial and necessary for student learning.

In addition to efforts outside the classroom to foster the development of intercultural competence among students, college classrooms are also important locations for students' engagement with diversity as they offer a multitude of opportunities for students to interact across differences because they learn how to manage differences when working with diverse groups (Laird, et al., 2005).

Colleges are increasingly offering classes about diversity as well as adapting instruction to meet the needs of students. As Ayers, Wheeler, Fracasso, Galupo, Rabin, and Slater (1999) commented, "promoting diversity across the curriculum subtly alters the university, enhancing the development of empathy, caring, and social skills among its students by inviting them to acknowledge, embrace, and work with differences among people" (p. 163).

Ortiz (2000) argued that the ability to take the perspective of culturally different others leads to the development of intercultural competence. She describes interculturally competent students as critical thinkers. They suspend judgment until they obtain evidence upon which to make decisions and interpret situations; they are selfaware and have the ability to manage difficult situations that have arisen from cultural differences. In keeping with Ortiz's perspective, Bennett (2009) stated that intercultural competence is "most often viewed as a set of cognitive, affective, and behavioral skills 
and characteristics that support effective and appropriate interaction in a variety of cultural contexts" (p. 97).

Accordingly, instructors play a crucial role in creating learning environments that promote interaction with diverse others and stimulate active thinking skills (Hurtado, 2007). Spanier (2001) stated that "as the primary point of educational contact with students, faculty have a particularly important role to play in retention efforts, and more specifically, in creating an environment in which all members of a diverse academic community can learn from one another" (p. 111).

Designing learning environments that will include different ways of knowing and teaching will promote student success and satisfaction as well as help students to succeed in diverse fields (Clayton-Pederson, Parker, Smith, \& Teraguchi, 2007). Barnett (2011) claimed "college instructors in every discipline are uniquely positioned to design learning that enables students to learn from each other. Facilitating discussions with diverse students allows them to broaden their horizons, and view the world, academic disciplines and themselves through new, even challenging lenses" (p. 674). Similarly, Quaye and Harper (2007) stated that "when faculty interweave multicultural perspectives into classroom discourse, students can challenge preconceived notions and learn about the unique knowledge that their peers of diverse backgrounds hold and bring to the classroom" (p. 34).

Although made in relation to K-12 educators, Banks' statement on the necessity of interculturally competent teachers is true for teachers in any educational setting. Banks (2001) argued "it is the teachers who must develop reflective cultural, national and 
global identifications themselves if they are to help students become thoughtful, caring and reflective citizens in a multicultural society" (p. 5).

In order to respond to diverse students' needs, instructors themselves need to develop cognitive, affective, and behavioral dimensions of intercultural competence. According to Cushner, McClelland, and Stafford (2009), interculturally competent educators have the ability "to solve problems and take appropriate risks, shift their frame of reference as required, recognize and respond appropriately to cultural differences, listen emphatically, perceive others accurately, maintain a nonjudgmental approach to communication, and gather appropriate information about another culture" (p. 151).

Ting-Toomey (1999) added that intercultural competence is a skill that enables educators to manage differences "flexibly and mindfully" (p. 3). Furthermore, if faculty know about and are responsive to their students' linguistic and cultural backgrounds, they positively contribute to their academic achievement and retention rates (Hogan, 2008; Kanu, 2007; Sleeter, 2001) as well as setting the "intellectual and behavioral norms on most campuses" (Rankin \& Reason, 2005, p. 58), and contribute to the overall cultural competence of the college climate.

Interculturally competent higher education faculty are important in creating successful learning environments that promote intercultural competence as well as maximize student success. It is arguably even more important for community college faculty to be interculturally competent considering the more diverse student body they interact with on a regular basis. Again, community colleges are entry points to the U.S. higher education system for many students, and they attract students from diverse cultural 
backgrounds more so than four-year higher education institutions. In fact, the number of students who herald from different ethnic and cultural backgrounds, including recent immigrants, make up a considerable portion of community college student demographics (Harbour \& Ebie, 2011; Koltai, 1993; Moore, 2006; Nevarez \& Wood, 2010).

\section{Statement of the Problem}

Community colleges have an important role in preparing students to live in an increasingly interdependent, global, and diverse society. Students must become interculturally competent to prepare to enter the workforce and succeed in the global market and diverse societies (Knight, 2007). Therefore, in addition to their expertise in the subject matter that they teach, faculty need to possess intercultural skills necessary to foster the development of culturally appropriate skills in students. Furthermore, faculty need to be interculturally competent in order to respond to their culturally and linguistically diverse students' needs and provide culturally appropriate and responsive educational opportunities for them (Fueyo, 1999; Gay, 2000). As faculty develop more intercultural competence themselves, they can guide their students toward being interculturally competent (Deardorff, 2009a) as well as providing culturally responsive teaching practices.

Although there is an abundance of evidence that student learning is enhanced by diversity in the learning environment, many college instructors continue teaching without adjusting their instructional practices to meet the needs of the diversity of students in their classes (Garcia \& Smith, 1996; Quaye \& Harper, 2007). According to Anderson (2008): 
In the college classroom, diverse backgrounds, skill levels, perspectives, and worldviews have become the norm and not the exception. The challenge for instructors is to recognize the needs and rights of contextual learners, and to create equitable learning environments that allow them to find their place in the academy. (p. 81)

Instructors must use pedagogical strategies that will promote students' ability to engage with diverse others in constructive ways. Wallace (2000) argued that the increased diversity and growing interaction between people with culturally diverse backgrounds necessitates that faculty have cultural knowledge, skills and attitudes, such as respect for others and suspending judgement in order to understand and engage constructively with their students.

Bok (2006) claimed that faculty in higher education institutions do not put enough emphasis on pedagogy, but are more involved in discussing which courses should be taught rather than discussing best pedagogical approaches to teach a particular course in order to achieve educational goals. Bok maintained that most often, faculty members are reluctant to modify their traditional ways of teaching and learn new skills.

\section{Reasons for Adapting Instruction to Meet Student Needs}

Anderson (2008) offered two reasons why faculty may not be ready or motivated to recognize the value in changing their curricular and pedagogical practices: they may simply not be aware of best practices or they may not have built a commitment to adapting instructional practices to meet the needs of their diverse students. Quaye and Harper (2007) posited that a reason for this lack of readiness to adapt teaching practices 
may be that faculty are not trained in changing their pedagogical methods to accommodate diverse learners. They added that most faculty, in their graduate years, have not had professors who modeled appreciation of diversity, emphasized inclusive teaching methods, and engaged in culturally appropriate pedagogical practices. As a result, many instructors enter their own classes emulating their former professors instructional strategies based on this tacit, unexamined stance towards teaching and learning.

The capacity for faculty to engage diverse learners within classroom depend on several core factors, such as intention, awareness, knowledge and skills developed over time (Lee, Poch, Shaw, \& Williams, 2012). According to Helms (2003), professional development support for higher education faculty members to develop these cultural competency skills is not treated as a priority. However, a study conducted by Eddy (2007), showed that one of the top three challenges facing community college faculty, especially those teaching in urban colleges, was dealing with multicultural issues and changing student demographics. Despite this tremendous pressure, the lack of professional development support in this area is not surprising according to Twombly \& Townsend (2008) who stated that in many cases, possessing some teaching experience or showing the capacity to become a good teacher and ability to work harmoniously with the college mission are enough reasons to be hired as an instructor.

According to Grubb and Associates (1999), community colleges claim to be concerned about teaching and learning when in fact many colleges seem to have no instructional commitment for ongoing professional development related to pedagogy and 
specifically, adaptive teaching practices. Unfortunately, according to a study Murray (2001) conducted, community colleges tend to provide seemingly random professional development opportunities for their faculty, many of which lack a readily apparent purpose related to specific learning outcomes.

Notwithstanding, regardless of whether sporadic professional development is made available to community college faculty members, intercultural competence is not easy to attain in a short period of time by attending workshops. Anderson (2008) proposed "faculty can benefit from a well-designed and supported, comprehensive, and systematic initiative" (p. 85). However, despite calls for well-conceived, comprehensive support, Cohen and Brawer's (2003) findings support Murray's conclusion in that community colleges do not choose to use professional development to train their faculty, but rather employ people who they think have adequate training, and offer professional development only when they feel it is necessary.

On the other hand, in her literature review, Schuerholz-Lehr (2007) found that even though a range of studies have been conducted examining the impact of various factors on the level of instructors' intercultural competence, none of these studies were able to link the level of intercultural competence in faculty back to their classroom practices (e.g. Grant and Sleeter, 1985; Johnson and Inoue, 2003, as cited in SchuerholzLehr, 2007). Indeed, studies that examine the impacts of intercultural competence among higher education faculty on teaching and learning in any context has been very limited overall. According to Schuerholz-Lehr (2007), it is still an important debate about how levels of intercultural competence "translate or fail to translate into more culturally 
sensitive and interculturally appropriate teaching approach" (p.188), in higher education settings.

Despite increasing recognition of the need for higher education faculty to be interculturally competent, little research has been undertaken that examines how higher education faculty, especially in community colleges, have responded to the changes in the demographics of the classroom both pedagogically and professionally. In fact, this researcher could not locate any studies that explored classroom practices of instructors in higher education, let alone community college education. This area clearly needs further research. Therefore, additional research may potentially influence the choices community college faculty make regarding professional development, expanding it from field specific professional development to more inclusive, culturally competent instructional practices. Furthermore, this research may also impact professional development planning for faculty at the institutional level.

\section{Purpose of the Study}

Community colleges should strive to adequately prepare their students to successfully participate and function in the twenty-first century. Having interculturally competent faculty is a key factor in serving a diverse student population more effectively and supporting the development of interculturally competent students. The primary purpose of this study was to explore the pedagogical choices of ten community college faculty members made regarding diversity in their classes. The research questions that frame this research are: 
1. What specific culturally competent pedagogies do effective community college instructors use?

2. What motivates these effective community college instructors to use these culturally competent pedagogies?

For the purpose of this research study, the term effective instructor is defined as professors who are acknowledged by peers and students for facilitating student learning with instructional methods and materials, having a good rapport, having knowledge in the subject matter they teach, and exhibiting professional skills. Detailed information about the selection process of these effective instructors will be provided in Chapter three.

\section{Summary and the Outline of the Dissertation}

Community colleges have the responsibility of preparing their students for the increasingly globalized world and job market, which demand that graduates to be interculturally competent. In addition, community colleges today are experiencing dramatic changes in the demographics of their student bodies; community college students are more diverse than ever. All of these changes necessitate highly effective faculty who are able to successfully engage diversity and, at the same, time instill intercultural competence in all students. However, to be able to teach for diversity and promote intercultural competence among students, faculty themselves need to be interculturally competent and have the ability to adjust their instructional practices to achieve desired learning outcomes.

This dissertation is comprised of five chapters. Chapter one introduced the current situation regarding the demographic changes higher education settings in the 
U.S., focusing especially on community colleges and the need for culturally competent faculty. The problem statement section discussed lack of use of culturally competent pedagogies in college classrooms and reasons why faculty needed to use these pedagogies in order to support diverse students' learning. Chapter two will present a brief review of theories related to intercultural competence and discuss literature that examines benefits of diversity and need for culturally competent faculty as well as best practices for teaching diverse learners.

Chapter three describes the methodology used in this study. It describes the qualitative research design and narrative inquiry approach used in this study, the role of the researcher, research site, and the data analysis methods employed.

Chapter four presents the findings from the data analysis, including the themes that emerged from the data. It also introduces the participants' profiles and limitations of the study.

Chapter five presents further analysis and interpretation of the findings in relationship to the literature described in chapter two. The chapter will discuss the implication of the findings as they relate to community colleges as institutions and to individual faculty members, as well as provide suggestions for further research.

The following chapter two will present a literature review of intercultural theories, benefits of diversity and the need for interculturally competent instructors. It will also present best practices regarding culturally competent instructional practices. 


\section{CHAPTER II}

\section{REVIEW OF THE LITERATURE}

This section will review key relevant theories on intercultural competence and what makes an individual an interculturally competent person. The chapter will provide examples from the literature of effective teaching practices in diverse classrooms. However, before examining what intercultural competence is and how it appears in a teaching and learning environment, it is important to establish a strong understanding of what culture is, especially from the perspective of intercultural communication.

\section{Definitions}

Culture provides a framework that people can use as a reference to make sense of their environment, which can make them feel more comfortable with who they are (McDaniel, Samovar, \& Porter, 2012). Culture is not a static phenomenon; culture is constantly changing in relation to the world in which we live. What may have been true hundreds of years ago for one society, may not hold true today. In fact, any specific cultural characteristic that defines a particular group may eventually change with time (Singer, 1987). Importantly, Bennett (1998) stated that "cultures are different in their languages, behavior patterns, and values. So an attempt to use one's self as a predictor of shared assumptions and responses to messages is unlikely to work"(p. 3).

Kroeber and Kluckhohn (1952) identified more than 164 definitions of culture across disciplines. In their work, the researchers characterized each group with an outline of the different analytical emphases on distinct definitions and aspects of culture. They 
categorized definitions into six groups: descriptive, historical, normative, psychological, structural, and genetic groups.

Fifty years later, in his survey of concepts of culture across disciplines, Dorjee (2002) found that there were several recurring themes across the disciplines of anthropology, sociology, psychology, and communication such as word patterns, symbols, beliefs, meanings, and values. Dorjee explained that these characteristics of culture create a conceptual map for people that is learned and shared by the society.

A brief look at the definitions of leading communication scholars reveals that the above-mentioned recurrent concepts appear consistently in the definitions offered by leading scholars in the field of communication. For example, Singer (1987) defined culture as "a pattern of learned, group-related perceptions-including both verbal and nonverbal language, attitudes, values, belief systems, disbelief systems, and behaviorsthat is accepted and expected by an identity group" (p. 6).

Two leading communications scholars, Kim and Ruben (1992), defined culture as "the collective life patterns shared by people in social groups such as national, racial, ethnic, socioeconomic, regional, and gender groups (p. 404). Similarly, Hofstede (2012) defined culture as "the collective programming of the mind that distinguishes the members of one group or category of people from another" (p. 20). He believed that culture provides people with varying degrees of freedom to think, feel and act, but only within the limits of the social environment in which they live in.

The following definition offered by Ting-Toomey and Chung (2005) encapsulates all of the definitions above. According to Ting-Toomey and Chung, culture is "a learned 
meaning system that consists of patterns of traditions, beliefs, values, norms, meanings, and symbols that are passed on from one generation to the next and are shared to varying degrees by interacting members of a community" (p. 28).

The definitions that have been described in the chapter thus far suggest that there is some degree of general agreement on the definition of culture. At its root, the construct known as culture is perceived of as a shared knowledge system by the members of a society, which, provide guidelines that enable members to act appropriately in particular social situations.

However, culture is too diffuse a concept to be explained by a few broad definitions. It is in fact, a highly multidimensional construct. For example, Bennett (1998) mentioned two aspects of culture. The first one is culture with a capital $C$, which refers to things like art, literature, music, and dance. This aspect of culture is also known as objective culture. The second aspect of culture is one with a small " $c$ ", which is known as subjective culture. This second aspect of culture pertains to perceptions such as values, beliefs, and patterns of thinking. It is not as external as objective culture. It is less visible and tangible, and therefore, more difficult to define.

In the same vein, Hofstede (2012) noted a distinction between culture one and culture two. What Hofstede refers to as culture one is "civilization or refinement of the mind and in particular the results of such refinement, like education, art, and literature" (p.235). He describes this definition as defining "culture in a narrow sense" (p. 235). Hofstede believes that culture two is a type of "mental software" which is "usually unconscious conditioning which leaves individuals considerable freedom to think, feel, 
and act but within the constraints of what his or her social environment offers in terms of possible thoughts, feelings, and actions" (p. 235). Although objective culture can easily be learned, subjective culture is not as easy to learn because it deals with the psychological and less obvious aspects of culture (Brooks, 1997; Cushner \& Brislin, 1996).

\section{Intercultural Communication}

The idea of understanding cultural differences for successful communication is one of the key concepts of intercultural communication (M. J. Bennett, 1998). In his seminal work, Silent Language, Edward Hall (1959) introduced an extensive analysis of how culture shapes the way people communicate. Hall asserted that the way we communicate is influenced by our culture and our culture exhibits itself in the way we communicate. Therefore, members of the same or similar cultures communicate with ease as they share a sense of values, worldviews and beliefs.

As Gudykunst and Kim (1992) explained, in order for people to communicate successfully, they need to share a similar meaning system. Thus, in order to be able to communicate effectively with people from different cultures, people need to be aware of different value systems, beliefs, traditions, and cultural norms.

However, people are often not even aware of their own cultural norms. As Hall (1959) expressed, "culture hides much more than it reveals, and strangely enough what it hides, it hides most effectively from its own participants" (p. 53).

Similarly, Condon (1986) said that people are not generally cognizant of the fact that their own culture has shaped their normality until they interact with people from 
another culture who do not share their sense of normality and who violate their norms. Condon argued that people who belong to the same culture typically understand how to “act appropriately in any given situation" (p. 13). He claimed that the problem begins when people encounter people from other cultures, because they judge others against their own cultural values and norms (Condon, 1986; Ting-Toomey \& Chung, 2005).

Because of this tendency to misinterpret behavior based on conflicting cultural norms, building intercultural competence is crucial in order to avoid conflicts and other forms of misunderstandings that can arise from cultural differences. However, before exploring the construct known as intercultural competence, it is helpful to review some relevant definitions of intercultural communication.

The idea of understanding cultural differences for successful communication is one of the key concepts of intercultural communication (Bennett, 1998). However, the term intercultural communication itself is defined differently by various scholars. TingToomey and Chong (2005) defined it as "the symbolic exchange process whereby individuals from two (or more) different cultural communities negotiate shared meanings in an interactive situation" (p. 39). Similarly, Bennett (1986) defined intercultural communication as the study of communication processes between people from significantly different cultural backgrounds.

Many scholars assert intercultural communication focuses on face-to-face interactions between people from different cultural backgrounds (Bennett, 1998; Kim, 1992; Kim \& Ruben, 1992). From this perspective, it would be true to say that understanding subjective culture is crucial for successful intercultural communication as 
subjective culture influences behavior regarding communication and is important for developing intercultural competence.

\section{Intercultural Competence}

An initial review of literature reveals that intercultural competence has been

defined by many scholars across various disciplines. Fantini (2009) lists a multitude of terms used interchangeably for intercultural competence such as "biculturalism, multiculturalism, bilingualism, multilingualism, pluralingualism, communicative competence, cross-cultural adaptation, cross-cultural awareness, cross-cultural communication, cultural competence, cultural or intercultural sensitivity, effective intergroup communication, ethnorelativity, intercultural cooperation, global competitive intelligence, global competence, international competence, international communication, intercultural interaction, metaphoric competence, and transcultural communication" ( $p$. 457). Similarly, many of these terms appear in Deardorff's (2004) study that was conducted to determine the definitions and concepts of intercultural competence. According to Kim and Ruben (1992), the term intercultural is more suitable for use than other terms because it is "more general and inclusive than other terms without implying any specific cultural attributes" (p. 410). After reviewing the literature, it can be seen that two widely used, interchangeable terms are intercultural competence and intercultural communicative competence. The preference for the use of one term over another appears to be based upon the background and specific disciplines of the scholars rather than a significant difference in the connotation of the terms. 
In contrast, there does not seem to be a consensus on what makes a person interculturally competent or how a person develops intercultural competence. Many earlier descriptions of intercultural competence emphasized personal traits and behaviors, such as the ability to deal with psychological stress, communicate effectively, and establish interpersonal relationships (Hammer, Gudykunst, \& Wiseman, 1978), and social skills and relations (Brislin, 1981). Some authors included personal knowledge, attitude and behaviors (Spitzberg \& Cupach, 1984), and personal and individual sensitivity (Bennett, 1986).

Ting-Toomey (1993) explored intercultural competence from an identity negotiation point of view, arguing resourcefulness is a personal trait that enables people to communicate successfully. Later, she built on this concept developing the identity negotiation theory, adding the concept of mindfulness is "a learned process of 'cognitive focusing' with repeated skillful practice" (Ting-Toomey, 1999).

Based on the data collected from twenty-three intercultural experts through a Delphi study, Deardorff (2004) attempted to establish a working definition of intercultural competence and concluded that the top rated definition for intercultural competence was the "ability to communicate effectively and appropriately in intercultural situations based on one's intercultural knowledge, skills, and attitudes" (p 184). Although Deardorff's study demonstrated a consensus on the definition of intercultural competence by experts, it is also necessary to look at what various leading scholars offer in terms of specific components and characteristics of intercultural competence in recent literature. 


\section{Characteristics of Intercultural Competence}

Different scholars have proposed models of an interculturally competent person. Indeed, over the past ten years, a variety of models of intercultural competence have been developed. Many of these models share common characteristics as to what constitutes intercultural competence, such as appropriateness and effectiveness as well as motivation, knowledge, skills and attitudes, (Bennett \& Bennett, 2004; Byram, 2000; 2009; Deardorff, 2006; Lustig \& Koester, 2003; Wiseman, 2002). However, some of models also involve additional characteristics such as foreign language competence (Kupka, Everett, \& Wildermuth, 2007) and context (Kupka, et al., 2007; Lustig \& Koester, 2003; Spitzberg, 2000).

Most of these intercultural competency models were built on earlier models. For example, in his survey of the major works in literature, Paige (1993) reported what other scholars (Dinges, 1983; Kim \& Gudykunst, 1988; Kim, 1988, Hannigan, 1990; Grove \& Torbiörn, 1993; Bennett, 1993) cited as important characteristics used to describe intercultural competence. He uses the term "intercultural effectiveness" (p. 171) and concluded that it is a complex concept comprised of the following six elements:

- Knowledge about the target culture;

- Personal qualities, such as, openness, flexibility, tolerance of ambiguity, and sense of humor;

- Behavioral skills, such a communicative competency, culturally appropriate behavior, and ability to relate well to other;

- Self-awareness, especially with respect to one's own values and beliefs; 
- Technical skills, including the ability to accomplish the task within the new cultural setting;

- Situational factors, such as relative similarity of the target culture to one's home culture, receptivity to foreigners, political/economic/social conditions in the second culture, clarity of expectations regarding the role and the position of the foreigner and similarity of the sojourner to the target culture and the psychological pressures associated with the experience (p. 171).

Intercultural Communicative Competence model. Drawing mostly from the earlier research of Spitzberg and Cupach (1984), Spitzberg (2000) created a systems model of Intercultural Communicative Competence that outlined a long list of factors that lead to intercultural competency. Spitzberg's model offered three systems: individual, episodic, and relational systems.

The individual system involves characteristics, such as motivation, knowledge, and skills that a person may possess that facilitate competent interaction between people. The episodic system refers to those features that enable a person to interact competently with a particular person from another culture and whether he is viewed as competent by this particular person in a given encounter. Finally, the relational system involves those components that help an individual's "competence across the entire span of relationships rather than in just given episode of interaction" (p.380).

Spitzberg (2000) argued that the use of these three propositions, each broken down into three levels of analysis, provide a more integrative approach that may be used 
to examine two-party interactions where motivation to communicate, knowledge of language and specific cultural rules, and skills to apply this knowledge to appropriate and effective communication apply to a specific context. He posited that these components are interdependently connected emphasizing that context plays an important role in determining one's intercultural competence. This is because understanding the initial conditions found within the context of a social situation determines whether or not someone is able to choose appropriate and effective behaviors suitable for use in a particular social situation. Without the awareness of specific cultural knowledge, skills to use this knowledge and motivation to use these skills, it is not possible to correctly interpret the initial conditions found with a social context, develop realistic expectations for the person or episode and create culturally appropriate and effective communication (Spitzberg, 2000).

Similarly, Wiseman (2002) suggested that intercultural competence is comprised of knowledge, skills, and motivation, which facilitate effective and appropriate interaction with people from different cultures. Wiseman added motivation as a new element that had not been included in some of the earlier definitions of intercultural competence. He defined motivation as "the set of feelings, intentions, needs and drives associated with the anticipation of or actual engagement in intercultural communication" (p. 4).

Much in the same vein, Lustig and Koester (2003) viewed intercultural competence as contextually defined by relationships and situations. They posited that both appropriateness, which is proper and suitable culture specific behavior, and 
effectiveness, which means achieving desired goals, are two important elements of competence. They added that knowledge, motivation, and actions are key elements to successful intercultural competence.

The authors asserted that culture-general and culture -specific knowledge, as well as knowledge about one's own culture, are crucial. For Lustig and Koester (2003) the term motivation refers to "emotional associations" (p. 70) as associations or expectations people bring to their interactions with culturally different others, such as willingness to experience some uncertainty. Finally, Lustig and Koester (2003) claimed that with the appropriate knowledge and motivation, people can act appropriately and effectively.

Rainbow Model of Intercultural Competence. Drawing attention to the limitation of existing intercultural competence models, Kupka, Everett, and Wildermuth (2007) offered the Rainbow Model of Intercultural Competence that draws from "systems theory, social construction of reality theory, social learning theory, social identity theory, identity management theory, and anxiety/uncertainty management theory" (p. 22). This model added five more components to Spitzberg and Cupach's (1984) five-factor model of intercultural communication competence: (a) foreign language competence, which is essential to facilitate communication with others from other cultures; (b) cultural distance that is necessary to recognize cultural differences and adjust behavior accordingly; (c) self-awareness, which is a comparison of self to the new cultural environment; (d) knowledge of cultural rules; (e) skills to apply this knowledge; (f) motivation to uses these skills; (g) appropriateness, which means following valued norms and expectancies of the relationship; (h) effectiveness that is related to whether the communicative goals 
have been accomplished or not; (i) contextual relationships that refer to the relationship between communicators and circumstantial characteristics; and (j) cultural affinity that refers to emotional disposition towards one's own culture and other cultures (Kupka, Everett, and Wildermuth, 2007).

The Deardorff process model. Deardorff (2006) offered a process model of intercultural competence that is a grounded theory based model she constructed through a study that explored the definition of intercultural competence by the most prominent scholars in this field. This model consisted of four levels that described intercultural competence through cyclical movements among each level. The model represented movement from individual levels to interaction level. The individual levels were comprised of two levels.

The first level was attitudes that consist of respect in terms of valuing other cultures, openness in terms of withholding judgment, and curiosity and discovery in terms of tolerating ambiguity. The second level was knowledge and comprehension. This level included cultural self-awareness, deep cultural knowledge, and sociolinguistic awareness. In this level, individuals needed to have skills such as ability to listen, observe, and evaluate in addition to skills used to analyze, interpret and relate to others.

The third and fourth levels of the Deardorff process model consist of the interaction levels. The third level refers to internal outcomes described as an informed frame of reference shift. This stage involves skills such as adaptability, flexibility, having an ethnorelative view, and experiencing empathy. 
The fourth level refers to external outcomes, which are characterized by effective and appropriate communication and behavior within the context of an intercultural situation. According to Deardorff, a person does not have to fully attain a reference shift as an outcome in the third level in order to reach the external outcomes of intercultural competence. Nevertheless, the degree of appropriateness and effectiveness of an interaction will be restricted when one or more parties involved lack the third level skills such as flexibility and empathy.

The following diagram illustrates the relationship between each of the levels described by the process orientation model:

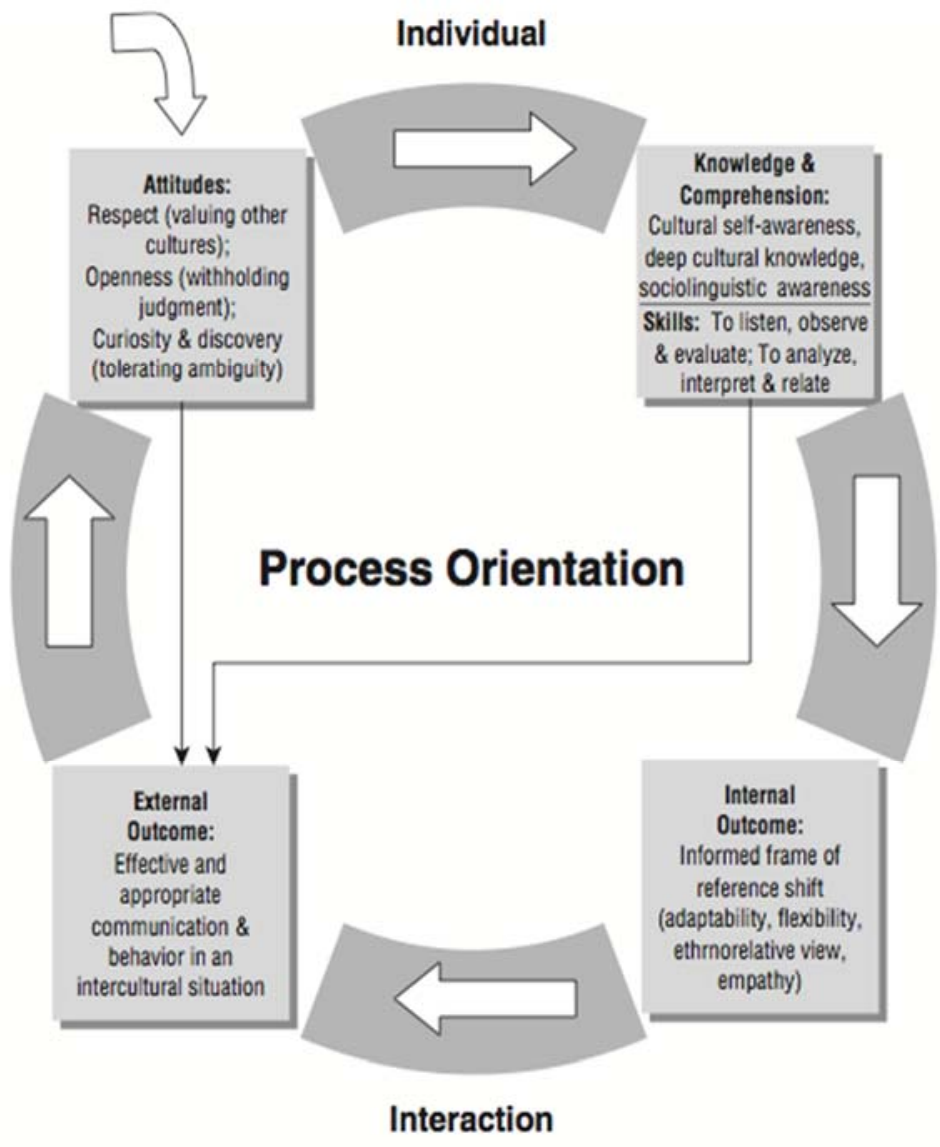


Figure 1. Deardorff's Process Model of Intercultural Competence

Note: From "Identification and assessment of intercultural competence as a student outcome of internationalization" by D. K. Deardorff, 2006, Journal of

Studies in International Education, 10, p. 266. Copyright 2006 by Darla

Deardorff. Reprinted with permission.

Byram's model. Looking at intercultural competence from a sociolinguistics point of view, Byram $(1997,2009)$ offered a model that involved five factors: Attitudes such as curiosity and openness; knowledge of other cultures and oneself; skills to understand, explain, and relate to cultural events from another culture to one's own culture; skills to discover and understand new cultural knowledge and interact accordingly; and critical cultural awareness which enables an individual to critically identify and assess situations caused by cultural misunderstandings.

Bennett (2009) drew attention to the growing agreement related to the characteristics of intercultural competence when he stated that it is "most often viewed as a set of cognitive, affective, and behavioral skills and characteristics that support effective and appropriate interaction in a variety of cultural contexts (p. 97). He said that cognitive skills are comprised of cultural self-awareness, culture-general knowledge, culture-specific knowledge, and interaction analysis. Bennett (2009) referred to affective skills as those that involve curiosity, cognitive flexibility, motivation, and openmindedness. Finally, he described behavioral skills as including relationship building skills, listening, problem-solving skills, empathy, and information gathering skills. 
To summarize, the models and definitions that have been described here have many characteristics in common. Nevertheless, this review also reveals that there is not a definitive consensus on how an individual develops intercultural competence and the precise skills involved. Many scholars (e.g. Bennett, 2009; Byram, 1997; Deardorff, 2009a) however, emphasize the importance of culture specific and culture general knowledge and behaviors and skills to utilize this knowledge for effective and appropriate intercultural communication in relevant contexts. They also agree that the key components of intercultural competence include, motivation, knowledge, skills and attitudes. In fact, Spitzberg and Changnon (2009) have observed over a fifty-year period that the core components of intercultural competence are "motivation (affective, emotion), knowledge (cognitive), and skills (behavioral, actionable)" (p. 7).

However, further explanations of these elements may vary depending on the scholar's field. For example, depending on their field, scholars may add different components to their definition of intercultural competence such as foreign language competence, self-awareness, curiosity, openness, technical skills, and empathy.

\section{Developmental Model of Intercultural Sensitivity}

One of the cultural competence assessment tools that has been developed and is currently in use is the Intercultural Development Inventory (IDI) developed by Hammer, (1998). As described in greater detail in chapter three, this study employed the use of the IDI as a data-gathering tool. The IDI is a psychometric assessment tool that is grounded in the Development Model of Intercultural Sensitivity (DMIS) instrument that was originally developed by Bennett (1986; 1993). 
By employing concepts from cognitive psychology and constructivism, Bennett proposed a theoretical model that posits "a continuum of increasing sophistication in dealing with cultural difference" (Bennett, 1993, p. 22). There are several assumptions underlying the DMIS. First, one's experience of cultural difference determines the level of intercultural competence. That is, as one is engaged in more complex and sophisticated cultural experiences, that person develops a stronger level of competence in intercultural relations (Hammer, et al., 2003). This kind of experience, which Bennett also refers to as intercultural sensitivity enables a person to understand and accommodate cultural difference.

Bennett (2004) considered intercultural sensitivity as involving a cognitive process that represents how a person perceives intercultural events, ways of being, and cultural differences. According to Bennett, the relationship between intercultural sensitivity and intercultural competence is based on the assumption that as an individual becomes more sophisticated at forming an accurate perspective of the initial cultural conditions, he or she develops an ability to acquire and select culturally appropriate attitudes and behaviors.

Another assumption that Bennett posited is that intercultural sensitivity is experienced at different levels in developmental terms (2004). If an individual is socialized in a monocultural setting, it is hard for that person to construe differences between his/her own culture and others' cultures as the person may have only been exposed to only one worldview. Similarly, if a person is exposed to more than one culture, that person is more likely to become aware of his or her own cultural worldview 
and therefore experiences the difference between cultures by engaging in a more complex meaning-making process. Therefore, that person progresses on a continuum from an ethnocentric stage to a more ethnorelative stage, which assumes that "cultures can only be understood relative to one another, and that particular behavior can only be understood within a cultural context" (Bennett, 1993, p. 46).

From this perspective, people are not born with intercultural sensitivity; rather they learn and develop sensitivities throughout their lives. According to Bennett (2004), greater levels of intercultural sensitivity parallels a greater ability to exhibit intercultural competence.

The DMIS has two major stages with three orientations in each stage (see Figure 2). Each stage indicates a particular worldview structure that describes attitudes and behavior towards cultural difference (Bennett, 1998; Hammer, et al., 2003). The first stage is the Ethnocentric stage. This stage involves three orientations: denial, defense, and minimization. The second stage is the Ethnorelative stage also involving three orientations: acceptance, adaptation, and integration.

Denial $\rightarrow$ Defense $\rightarrow$ Minimization $\rightarrow$ Acceptance $\rightarrow$ Adaptation $\rightarrow$ Integration $\mid$

ETHNOCENTRISM ETHNORELATIVISM

Figure 2. Developmental Model of Intercultural Sensitivity

Note: Adapted from. "Measuring intercultural sensitivity: The intercultural development inventory”. By M.R. Hammer, M.J. Bennett, and R. Wiseman, 2003, International Journal of Intercultural Relations, 27, p, 424. 


\section{Ethnocentric Stages of the Developmental Model of Intercultural Sensitivity}

Bennett (1993) described the term ethnocentric as "assuming that the worldview of one's own culture is central to all reality" (p. 30). Depending on the way a person construes and interprets difference, the meaning that an ethnocentric person will give to cultural difference ranges from denial, to defense, to minimization. Here, I will describe each of these three distinctions.

Denial People in this stage cannot construe cultural difference in a complex way. As they see their cultural reality as the only reality, they do not differentiate between other cultures, basically denying their existence. This stage is generally the default condition for people from monocultural societies. People in this stage are not usually interested in differences. They generally refer to culturally different others using general descriptors, such as "foreigner", "immigrant”, or “African” (M. J. Bennett, 1998; Hammer, et al., 2003).

Bennett (1993) describes these behaviors as the isolation form of denial. Bennett also describes the separation form of denial as "the intentional erection of physical and social barriers to create distance as a means of maintaining as a state of denial" (p. 32). Although people in the denial stage are not necessarily negative, they view others as people to be tolerated, exploited, or eliminated. In general, non-dominant culture members do not experience denial, because in order to function successfully in the dominant culture, they have already developed an understanding of cultural differences (Hammer, 2009; Hammer, et al., 2003). 
Defense. In this stage, people perceive cultural differences as threatening and evaluate them negatively. Rather than denying the difference, they recognize certain cultural differences, but they see their own reality as the absolute truth. They perceive that their values are under attack when confronted with differences; therefore, they tend to fight the differences directly, viewing their own culture as superior to others (Bennett, 1986; 1993; 1998; Hammer, 2009). Fighting the differences manifests itself in three forms: denigration, superiority, and reversal.

Denigration is a way to protect one's worldview by negatively evaluating and stereotyping others. Polarization of groups is common, such as a superior form of $u s$ versus inferior them. Movement beyond this stage may be difficult as people have a tendency to retreat to the denial stage.

Those who progress from denigration often utilize a superiority-mind set form of defense. They evaluate their own worldview positively, but they do not necessarily belittle others. They believe that "cultural difference needs to be overcome for the construction or maintenance of superiority" (Bennett, 1993, p. 37).

The final form of defense is a reversal that is viewing one's own culture negatively with the assumption that other cultures are better. People experiencing reversal tend to see themselves separate from their own culture and identify more with the other culture that they see superior. They may use belittling comments about their own culture with the hope that they will fit in more in the other culture. This attitude is still ethnocentric as a person evaluates culture from a single perspective with no or little cultural understanding (M. J. Bennett, 1993). 
Minimization. The last orientation of ethnocentric stages is minimization. Although cultural differences are significantly acknowledged and not evaluated negatively, cultural differences are not perceived as being important. In this mind-set, assumptions about culture are universalistic in nature. People at this stage recognize superficial differences, but they believe all people are the same at the core (Bennett, 1998).

According to Bennett (1993), people in mainstream cultures are more likely to make these universalistic assumptions as they see their own cultural norms as being universal in nature. They are not able to understand deep cultural differences, typically because they have not had enough experience with other cultures, and they interpret differences they encounter through their own cultural lenses. Therefore, they generally stay at this level and maintain a universalistic view more than others may do, for example, people of oppressed cultures.

Forms of minimization are divided into two aspects: physical universalism and transcendent universalism. People that tend to adhere to the assumptions associated with a physical universalism perspective believe that all people are biologically the same and have the same basic needs such as the requirements for food and shelter. From a solely physical universalism perspective, cultural differences are considered to be superficial and unimportant.

The second form of minimization is transcendent universalism. This view is generally observed among religious people who see all human beings as being created by the same divine power, such as God. Another application of this perspective may arise 
from the belief that given that all people are victimized by the same economic or political force(s), all are all motivated by the same drivers.

What makes this stage ethnocentric is the "naïve assertion that, despite differences, all people share some basic characteristics" (Bennett, 1993, p. 42).

Therefore, people at the minimization stage can easily move back to the defense stage if they fail to interact with culturally different others because their assumption of commonalities are not proven to be correct (Bennett, 1993). On the other hand, Bennett (2004) explained that it is possible for people in this stage to transition to ethnorelative stages. According to Bennett, what needs to be resolved in this stage is the recognition of one's own culture, which is cultural self-awareness. In this stage individuals start seeing their beliefs, behaviors, and values are influenced by the cultural context they were raised within.

\section{Ethnorelative stages of the developmental model of intercultural sensitivity.}

Ethnorelativism is defined as "the assumption that cultures can only be understood relative to one another and that particular behavior can only be understood within a cultural context" (Bennett, 1993, p. 46). That is, there is no superior or inferior culture. People in ethnorelativistic stages do not see cultural differences as threatening. They construe differences positively and find them enjoyable and exciting. There are three orientations involved in this stage: acceptance, adaptation, and integration. Here, I will describe each of these stages.

Acceptance. In this stage, people recognize and accept cultural difference. They do not see their own worldview as central to reality, rather it is accepted as one of many 
worldviews. They view others as different but not as inferiors "by discriminating differences among cultures (including one's own) and by constructing a metalevel consciousness" (Hammer, et al., 2003, p. 425).

The appreciation of other cultures can be demonstrated through respect for behavioral differences and respect for value differences. The most obvious behavioral differences are language and communication style. People accept unfamiliar behavior as cultural differences rather than just another variation of universal norms.

Acceptance does not mean that one has to agree with each and every cultural difference. Respect for value differences is at the crux of intercultural sensitivity. Some differences even may be evaluated negatively without being ethnocentric; the important thing is to "accept the relativity of values to cultural context (and thus to attain the potential to experience the world organized by different values)"”.

The main problem for progressing from this stage is that when a particular difference is viewed as disrespectful or unacceptable, the person may retreat to one of the ethnocentric stages. The worldview associated with this stage allows a person to have personal opinions but disallow the opinion to become ethnocentric (Bennett, 1993). Namely, a person develops respect for differences in values and behaviors without judgment.

Adaptation. At this stage, people have developed skills that enable them to perceive and appreciate cultural differences and act appropriately. Adaptation does not equate to assimilation. People preserve their own worldview, but at the same time, they 
broaden it with other constructs from other cultures to be able to communicate with culturally different others.

Adaptation involves two phases of development: empathy and pluralism. Empathy is "the ability to take perspective or shift frame of reference with regards to other cultures" (Hammer, Bennett, \& Wiseman, 2003, p. 425). The ability to shift perspective is central to empathy; otherwise, people can easily revert to ethnocentrism. At the same time empathy is only temporary as people change their perspectives and behavior to adapt to the immediate cultural context. If this perspective shift becomes habitual at a deeper level, it may result in biculturality or multiculturality, which is called pluralism (Bennett, 1993; Hammer, et al., 2003).

Most people at this stage are already interculturally sensitive. However, some bicultural people, although they can easily function in two cultures, may not exhibit the same adaptation skills when they encounter people from other cultures beyond those that they are familiar with (Bennett, 1998).

Integration. Integration is the final stage of the DMIS. Integration is the ability to change one's way of thinking and acting depending on the cultural context. People in this stage see themselves within different worldviews in addition to their own worldview. They internalize multiple cultures, which may result in "internal culture shock" and in turn "cultural marginality" as some of these internalized frames of reference may contradict one another, and people may find it hard to identify with any one of these one of these frames them, as they construe their identities at the margins of multiple cultures (Bennett, 1993, p. 60). 
Cultural marginality has two forms. The first one is constructive marginality where people view being multicultural as a positive asset and can easily move in and out of different cultures as needed. The second form is encapsulated marginality that describes the feeling of being alienated as a result of a constantly shifting frame of reference and feeling stressed because of not belonging to one culture.

According to Hammer and his colleagues (2003), even though integration is the final stage of the continuum, it is not necessarily the stage people need to arrive at in order to be considered interculturally competent. Often times, it is a stage that describes people who are viewed in some manner as a minority, such as members of oppressed groups or people who lived abroad long term.

In summary, the DMIS is a continuum with different stages, each of which describes the way people construe cultural differences as they develop intercultural sensitivity. Ethnocentric stages represent worldviews less sophisticated and complex in terms of viewing cultural differences either in the form of denying, defending, or minimizing them as the result of lack of or insufficient intercultural experiences.

Ethnorelative stages describe ways of viewing cultural differences by accepting their importance, adapting a frame of reference or integrating them into the self-identity. Bennett (1993) argued that ethnocentrism is an innate reaction when we encounter different cultural worldviews from our own. He maintained that training in intercultural communication is a way to change ethnocentric behavior to ethnorelative perspectives. The next section will present how diversity can help student learning and development of intercultural sensitivity. 


\section{The Benefits of Diversity to Student Learning}

It is evident from the literature that students learn better in educational environments when there is a meaningful relationship between students and faculty and when diversity is actively appreciated and engaged. According to Rendon and Valadez (1993), when faculty do not strive to develop cultural understanding of their students, it may be hard for students to see value in continuing their education.

In the same vein, Sanches (2000) argues that students' learning preferences are culturally formed, leading to students' processing information differently. Therefore, a lack of understanding of students' culture specific experiences on the part of instructors may impede student learning. Astin's (1993c) longitudinal study found that faculty's emphasis on diversity had a positive effect on openness to racial and ethnic understanding and overall positive experience of college.

In their survey of Mexican Americans, African Americans, and Native Americans in a predominantly White university, Mayo, Murguia and Padilla (1995) found that the most significant factor that affected African Americans was their relationship to faculty through advice or outside of class meetings. Similarly, Figueroa (2014) argued that it is the connections that are built outside the class with the belief that all students have the capacity to learn. What all faculty should be cognizant of is the fact that not all students have the same background and learn at the same pace. In fact, some need to be reached outside the classroom environment to realize their true potential. Indeed, in a collaborative self -study, Han, Vomvoridi-Ivanovic, Jacobs, Karanxha, Lypka, Topdemir, and Feldman (2014) found that building meaningful relationships with students through 
both course instruction and advising were the ways they incorporated culturally responsive pedagogy in higher education settings.

Research (e.g. Astin, 1993a, 1993b; Chang, Astin, \& Kim, 2004; Gurin, Dey, Hurtado, \& Gurin, 2002; Hu \& Kuh, 2003) indicates that curricula and culturally competent classroom practices that introduce students to racial and ethnic diversity help students to use and develop their cognitive skills and levels of intellectual engagement and aids in overall social development. These researchers found that students' persistence, retention, success and attitudes about the college experience are positively correlated to their engagement in diverse learning environment.

Astin (1993a) found that students who attended colleges where faculty emphasized diversity in their teaching practices and research reported positive cognitive and affective gains. Villalpando (2002) conducted a study drawing data from 15,600 students from 365 higher education institutions and found that without exception all students, especially African American and white students, were positively affected by and satisfied with faculty who used instructional practices that respected and included content on racial and ethnic issues and required writing addressing issues related to women, race, and ethnicity.

After examining two large datasets from the University of Michigan and from a national sample of college students, Gurin, et al (2002) established that curriculum content that provides opportunities for students to be exposed to racial and ethnic diversity had a positive influence on educational outcomes. They maintained, "The 
success of these curricular initiatives is facilitated by the presence of diverse students and a pedagogy that facilitates learning in a diverse environment" (p. 359).

Similarly, in a study that Light (2001) conducted, students reported that they learned most when they interacted with diverse others and when they had opportunities to study academic content that included multicultural issues. Specifically, the white participants stated that they had positive learning outcomes when they had interacted with racially and ethnically different others.

Chang et al. (2004) noted significant differences in students' beliefs and perceptions about people from diverse backgrounds when these students were engaged in collaborative and cooperative learning activities. Similarly, Gurin (1999) argued that students learn more and develop more complex and active thinking skills if they are in diverse classroom environments and are engaged in interactions with others ethnically and racially different from themselves. She posited that formal, purposeful instructional activities should be designed to encourage to students think in complex ways and discourage them from gravitating towards familiar thinking patterns.

Rankin and Reason (2005) posited that classroom experiences that stimulate exploration of issues of race and encourage interaction with diverse others are necessary for positive educational outcomes. In the same vein, Quaye and Harper (2007) argued that when students engage in "meaningful, but sometimes uncomfortable, discussions about racial/ethnic, gender, religious, and socioeconomic differences, as well as privilege in all its forms" (p. 34), they have the opportunities to think critically about issues that have not been aware of previously. According to Hurtado (2005), students' frequent 
interaction with more diverse others help them to "become accustomed to social difference, hone intergroup skills, and prepare them for diverse workplaces" (p. 606).

In another study, Mayhew and DeLuca Fernandez (2007) found that students learned more when their instructors employed classroom practices that required reflection, peer interactions and discussions about diversity. They concluded that students who "reflected on material, examined materials from different perspectives, and applied this knowledge to analyzing societal problems consistently gained a better understanding of themselves and issues related to diversity, regardless of course content" (p. 75).

\section{The Need for Interculturally Competent Faculty}

Increasing national diversity and the interdependence of people caused by emerging globalization necessitate that everyone in the $21^{\text {st }}$ Century be interculturally competent. Intercultural development is not an innate ability or "a requirement to be checked off some list but is something beyond the somewhat rigid categories of knowledge, skills, and attitudes; it involves continuous critical refinement and fostering of a type of thinking and knowing - a critical consciousness - of self, others, and the world.” (Kumagai and Lypson, 2009, p. 783). In order to develop necessary intercultural skills, students need ongoing practice and be exposed to opportunities to develop over time in new and changing contexts (Lee, Poch, Shaw, \& Williams, 2012).

Even though research indicates that students benefit from diversity-rich learning environments, Bowman (2010) reported that students can benefit from educational environments rich with diversity only to the extent that they had meaningful interactions 
with one another. This means students need to be engaged in intercultural activities that are intentionally planned and involve actively facilitated learning environments.

Accordingly, in addition to being experts in their fields, higher education faculty need to possess new skills and qualities in order to be successful and effective in the classroom. Faculty must be interculturally competent to be able to respond appropriately to working with ever increasing diverse populations found within college classrooms and instill intercultural competence in students.

Community colleges are often the first choice of diverse population seeking postsecondary education because of their open access policies and affordability. As a result, low-income citizens, historically underrepresented populations from various ethnic and cultural backgrounds, and immigrants make up a considerable portion of community college student demographics (Harbour \& Ebie, 2011; Koltai, 1993; Moore, 2006; Nevarez \& Wood, 2010).

Faculty can no longer assume that the students in their classrooms will understand and respond to their own cultural mindsets and competently share the same language as that of the instructor (Bennett \& Salonen, 2007). Accordingly, instructors and administrators need to "design and implement curricula, campus activities, programs and services focused on meeting the needs of a diverse student body and educating for participation in an increasingly diverse world" (Roper, 2004, p. 48).

Townsend (2000) argued that the teaching practices of most White faculty who teach at community colleges have been influenced by their own learning styles and shaped by their own cultural backgrounds. According to Townsend, one way of 
overcoming this problem is that faculty learn about how people's cultural background affect teaching and learning.

For many students, college campuses may be the only places where students will experience meaningful intercultural interactions. Once they graduate, students may never have the opportunity to develop intercultural skills with the support of knowledgeable guides. They are however, highly likely to find themselves trying to navigate a myriad of challenges found in the diverse workplace and other social environments (Green, 2007; Stearns, 2009).

According to Gurin and et al (2002), higher education institutions can and should provide a diverse and complex context that encourages students' intellectual experimentation and identity development. In order to optimize students' experiences, faculty must become adept in the intercultural aspect of teaching and will need to create an inclusive classroom environment, promote and sustain diversity for student success and to help students to be globally and interculturally ready in this new century (Armstrong, 2011).

Furthermore, in order for community colleges to be successful in their efforts to internationalize the campus, it is crucial to have motivated faculty who possess expertise in international, intercultural and global issues (Green, 2007). The next section will present relevant research on intercultural competence among higher education faculty.

\section{Research on Intercultural Competence and Higher Education Faculty}

There is a growing literature base on the impact of various factors on the level of instructors' intercultural competence. For example, several studies have focused on the 
effects of teachers' experiences abroad, especially as a part of their practicum requirements.

In one study conducted over a period of five years, $\mathrm{Bu}$ (1995), focusing on the affective experiences of 15 U.S. teachers, found that teachers who taught one or two semesters in China gained insights into their own learning about cultural differences. $\mathrm{Bu}$ used in-depth ethnographic interviews and used culture bump analysis to determine emotional reactions of teachers towards cultural differences. The findings revealed that teachers went through a continuous learning process that they perceived as a positive outcome. Bu also reported that the teachers gained new interpersonal skills that helped them to interact with the Chinese, which in turn enhanced their personal behavior skill sets.

In another study, Roberts (2003) examined experiences of both pre-service and practicing teachers who taught in Costa Rica for four weeks during a summer project. The participants took intensive Spanish and culture learning classes for two-weeks prior to their departures to Costa Rica. They were actively involved in learning about Costa Rican culture through planned events and they were required to keep reflective journals throughout the entire experience.

Upon returning, the participants wrote a final report and took part in focus group meetings. Roberts reported that the participants found their experiences to be lifealtering. They thought that cultural practices and cultural differences that they encountered during their stay in Costa Rica were equal to their own cultural frameworks in terms of complexity. Roberts reported that interaction with others in an international 
context and experiential learning are ideal for teachers to develop perspective consciousness about the world.

Emert (2008) conducted a research study to examine the experiences of 12 teachers who taught from six-months to one-year abroad through Fulbright Teacher Exchange Program. She utilized the Intercultural Development Inventory and the Strategies Inventory for Learning Culture to collect quantitative data and used journals, and interviews for qualitative measures. While she did not find a significant difference between the pre- and post-test results of the IDI, the qualitative data showed that the participants gained an increased cultural self-awareness in terms of core values, identity, and personal weaknesses and strengths. They also gained an increased recognition of the value of interacting with people from other cultures as well as an increased ability of perspective taking, which is the ability to understand how a situation may look to another person.

Several studies have focused on multicultural education and faculty perspective related to this topic. For instance, Marshall (1996) examined the nature of concerns related to teaching culturally different students and if these concerns reveal any unique features to inform the practice of multicultural teacher education. She surveyed both students and experienced practicum teachers. The results revealed that teachers were mostly concerned about what culturally diverse students think of them and if they have the ability to judge students fairly regardless of their background. These results suggested that teachers' primary concern when working with culturally diverse students was their own abilities to relate to their students. 
In their survey of higher education faculty in a small American Pacific Island university, Johnson and Inoue (2003) researched faculty's perceptions and attitudes towards multiculturalism and how it is reflected on their classroom practices. They reported that many faculty ranked high on many indicators for knowledge, openness, and awareness of multicultural issues; however, they did not necessarily know how to incorporate multicultural pedagogy and materials into their teaching.

As many as a quarter of the faculty participants reported that they "only seldom or "very seldom" incorporate multicultural materials in their pedagogical practices. The researchers attributed these answers to the lack of training provided to higher education faculty in terms preparation for the use of instructional and assessment strategies that they could incorporate into their teaching practices. They suggested that further qualitative research is needed in order to measure the actual practices of faculty in the classrooms and gain deeper understanding of the relationship between how faculty perceive their own educational practices, what their actual pedagogy is, and what is really happening their classrooms.

Ellingboe (1998) claimed that graduate school preparation plays a significant role in the development of intercultural competence in faculty. Ellingboe also argued that many graduates were not eager to employ cross-cultural teaching because it was not the way they were educated.

During her doctoral experience, Helms (2003) investigated the level of cultural sensitivity and demonstration of cultural competence among faculty at three U.S. liberal arts institutions. She utilized the Multicultural Competence Questionnaire and the 
Intercultural Development Inventory to collect quantitative data and she supported it with eight open-ended questions to provide qualitative insight in conjunction with the Multicultural Competence Questionnaire.

Helms reported that the faculty benefited most from the course work and immersion in other cultures during their graduate professional preparation in terms of developing intercultural competence. Also, travel and living in other cultures were identified as having a significant effect on faculty's own cultural perspectives.

Helms also reported that the study did not find any significant difference between intercultural levels of faculty across disciplines; however, they saw themselves much more interculturally competent than they were actually assessed by the IDI. Faculty saw themselves at the ethnorelative stages (acceptance/adaptation) of the developmental continuum; however, they were actually at the minimization stage, which is the last ethnocentric stage.

In a meta-analysis of the pertinent literature, Schuerholz-Lehr (2007) examined the relevant theoretical frameworks of personal and practical knowledge and professional experience. She also examined evidence linking higher education faculty's cultural competence to classroom practice. After analyzing the literature from the past twenty years, she concluded that there are a significant number of empirical studies that have been conducted that explore different aspects of faculty experiences, background and so forth and how these variables affect intercultural sensitivity, cultural competence and world-mindedness. However, Schuerholz-Lehr observed that the research that focused 
on how these traits in faculty translated into classroom practice tends to be less than conclusive.

In a recent research study conducted by Linder, Harris, Allen and Hubain (2015), students of color experience significant racism in the higher education settings. They found that the instructional activities were designed to educate students in dominant groups and the faculty failed to facilitate classroom discussion related to diversity issues. Students reported they felt marginalized and often found themselves in an educator position as the faculty often did not intervene to guide classroom conversations in an inclusive manner. The researchers concluded that faculty in higher education urgently need to take responsibility to engage in culturally responsive pedagogy to avoid such situations.

This literature review on intercultural competence among higher education faculty has shown that traveling abroad, living and teaching in another culture, engaging in graduate work, and professional development activities have positive impacts on faculty and how they perceive themselves and people from different cultures. Almost all of the studies mentioned thus far concluded that such experiences contribute to the development of cultural competence of faculty in some way; however, none of these studies were able to provide concrete proof whether this increased cultural competence have any impact on their pedagogical beliefs or practices. The next section will report the effective teaching strategies found in the literature. 


\section{Best Practice Teaching Strategies}

College students come from diverse cultural backgrounds more than ever before. According to Fallon and Brown (2010b), more students were involved in the globalized society and may be more cognizant of other cultures than students of past years. Therefore, it is more important than ever for students today to be interculturally competent so that they are ready to function effectively in a more diverse and globalized society and workplaces.

One place where students may develop intercultural competence is the classroom. Accordingly, higher education faculty today need to be interculturally competent and teach in a manner that will accommodate all types of students and create inclusive learning environments by creating culturally relevant curriculum (Howard-Hamilton, 2000). Fallon and Brown (2010b) defined inclusive teaching as teaching in a manner "so all students can process and understand the material in whatever ways are best for them" (p. viii). Fallon and Brown maintained that today's college instructors must understand that past teaching practices will not work with the new generation of students.

According to Ginsberg and Wlodkowsky (2006), inclusion occurred as a result of instructional practices in every lesson of every course. Lee et al. (2012) argued that the necessary change in teaching practices called for in order to provide culturally sensitive and relevant instruction do not lie in changing what instructors teach but how they teach it. This requires "a fundamental shift in how we conceptualize instruction so that it is designed and implemented based on recognition that the acts of knowing and 
communicating are dynamic and complex as we increasingly understand the world to be" (p. 49).

After reviewing literature on pedagogy, Lee, Poch, Shaw, and Williams (2012) recommended a pedagogical approach that supports a continuous process for intercultural development by engaging diversity across curriculum. Using the term intercultural pedagogy, they offer three core principles that inform the how of intercultural pedagogy.

The first principle is about maximizing and facilitating purposeful interactions. They argued that working with people with different ways of thinking is one way to challenge students' current ways of thinking, which will eventually create communities where different perspectives and voices will be valued. Engaging in others' perspectives will facilitate intercultural attitudes and skills, such as valuing different point of views and managing one's own anxiety.

The second principle is valuing the assets students bring to the classroom. Faculty who operate from this principle understand that the different perspectives and insights students bring to class are valuable and add to deeper understanding of topics. This means instructors need to pay attention to the cultural differences that students bring to the classroom and understand that these differences can create rich learning and teaching environments (Lee, Poch, Shaw, \& Williams, 2012).

Employing this principle eliminates the pressure on faculty who feel that they need to be intercultural experts and emphasizes the fact that they need to facilitate student engagement in diverse perspective by capitalizing on what students bring to the classroom and by helping them shift their frames of reference and accept the existence of 
different ideas (Lee, Poch, Shaw, \& Williams, 2012). The authors also asserted that creating opportunities for students to use their experiential knowledge will help them to connect their affective experiences and cognitive frames. They suggested that one way of doing this is to integrate narratives in class where students can choose an object from their lives that reflect some aspect of their cultural identity and introduce it to others in class. These kinds of activities designed to include artifacts or objects from students' cultural backgrounds allow others to be exposed to different ideas and perspectives. The third principle is about balancing support and dissonance. Facilitating intercultural development entails affective, cognitive, and behavioral unsettling. In order for development to take place, individuals need to be engaged in planned activities that disrupt their current ways of thinking and behaving. However, instructors need to be able balance challenge with support as activities designed to facilitate new ways of thinking can also create anxiety that may cause one to strengthen one's self-defense mechanism and become prejudiced (Lee, Poch, Shaw, \& Williams, 2012). Managing anxiety is one of the important components of intercultural competence (Gudykunst, 2002); however, few students possess this skill in their early days in college. Therefore it is the instructor's responsibility to manage the anxiety level in the classroom (Lee, Poch, Shaw, \& Williams (2012).

On the other hand, Hartley and Petrucci (2004) argued that creating a safe environment is a challenge for many higher education instructors because, for some students, a safe environment can be a place where no one shows their anger and does not articulate their feelings, which can be viewed by other students, especially by students of 
color, as a way to suppress feelings of anger when talking about issues like racism. Lee Poch, Shaw, \& Williams (2012) emphasized the importance of recognizing these differences and responding to them by facilitating and providing support during the discussion of conflicting ideas are an important part of intercultural competence.

Gudykunst (2005) posited that students feel safe in environments if they believe that they have equal status with others in the classroom. Students may have a different perceived status and may feel empowered or disempowered depending on different factors, such as the language they speak, the skin color they have, and the religion or cultural heritage with which they identify. Lee et al. (2012) suggested that laying down the ground rules of classroom interaction can help students to feel everybody has equal saying in class. He also recommended that asking students on the first day of the class what kind of classroom environment they find safe and engaging may be helpful in terms of empowering students. Another suggestion was having students write reflectively about formative educational experiences and behavior and qualities that impacted their learning. This can be used later to create a mutual agreement among students about safe classroom practices guidelines that support student engagement.

Lee et al. (2012) also argued that building a respectful classroom environment begins with modeling the skills instructors ask their students to use and develop. Specifically, he claimed that it is important that instructors serve as positive role models who demonstrate tolerance of ambiguity and manage anxiety when dealing with the unfamiliar in constructive ways. Lee and colleagues (2012) added that if instructors themselves exhibit discomfort and anxiety with student responses, students will detect it. 
Acknowledging the discomfort and tension, if they do arise, and having an honest discussion will decrease the affective barriers to learning. Lee et al. (2012) explained that "a classroom climate where dissonance is expected, ambiguity is tolerated and anxiety is respectfully acknowledged enables students to maintain a healthy curiosity in the course content as well as diverse identities and perspectives of their classmates" (p. 89).

In order to promote a positive environment, instructors may have to handle biased comments during class discussions. Weinstein and Obear (1992) explained that such comments create defensiveness and lead to unproductive discussions. They argued that instructors need to address such comments rather than remaining silent. However, Weinstein and Obear acknowledged that addressing potentially inflammatory comments immediately may stifle the class discussion or generate anger. Therefore, establishing a way to deal with such triggers at the beginning of the class and creating a way of facilitating understanding of multiple perspectives are important aspects of classroom culture.

Kitano (1997) discussed three types of pedagogical categories used to describe the nature of courses. The first category is an exclusive course, which is defined as a course that:

...presents and maintains traditional, mainstream experiences and perspectives on the disciplines. If alternative perspectives are included, they are selected to confirm stereotypes. The instructor conveys information in a didactic manner, and students demonstrate their acquisition of knowledge through objective or subjective written examinations. Classroom interactions are limited to 
question/answer discussions controlled by the instructor without attempts to support participation by all students. In the exclusive classroom, class time is not given to discussion of social issues not directly related to the discipline. (p. 23)

The second category is the inclusion course, that Kitano described as one that:

...presents traditional views but adds alternative perspectives. Content integration in an inclusive course can range from simple addition of viewpoints without elaboration to efforts at analyzing and understanding reasons for historical exclusion. The instructor uses a wide array of teaching methods to support students' active learning of course content. Evaluation of students occurs through several different types of assessment to ensure consideration of individual differences terms of how students demonstrate and express knowledge. The instructor monitors student participation and employs learning activities that support participation by all students (p. 23).

Finally, the third category, a transformed course, looked like the following: A transformed course challenges traditional views and assumptions; encourages new ways of thinking, and conceptualizes the field in light of new knowledge, scholarship, and ways of knowing. The instructor restructures the classroom so that the instructor and students share power (within the limits of responsibility and reality). Methods capitalize on the experience and knowledge that students bring and encourage personal as well as academic growth. Alternatives to traditional assessment procedures are used, including self-evaluation and projects that contribute to real-life change (p. 23). 
Cohn and Mullenix (2007) suggested that Kitano's three levels of course change model is useful for instructors who are considering revising the design of a course. According to Brookfield (2006), one useful starting point is to develop baseline knowledge of the community of learners in the classroom to inform classroom decisions. For example, it is helpful to determine the intensity and types of the diversity in class. He suggests using various instruments to assess personality types and learning styles, such as Myers-Briggs Personality Type Inventory or Kolb's Learning Styles Inventory. He also suggests finding out about student's backgrounds, racial and ethnic identities after offering information about his or her own.

Richard, Brown, and Forde (2006) cautioned against not acknowledging individual differences among students from diverse backgrounds. They explained, "...for teachers to ascribe particular characteristics to a student solely because of his/her ethnic or racial group demonstrates just as much prejudice as expecting all students to conform to mainstream cultural practices" (p. 8). Therefore, it is highly recommended that throughout the implementation of the course, it is important to find out how individual students react to certain classroom activities with the use of various assessment tools and draw on that data to inform instructional moves.

According to DeTurk (2001), the development of intercultural competence is facilitated through frequent and in-depth contact with diverse others. Pedagogical approaches that require students working with diverse peers, such as cooperative learning, service learning, and collaborative learning communities have been proven to facilitate students' intellectual development and multicultural competencies (Smith \& 
Associates, 1997). Lee et al. (2012) posited that designing purposeful interactions among students entail communication and cooperative skills which are foundational to intercultural competence.

Lee et al. (2012) argued that making some changes in a course syllabus is one way to convey the importance of students' active engagement. They explained that in addition to reading selections and the instructor's own way of communicating with students, "incorporating conditional language into the syllabus..., such as could be, observes, or possibilities include signals that there is intellectual room for students to interact with content and discuss concepts and ideas" (p. 68). They also added that instructors should include statements in their syllabi about the goals and assignments that support engaging diversity. Statements that clearly explain that behaviors and attitudes like active listening, respect, tolerance for ambiguity, and patience with disagreements are important components of students' learning that should be included in a course syllabus (Lee, Poch, Shaw, \& Williams, 2011).

Lee et al. also suggested that instead of simply presenting a list of assigned readings and other instructional materials, presenting the rationale behind choosing them and explaining that they were intentionally chosen to introduce students to "dissonant views on a given topic, divergent approaches to inquiry and interpretation and multiple construction of knowledge and among scholars in the discipline" (p. 69) is an empowering pedagogical move. In addition, they suggested that instructors should explicitly acknowledge that there may be disagreement and conflicting views during class discussions, and that this is part of intellectual inquiry process. They also added that 
students can be invited to expand the reading list by bringing in their own suggestions to be reviewed by the instructor and peers for potential discussion in class.

Brookfield (2006) posited that mixing students of different abilities, racial backgrounds, and learning styles prepares them for the realities outside the classroom where they will not have control over whom they will work with. He added that the only way to deepen students' understanding of and tolerance for different viewpoints is to create environments where they will work with and be challenged by different point of views.

Likewise, Anderson (2008) argued cooperative learning and service learning are two means of learning that provide students with structured learning opportunities that engage them cognitively and affectively. According to Anderson, cooperative learning experience connect students to the community, give them an idea how systems function, requires students to participate actively, and provide them with opportunities to think critically and reflectively about their experiences. Lee et al. (2012) posited that designing purposeful cooperative activities, such as goal oriented group work with diverse others, positively impacts learning and help students understand the value of working with others in achieving group goals.

According to Hurtado (2001), engaging in and collaborating with effectively diverse others, students can far more easily form cross-cultural friendships outside their own group. In addition, according to King (2002) carefully designed group activities facilitate high-level cognitive processing. King stated: 
...when students are exposed to alternative perceptions and conflicting views, and are put in such a state of cognitive imbalance, they are motivated to continue the discussion in order to resolve the cognitive conflict. Interaction with their peers requires students to confront any differences in each other's current understanding of a topic as well as their differing attitudes or perspectives. Then, through explaining and defending their views to their group, those conflicts can be reconciled ... they arrive at negotiated meaning ... individuals reformulate their own thinking and alter their knowledge structures--that is, they learn. (p. 36) Tatum (2000) posited that community building should be emphasized in the curriculum by assigning students to diverse discussion groups, which will help students interact with each other across their differences. According to Ortiz (2000), developing a sense of community in the classroom gives students a chance to learn about other worldviews, motivates them to share their own perspectives and encourages them to question other students' and instructors' about what they know.

Ortiz suggested that using activities that will provide students with opportunities to share information about themselves, their worldviews, cultural heritage and values is a good approach to support students' intercultural competency development. Gay (2002) posited that building community among diverse learners is an important part of culturally competent teaching. For example, many students of color grow up in environments where the well-being of the community is valued more than individual needs and communities pool their resources to solve their problems. Building a strong sense of community in class therefore, is not only beneficial for all students, but is particularly 
comfortable and familiar to those who were raised with collectivist attitudes towards what the concept of well-being means.

On the other hand, Tatum (2000) argued that community-building activities can be a challenge when discussion is focused on difficult issues such as racism, classism or any other "isms" since students may be polarized and become very passionate expressing and defending their views. Even though moderate conflict can be productive (Barnett, 2011), various strategies have been suggested to create a safe classroom environment, including establishing clear guidelines, (Tatum, 2000), especially student generated ones, (Brookfield \& Preskill, 2005; Timpson, Yang, Borrayo \& Cannetto, 2005) using dyads and small discussion groups (Tatum, 2000), and building trust (Barnett, 2011) over time.

Ortiz also stated that using cooperative, collaborative and active learning methods will facilitate the process of gaining confidence in their own meaning-making process and understanding the course content better because activities such as these provide opportunities for students to reflect on their own experiences in context. For instance, using case study analysis, participating in interactive discussion groups, and small group activities are good ways to achieve these goals (Ortiz, 2000).

In the same vein, Ginsberg and Wlodkowsky (2006) posited that collaborative and cooperative learning activities help develop relationships over time, encourage active student participation and engagement, and facilitate the learning process. Similarly, Fallon and Brown (2010a) explained that using cooperative learning groups is an excellent way to have students interact with each other in a productive way. 
It is highly recommended that in cooperative groups everyone have a role, for example, a leader, a time-keeper, and reporter so everyone contributes to the learning process and is actively engaged as thinkers rather than allowing one individual to dominate the discussion and do most of the thinking for the group. Furthermore, Fallon and Brown (2010a) emphasized the importance of assigning cooperative activities that take place outside of the classroom. They claimed that such experiences provide students with intellectual challenges and emotional support as well as provide learners with opportunities to see the course content from different standpoints (2010).

It is important to design assignments that engage learners in combining critical analysis of course content and their own personal experiences (Ortiz, 2000; Lee et al, 2012). According to Ortiz such assignments that include students' worldviews make perspective taking easier and more natural. Lee et al. suggested that writing assignments are a perfect way to facilitate reflection. They also provide instructors with a better understanding of students' anxiety levels when dealing with difference in the classroom.

Based on the literature he reviewed, Six (2005) suggested that trust is necessary in contexts of high ambiguity, uncertainty and high complexity because it provides a sense of security as well as encourages participants to take risks. Six also says the presence of trust encourages and maintains cooperation and it "encourages information sharing, enriches relationships, increases openness, and mutual acceptance and enhances conflict resolution and integrative problem solving" (p. 1).

From a motivational perspective, Ginsberg and Wlodkowski (2006) believe that creating a climate of respect promotes intrinsic motivation because students feel capable, 
safe, accepted, and connected in a learning group; as a result, students tend to act spontaneously and accept full responsibility for their actions.

Howard Gardners' (1993) Multiple Intelligences Theory has been also described as an inclusive pedagogy. Gardner proposed that people are intelligent in many ways and solve problems in relation to their cultural setting or community. He describes seven types of intelligences that people draw upon and develop. These seven intelligences include linguistic intelligence, logical/mathematical intelligence, musical intelligence, visual/spatial intelligence, bodily/kinesthetic intelligence, interpersonal and interpersonal and intrapersonal intelligence.

According to Barrington (2004), teaching and learning that is informed by Multiple Intelligences theory is an inclusive pedagogy because it considers different forms of intelligences as a way of learning and guide instructors in teaching and assessing students learning in various forms, which in turn provides a learning environment wherein students use and develop their own strengths.

Fallon and Brown (2010a) suggest that all of these learning styles and intelligences provide many possibilities for instructors to present the course content rather than relying strictly upon delivering lectures, an instructional strategy that many higher education instructors tend to rely heavily on. They recommended employing a combination of different methods of instructions, including visual, auditory and kinesthetic activities to have students actively involved in learning and teaching. They suggested using multiple modalities of instruction with the goal of appealing to different types of intelligences such as using Power Point lectures that include photos, videos, 
illustrations, and posing challenging questions that stimulate individual and group discussions.

Non-native speakers. There is also a body of literature on more inclusive environments for immigrant students in higher education settings (Alfred, 2009; Guy, 2002; Lee and Sheared, 2002; Wong, 2006). Alfred (2009) argued that faculty need to have an understanding of their non-western students and know about their country of origin, languages they speak, as well as their ethnic background, socioeconomic status, educational histories to be able to cater better to these students. Lee and Sheared (2002) suggested that faculty should be aware of how culture may affect these students' behaviors in class. They explained, for example, that silence among immigrant students may not mean disinterest or inability to learn rather it may be a sign of how they were taught to learn in their home countries. These students might find it easier to participate in small groups.

Alfred also explained that when designing instructional activities, "incorporating the knowledge that immigrants bring to the new country and relevant literature of their cultural group can enhance cross-cultural understanding and increase the responsiveness and relevancy of education programs aimed at creating equal opportunities and access for all students" (p. 143). She suggested designing instruction to create opportunities to share students' histories and cultural experiences, which would help all students learn from each other.

Guy (2002) asserted that building community among immigrant learners and native speakers help these students to learn more about the U.S. culture, such as 
navigating cultural systems like education, health, and workplace. Alfred (2009) suggested that group activities should be designed for these students who take part in cooperative learning. She also emphasized that group activities should both take place in and out of the classroom or in an online environment.

As the review of literature has shown, it falls on instructors to intentionally design learning environments to facilitate students learning and promote intercultural development. Clearly, instructors cannot force or produce intercultural competence for their students (Wong, 2006). However, they can carefully plan learning activities and provide multiple opportunities for students to engage in meaningful interactions that will challenge their ways of thinking and contribute their cognitive development.

\section{Conclusion}

The world in the $21^{\text {st }}$ Century is increasingly interconnected and interdependent, which requires people to be aware of diversity and be culturally competent both in workplace and social life. Possessing intercultural skills is crucial for college graduates so that they can be effective both professionally and personally. People become interculturally competent as they are engaged in experiences which provide them with opportunities to interact with culturally diverse others and reflect on those experiences. Thus, it is important that community college faculty be interculturally competent and create inclusive learning environments that accommodate culturally different learners and foster intercultural competence among learning communities.

This review of the literature has provided information on themes that are relevant to this study. These themes included intercultural competence, the purpose of community 
colleges, students and faculty in community colleges, and best practices in creating inclusive learning environments.

Little research has been conducted that focus specifically on how community college faculty adjust their pedagogical practices to accommodate culturally different learners and create interculturally competent graduates. However, this literature review has provided a foundation for the current study that explored the what specific culturally competent pedagogies effective community college faculty use. The next chapter will present the research methods used in this study. 


\section{CHAPTER III}

\section{METHODS}

The purpose of this chapter is to describe the research methods utilized in this study. The first section of the chapter discusses an overview of the study and the rationale for qualitative research, particularly the narrative approach. Then, a greater discussion of the research site, the sampling methods, the research participants are presented. The section that follows discusses the data collection procedures, data analysis, and reporting findings in general. The final section discusses ethical issues, validity, and the limitations of the study.

\section{Research Questions}

This research study explored the culturally relevant pedagogical approaches of community college instructors. The research questions are the following: 1) What specific culturally effective competent pedagogies do effective community college instructors use? 2) What motivates these effective community college instructors to use these culturally competent pedagogies?

\section{Rationale for Qualitative Research}

In order to gain a deeper understanding of what culturally relevant pedagogical approaches community college instructors use and the reasons behind their choices, this study utilized a qualitative research design. A qualitative approach was selected for this study because the purpose of the research was to understand the experiences of community college instructors regarding what teaching practices they use to 
accommodate students from different cultural backgrounds and promote intercultural competence among students.

Creswell (2007) argued that it is important to conduct qualitative research because the approach "allows the researcher to study the group, or population and identify variables than can be measured" (p. 37). Indeed, one of the main characteristics of qualitative research is that it emphasizes the participants' viewpoints, pays careful attention to the setting or the context in which they express their views, and highlights the meaning that people personally hold about educational issues (Creswell, 2005).

Furthermore, according to Denzin and Lincoln (2005), "qualitative research involves an interpretive, naturalistic approach to examining the world. This means that qualitative researchers study things in their natural settings, attempting to make sense of, or interpret, phenomena in terms of the meanings people bring to them" (p. 3). Since qualitative research is concerned with participants and their experiences, this type of research provided the opportunity to examine perceptions and the meanings that the instructors bring to their teaching practices and their experiences in class.

In qualitative studies, the researcher cannot be separated from the central phenomena, and therefore, it is not likely that the researcher can understand the phenomenon of effective classroom teaching in relation to intercultural competence without trying to make sense of instructors' pedagogical choices and their personal experiences in class. As Greene (1988) stated, “...qualitative research is concerned with meanings as they appear to, or achieved by, persons in lived social situations. Research of this kind cannot be carried out by people 
who see themselves as detached, neutral observers concerned with the kinds of observation, measurement, and prediction that are presumed to be unbiased, unaffected by the inquirer's vantage point or location in the world" (p. 175).

From an epistemological perspective, it is not possible to separate the researcher from what is being researched. Researchers in quantitative studies utilize an objective, value-free approach, whereas in qualitative studies researchers cannot be separated from the research phenomenon (Johnson, 1992). They bring their values to the research through the theories they use as guiding frameworks, through what they choose to include and exclude from the study, and through methodologies they choose to use (Johnson, 1992).

\section{Narrative Inquiry}

Narrative inquiry as a qualitative approach has become a viable way to study teachers, students and educators in educational settings (Creswell, 2005). Narrative inquiry is a way of knowing that helps the researcher understand an educational phenomenon or experience (Kramp, 2004). Clandinin and Connelly (1989) explained that the "narrative inquirers tend not to begin with an unspecified problem and set hypotheses. Instead they are inclined to begin with an interest in a particular phenomenon which could be understood narratively" (p. 14).

Narrative inquiry is a way to understand experiences as lived by people in time, in space, in person, and in relationships (Connelly \& Clandinin, 1990). Similarly, Wilson (2007) argued, "narrative inquiry allows the researcher to provide a rich description, contextual understanding, and explanation of the person, place, or event under 
observation" (p. 26). People narrate to make sense of themselves and their experiences over the course of time (Bochner, 2001). Fundamental questions in narrative inquiry are "what does this narrative or story reveal about the person and world from which it came? How can this narrative be interpreted so that it provides an understanding of and illuminates the life and culture that created it?" (Patton, 2002, p. 115)

In this kind of research, all participants have equal voice and previously unheard voices are given validation. In this sense, narrative inquiry is a gentle way to give educators opportunity, space and comfort to tell their stories (Connelly \& Clandinin, 1990).

The purpose of this study was to explore the culturally relevant pedagogical practices of community college instructors and the reasons behind their choices. Narrative inquiry lends itself nicely to this study because hearing the research participants' stories and experiences provided valuable insights into each individual research participant's classroom experiences and how they construct these experiences to create meaning.

In this study, I followed the seven steps that Creswell (2005) identified in conducting narrative research. The first step was to identify a phenomenon to explore followed by purposefully selecting an individual who can tell about the phenomenon. Once an individual was identified, I collected the story from that individual. The next steps were to retell the participant's story, to collaborate with the participant, to write a story about the participant's experiences, and finally to validate the accuracy of the report. The next section provides the details of the research. 


\section{Data Collection Strategies}

Research Site. I selected a northwestern community college as the research site for this study. This community college is located in a suburb of a city found in the Pacific Northwest and is one of the major community colleges in the state. It serves approximately 33,000 students annually. Classes are offered at a main campus site, two extension sites and in a few public schools located within the district. The college offers 120 associate degrees, certificate programs and transfer options.

Creswell (2005) stated that in qualitative research the best research site is "the one that can best help the researcher understand the central phenomenon. This understanding emerges through a detailed understanding of the people or site" (p. 204) because it allows

a researcher to learn about the phenomenon. He also adds that the research site should be easily accessible to the researcher because of the frequent visits that the researchers will make.

The main reason for the selection of the research site was the fact that the researcher was employed at this college at the time of the study and had easy access to the research site and research participants to conduct interviews. Another reason as to why this research site was a suitable site for this research is its relatively diverse student body. According to the latest data collected in 2010, the student body was comprised of 13.25\% Hispanic, 5.96\% Asian/Pacific islander, 4.24\% African American, 1.14\% Native American and 60.43\% Caucasian/Non-Hispanic.(Market Enhancement Study, 2010).

Sampling Strategy. Considering the qualitative nature of this study, a purposeful sampling strategy was used as it was the best strategy for identifying participants that 
would be highly likely to inform the research questions. According to Patton (2002), purposeful sampling is best suited for information-rich cases which are cases "from which one can learn a great deal about issues of central importance to the purpose of the inquiry, thus the term purposeful sampling. Studying information-rich cases yields insights and in-depth understanding rather than empirical generalizations" (p. 230).

In purposeful sampling, a researcher selects the site and participants intentionally to learn or understand the central phenomenon (Creswell, 2005). Maxwell (2005) described four goals for purposeful sampling: 1) achieving representatives or typicality of settings, individuals, or activities selected; 2) achieving the opposite of the first - to adequately capture the heterogeneity in the population; 3) examining cases that are critical for the theories that you began the study with, or that you have subsequently developed; and 4) establishing particular comparisons or illuminate the reasons for the differences between settings or individuals.

Creswell (2005) mentions nine strategies that educators often use for purposeful sampling. Homogeneous sampling is one of the nine strategies in which a researcher targets certain people because they share similar characteristics and traits. It also provides more "confidence that the conclusions adequately represent the average members of the population" (Maxwell, 2005, p. 89). This study employed a homogeneous sampling strategy in order to capture the homogeneity in the population. It was the most suitable for the purposes of this research as the researcher intended to seek out study participants who not only received formal public recognition for excellence in 
teaching in the form of awards, but were also widely known for their excellence in teaching in an informal sense.

The central phenomenon in this study was what specific culturally competent pedagogies community college instructors use. In order to provide a broader disciplinary picture of college instructors' effective pedagogical teaching strategies in dealing with culturally different students, I first tried to recruit participants recommended by department deans based on student evaluations. However, due to the strict college guidelines about recommending or releasing any teacher names who were known as effective teachers, it was impossible for me to obtain names of instructors who were known as their effective teaching practices in this manner.

As an alternative, I intentionally selected instructors who had been awarded the Distinguished Teaching Award or Faculty Award for Excellence in Teaching at the community college within the past five years. Each year, the school recognizes the outstanding work of up to three full-time faculty and three part-time faculty members. The chosen full-time faculty members are given the Distinguished Teaching Award, and the part-time faculty members are awarded Faculty Award for Excellence in Teaching. Each year the committee accepts nominations by any member of the college community, including students, who have personal and direct knowledge of the nominee's work.

In order to nominate someone, a form needs to be completed. In the form, a number of sections that attest to the unique and outstanding characteristics in support of the nominee's excellence in instructional service to students need to be completed. The criteria for the selection are as follows: 
1) Establishes good rapport and supports students,

2) Facilitates student learning with instructional methods and materials,

3) Knowledge of and enthusiasm for the subject matter,

4) Exhibits professional skill and behavior selection.

I contacted the recipients of these awards to request their participation in this study. Because the names of the recipients of either award were public knowledge and the selection criteria had a direct impact on the quality of instruction, I also contacted the teachers who were nominated for their excellence in teaching.

I first contacted the recipients in 2014 and kept contacting the past five years' recipients until a sufficient number of participants were reached. I contacted the past five years' recipients so that the participants would be selected from the most current recipients. In the end, ten instructors out of 25 accepted to participate in the study.

Sample size. Creswell (2005) stated that sample size varies from one study to the next. He added that "Qualitative researchers typically study a few individuals or cases. This is because the overall ability of a researcher to provide an in-depth picture diminishes with the addition of each new individual or site" (p. 207). Creswell explained that one reason why qualitative research is conducted is to be able to present the complex nature of data provided by participants.

On the contrary, Merriam (1998) stated that there is no one right answer to the question of how many people to interview. It depends on the research questions, the data, the analysis in progress, and resources available to the researcher. In the same vein, Patton (2002) stated "there are no rules for sample size in qualitative inquiry. Sample 
size depends on what you want to know, the purpose of the inquiry, what's at stake, what will be useful, what will have credibility, and what can be done with available time and resources" (p. 244).

Participant description. In this study, I did not differentiate between full-time and part-time faculty as there was no research supporting that the former was more interculturally competent or effective in teaching than the latter. Also, the number of the part-time faculty was significantly larger in some departments at the college; therefore, I did not want to limit myself to only full-time faculty and risk recruiting a smaller sample size than intended.

However, the majority of the part-time instructors who were contacted either did not want to participate in the study or did not return my emails or phone calls. Although I contacted full-time faculty in person in their offices, it was not always possible to catch part-time faculty members in their part-time offices. As a result, all but one of the ten participants recruited to this study were full-time faculty. I believe ten participants was a good number of people to involve in this study because this number allowed me to examine their stories in detail and gain a deeper understanding of their perceptions and to more fully contextualize their instructional choices.

\section{Data Collection}

Before the data collection process began, I submitted an Institutional Review Board (IRB) application to both the Human Subjects Research Review Committees associated with the university where I attend as a graduate student and the community college where I conducted the research. After the IRB applications were approved and 
the participants were identified, I obtained active written consent from each participant before I started collecting data.

After obtaining consent from the participants, I began collecting data using two approaches. The first approach that I will describe in the following section was the Intercultural Development Inventory and the second was one-on-one interviews with each of the ten participants in the study.

Intercultural Development Inventory. The IDI is an assessment tool that measures the level of intercultural competence across a developmental continuum for individuals, groups, or organizations (Hammer, 2011). The IDI is grounded in the Development Model of Intercultural Sensitivity (DMIS) that was originally developed by Bennett (2004). By employing concepts from cognitive psychology and constructivism, Bennett proposed a theoretical model that posits "a continuum of increasing sophistication in dealing with cultural difference” (M. J. Bennett, 1993, p. 22).

The IDI was chosen for this study as the means to determine the intercultural competence levels of participants because this theory-based psychometric test meets the standard scientific criteria for a valid and reliable instrument (Hammer \& Bennett, 2001). The IDI also measures cognitive, affective, and behavioral aspects of intercultural competence rather than attitude alone.

In order to be qualified to use this instrument, a researcher participates in a twoday IDI Qualifying Seminar. I completed this training in May 2011 prior to the datacollection cycle. 
The Intercultural Development Inventory (IDI) (Hammer \& Bennett, 2001) was used in this study to identify intercultural competence levels of instructors by placing them on an intercultural development continuum. The IDI is a 50 -item, theory-based instrument that can be taken either in paper and pencil form or online. It also has ten demographic questions that can be completed by the participants. Participants complete each of 50 items by choosing one of five options on a Likert scale: disagree, disagree somewhat more than agree, disagree somewhat and agree somewhat, agree somewhat more than agree, and agree in response to the question prompts. These response options consistently appear in the same order throughout the inventory.

The statements or prompts found in the IDI are derived from in-depth interviews with individuals from different countries and represent stages of the DMIS that are Denial, Defense, Minimization Acceptance, Adaptation, and Integration. The demographic questions consist of items related to gender, age, previous experience living in another culture, completed level of education, nationality and ethnic background, and region of residence during formative years through age 18. It takes approximately 20-30 minutes to complete the IDI.

Hammer (1998) reported that content validity was addressed during the development of the first version of the IDI and the results were acceptable. Factor analysis was utilized on 145 items to narrow in on items that were the most reliable and valid indicators of intercultural sensitivity (Hammer \& Bennett, 2001). Following an interview guide, in-depth interviews with culturally diverse sample of 40 individuals were conducted through the interviewing of culturally-diverse individuals rating the 
transcripts in terms of how consistent or not each orientation of DMIS were expressed by each interviewee.

Inter-rater reliability was calculated using Cohen's kappa with the results ranging from .66 to .86. (Hammer, Bennett, \& Wiseman, 2003). The results indicated that people construe their cross-cultural experiences in ways described by the DMIS theory (Hammer, 2011).

The IDI, version two was developed on a new cross-cultural sample of 591 respondents using confirmatory factor analysis (Hammer, Bennett, \& Wiseman, 2003). The subsequent item analysis resulted in a 50-item measure with a .80 or higher coefficient alpha for each scale.

In 2009, the latest version of the IDI (IDI v3) was developed by administering the survey to 11 distinct, cross-cultural sample of 4,763 respondents including a wide range of age groups and professions (Hammer, 2009). Results indicated distinctions between denial and defense orientations and acceptance and adaptation orientations, which resulted in seven scales: denial, defense, reversal minimization, acceptance, adaptation, and cultural disengagement. The findings provided support for the development of the continuum description and demonstrated the generalizability of the IDI across different cultural groups. (Hammer, 2009).

\section{Semi-Open Ended Interviews}

Creswell (2005) stated that it is important to have a structure in an interview. Having an interview protocol helps the researcher to remember the questions and take notes. An interview protocol is "a form designed by the researcher that contains 
instructions for the process of the interview, the questions to be asked, and space to take notes of responses from the interviewee" (p. 222). Creswell suggested including information about the interview, the purpose of the study, a reminder about the consent form, and recording equipment as well as other useful information that the researcher would like to include. In keeping with Creswell's advice, I prepared an interview protocol in order to use it as a guide during each interview.

When interviewing participants, the primary goal is to understand the perceptions of the person being interviewed relative to a specific topic or topics (Bogdan and Biklen, 2007). In-depth interviews help a researcher enter into participants' world and uncover perceptions that cannot be observed otherwise, such as feelings, thoughts, and intentions (Patton, 2002). Furthermore, unlike written questionnaires, the presence of an interviewer prevents the possibility of questions being unanswered and allows the interviewer to clarify questions if necessary, thus, making gathering relevant data easier (Babbie, 2001).

Patton (2002) argued that while collecting data, a qualitative researcher should aim strategically, philosophically, and methodologically to minimize the imposition of predetermined responses. Accordingly, Creswell (2005) stated that the researcher should determine the type of interview to be used. The interview-type should selected on the basis of which type will best help the researcher to understand the central phenomenon and answer the questions of the study.

Merriam (1998) stated that there are three types of interviews: 1) highly structured/ standardized, 2) semi-structured, 3) unstructured/informal. She pointed out 
that the best way to determine a type of interview is to decide the amount of structure desired.

The most structured interview is an oral form of a written survey where the researcher strictly adheres to predetermined questions. This type of interview is mostly used to gather socio-demographic data. In a semi-structured interview, the questions are more flexibly worded, and they are a mix of more and less structured questions. In this type of interview, participants are required to provide specific information, which can be gathered through more structured questions. The largest part of the interview is guided by a specific list of questions to be explored, but exact wording or the order of questions are not predetermined to allow the researcher to respond to the situation. This freedom also allows room for participants' new ideas or emerging worldviews.

Unstructured, informal interviews are more common for studies that are exploratory in nature. They are mostly used to learn about a situation to formulate more structured questions, and they are generally followed by observations. Totally unstructured interviews are seldom used as the sole way of collecting data (Merriam, 1998). In many studies, researchers combine all three types of interviewing-types. In this scenario, a set of standard open-ended questions are asked of each participant and some unstructured interviewing is allowed so that fresh thoughts and new perspectives may emerge from the conversations.

Creswell mentioned four types of interviews: one-on-one interviews, focus group interviews, telephone interviews, and e-mail interviews (2005). In this study, I determined that the best method to collect data was one-one-one interviews even though 
it is the most time consuming way of collecting data. In this type of interview, the researcher asks questions and records responses from only one participant at a time. This type of interview is ideal for participants who are able to express themselves well and do not hesitate to speak and share their ideas (Creswell, 2005). The participants in this study were all faculty members and were expected to be articulate and comfortable sharing their ideas by nature. As expected, during the interviews all of the study participants competently expressed their stories.

For this study, the semi-structured type of interview was ideal as this approach provides opportunities to elicit the perspectives, practices, and feelings of the participants in a flexible manner. Patton (2002) referred to semi-structured interview as the standardized open-ended interview wherein a carefully worded and arranged set of questions are posed to the participants in order to take each participant through the same sequence of questions.

According to Patton (2002), there are several advantages to using this type of interview. First, variation among topics discussed during interviews is minimized. Second, the participants' time is used efficiently because the interview is highly focused, and the analysis process is easier because responses are compared more easily. Patton stated that the addition of truly open-ended questions allow participants the freedom of selecting responses that are most relevant to the research and use whatever words they want to employ to clearly express themselves.

Building rapport and collaborating with research participants. Narrative research involves collaborative work between the researcher and participants to minimize 
the potential gap between what is told and what is reported (Clandinin \& Connelly, 2000). The collaborative research relationship is one that may be described as an equal and caring community that benefits both researcher and participants. Therefore, equality between parties, creation of a caring community, and shared purpose and goals are important factors in creating a successful relationship (Noddings, 1986).

In this study, I consciously worked to build a positive rapport and a collaborative relationship with each participant by keeping the above statements in mind. I respected the participants, valued what they had to say, actively worked to remain neutral, explained the research purpose, ensured the anonymity of the participants by using pseudonyms, and made it clear that they were equal partners in the study. In addition, although the participants were not fiscally compensated for their time, out of the belief that a small gift card is an appropriate way of showing appreciation of participants' time and expertise, each participant was provided with a small gift card to a popular local bookstore.

Interviews. According to Clandinin and Connelly (2000), the conditions in which the interviews take place determine the shape of the interview. For example, the location should be suitable for audio recording and free from distractions (Creswell, 2005). The most important goal of the researcher should be finding the best time and the most comfortable, non-threatening place for the participant.

Keeping these guidelines in mind, I made every effort to accommodate the participants' specific preferences regarding the time and location of the interviews. Once 
the participants consented to participate in the study, a sixty to ninety minute interview was arranged with each participant at a time and place of their choosing.

When we met for the interview, I acquired each participant's permission to audio record the interview prior to starting the recording. In each case, I explained to each participant the purpose of the study, the anticipated duration of the interview, the plans for using the results from the interview, and the availability of a summary of the study after it was completed (Creswell, 2005). I also explained that using pseudonyms would protect the confidentiality of each participant and the original transcripts nor the codebook with the participants' actual names would be shared with a third party.

Audio recording. Merriam (1998) stated that one of the basic ways to record data is to audio record the interview. This method ensures that everything that is said during the interview is preserved for analysis. It also frees the interviewer from the burdensome task of taking exhaustive notes during the conversation (Creswell, 2005).

On the other hand, Patton (2002) does recommend taking notes during the interview. He stated that doing so will help the researcher to formulate new questions during the interview in a reflexive manner. In this study, I audio recorded the interviews in order to have access to the conversations in their entirety and to ensure the accuracy of the data. In keeping with Patton's advice, I also took notes of important points that required clarification and informed the formulization of new questions throughout the interviews.

Creswell (2005) recommended sticking to the prepared interview questions yet being flexible enough to allow the conversation to follow its course at the same time. He 
also suggested using probes to gather additional information from each participant. Probes are sub questions that follow up on the main questions asked by the researcher. They are used to clarify points or to have the participant elaborate on a point.

During the interviews, there were such moments that I thought required further explanation. Therefore, I also asked questions to encourage the participants to elaborate on their statements. These questions typically asked the reasons behind their decisions or specific examples that would clarify their points.

Creswell also advised researchers to limit the time-spent discussing each question to a pre-determined specified time limit and to be respectful and courteous of the participants. In keeping with this advice, I was cognizant of the time and actively worked to stick to the pre-specified time limit for each question. None of the interviews exceeded the specified time limits.

In this study I made every effort to make the participants feel comfortable and be respectful and polite towards them. I thanked them at the end of the interview and assured them of the confidentiality of the data as well as offering them the summary of the results. I will keep the original data locked in a private file cabinet at my home for two years and destroy them afterwards.

Interview Protocol. Creswell (2005) emphasized that it is important to have a structure in an interview. Having an interview protocol helps the researcher to remember the questions and take focused notes. An interview protocol is "a form designed by the researcher that contains instructions for the process of the interview, the questions to be asked, and space to take notes of responses from the interviewee" (p. 222). 
Creswell suggested including information about the interview, the purpose of the study, a reminder about the consent form, and recording equipment as well as other useful information that the researcher would like to include. I also used an interview protocol as a guide during the interviews (see Appendix A).

While I did use my interview protocol as a guide throughout each semi-structured interview, I did not strictly follow the same exact order of questions during each interview. I also asked some clarifying questions as I felt necessary as well as questions that would help the participants to further think about examples of instructional activities that they used in class. This approach successfully elicited unexpected responses. For example, one participant revealed that she attended several professional development sessions on diversity, which raised awareness of her own identity and helped her improve her teaching practices to better engage diverse students and approach issues related to diversity in class in a culturally sensitive manner. After the interview with this participant, I decided to ask others about whether they had experienced formal training such as professional development courses or workshops on how to teach diversity in order to gain better understanding of what informs their teaching practices.

According to Patton (2002), making sense of large amounts of data is the challenge of qualitative analysis, which "involves reducing the volume of raw information, sifting trivia from significance, identifying significant patterns, and constructing a framework for communicating the essence of what the data reveal" ( $\mathrm{p}$. 432). The following describe the process used to prepare and analyze the data beginning with a presentation of the transcription process. 
Transcribing Data. Recall that the participant interviews are one of two sources of data used in this study. For transcription purposes, I hired an online transcription service. Following each audio-recorded interview, I sent the audio recording to them and had them transcribe it verbatim.

Oliver, Serovich, and Mason (2005) proposed that there are two types of transcription: naturalized and denaturalized transcription. Naturalized transcription reflects every utterance and nonverbal cue in detail and is used in conversational analysis studies. On the other hand, a denaturalized transcript approach leaves out the nonverbal cues and focuses on verbal utterances only (with corrected grammar). This approach, which is most often used in grounded theory and discourse analysis studies, focuses more on the meanings and perceptions created and shared during the interview.

In this study, I adopted the naturalized transcription approach in order to conduct conversational analysis to capture the rich details found within the data. I chose the naturalized approach since the denaturalized approach could leave out important features, such as non-verbal cues which are "as valuable as verbiage to achieving a deep understanding of the content of a conversation" (Oliver, Serovich, \& Mason, 2005, p. 1285). Thus, by utilizing the naturalized approach, I was able to better contextualize the utterances to develop a deeper sense of the intended meaning of the speakers. Since I did not transcribe the data myself, I read each transcript carefully in combination with my notes before starting the analysis process in order to familiarize myself with the data, including the nonverbal cues. 


\section{Data Analysis}

There is no one single correct strategy or method used to analyze qualitative data. That said, various researchers suggest that the initial step should be reading the data and make sense out of it (Bogdan and Biklen, 2007; Creswell, 2005; Maxwell, 2005). Maxwell explained that this first step of data analysis involves reading the interview transcripts and writing notes and memos on what is seen or heard in the data and form tentative ideas about categories. In this research, I followed this advice and began the coding process by reading through the transcripts carefully to familiarize myself with the contents.

Next, during the preliminary exploratory analysis stage, I worked with "the data to obtain a general sense of [the] data, memoing ideas, thinking about the organization of the data (Creswell, 2005, p. 237). According to Bogdan and Biklen (2007), this type of "analysis involves working with the data, organizing them, breaking them into manageable units, coding them, synthesizing them, and searching for patterns" (p. 159).

After re-reading my memos, I began the process of coding the data, the main categorizing and synthesizing strategy used in qualitative research (Maxwell, 2005). The purpose of coding is to make sense out of the data, break it into segments with codes, examine codes for overlap and redundancy and collapse them into more general themes (Creswell, 2005).

Bogdan and Biklen (2007) have suggested several steps in coding data that I employed in this study: search through data for patterns and topics; create coding categories by writing down words and phrases to represent these topics and patterns; and 
use these categories to sort the descriptive data collected. Similarly, Creswell (2005) explained the coding process as "identifying text segments, placing a bracket around them, and assigning a code word and phrase that accurately describes the meanings of the text segment" (p. 238). He defined a text segment as sentences or paragraphs that relate to one single code, and codes are defined as labels. Likewise, I identified sentences and paragraphs that represented the same or similar meanings. I assigned a phrase to each of these segments. Later, I merged some of these codes and assigned them labels.

Bogdan and Biklen (2007) presented some coding families that I used in developing the coding categories. These categories include setting/context codes which refer to the general information on setting, subjects, or topics; definition of the situation codes that are used to label how participants define a certain topic; perspectives held by subjects that define participant's perspectives about a particular aspect of a setting or topic; subjects' ways of thinking about people and objects which describes participants' understanding of others; process codes that are words and phrases that facilitate categorizing sequences of events or changes over time; activity codes that are used to categorize regularly occurring behavior; event codes for specific activities in participant's lives; strategy codes that refer to methods, techniques or other conscious ways that people accomplish various things; relationship and social structure codes that define regular pattern of behavior among people not defined by the organizational chart; narrative codes that describe the structure of talk itself; and methods codes that isolates materials pertinent to research procedures, problems or dilemmas. 
After coding an entire text, Creswell (2005) suggested making a list of all code words and grouping similar codes and identifying redundant ones in order to shorten a list of codes to a more manageable size. For this study, I listed all the code words, identified words with the same meaning and selected the most salient terms in order to reduce the data to a shorted list of codes. I then looked for themes to group the codes under and as I did so, I collapsed the codes into a shorter list beneath each of these themes. This was done as an iterative process wherein I continuously returned to the text to see if new codes emerged and then reduced them and grouped the remaining codes under five to seven themes. Finally, all of the codes were collapsed into a final set of themes.

\section{Ethical Issues}

Regardless of the research design, researchers in qualitative study face many ethical issues during data collection, analysis, and dissemination of findings (Creswell, 2007). Viewing interviews as interventions, Patton (2002) strongly suggested that researchers have an ethical framework in dealing with issues that put participants at risk. Patton explained this as follows:

Because qualitative methods are highly personal and interpersonal, because naturalistic inquiry takes the researcher into the real world where people live and work, and because in-depth interviewing pens up what is inside peoplequalitative inquiry may be more intrusive and involve greater reactivity that surveys, tests, and other quantitative approaches. (p. 407)

Patton offered a nine-item checklist of ethical issues as a starting point in considering ethical issues in design, data collection, and analysis. His checklist involves 
explaining the purpose of the research, promises and reciprocity, risk assessment, confidentiality, informed consent, data access and ownership, interviewer mental health, advice, data collection boundaries, and ethical versus legal issues.

I followed Patton's ethical issues checklist and informed the participants about the purpose of the research. I explained to them ways that I anticipated that this research would contribute to the literature and help improve pedagogical methods that would serve students better. Also, I assured the participants that the interviews would not put them at any risk and promise confidentiality by assigning pseudonyms to all participants. I also gave the participants an active informed consent letter and asked them to sign it before they took the IDI online.

Through the process, I maintained a professional and ethical relationship with the participants and did not push them to respond if they showed any discomfort about answering any of the questions. I did not anticipate talking about any topics that would impact the participants in a negative manner; indeed, none of the participants reported any negative effects from the experience.

The researcher submitted a human subjects research application form to both the community college and university campuses and did not start the data collection process before both schools granted permission, which was later was granted. The audio files were kept on my password protected computer. The hard copies of transcriptions were kept in a personal locked file cabinet that only I have access to in my private residence. 


\section{Validity}

Creswell (2005) defines validating findings as determining the accuracy or credibility of the findings through various strategies. I used several strategies to ensure the internal validity of this study. The first strategy was triangulation. This means verifying data from different sources in one study (Creswell, 2005; Patton, 2002). The researcher finds evidence in each data source to support a theme. Since the study draws on multiple sources of data, individuals or processes, the accuracy of the study is ensured. In this study, I collected data from multiple individuals through interviews. I examined each transcript and found evidence to support a theme. This method increased the validity of the study because the data was drawn from multiple participants (Creswell, 2005). Another source of data was the IDI, which provided baseline data on participants' intercultural competence levels that helped to better understand the meaning of each person's words during the interviews.

Member checking is another way to increase validity of a study. Member checking, also referred as respondent validation (Maxwell, 2005), means taking the transcript and data analysis findings to one or two participants in the study and asking them about the accuracy of the account (Creswell, 2005; Patton, 2002). This is the only way to rule out the possibility of misinterpreting the data as well as a powerful approach to identifying researcher's biases and misunderstandings (Maxwell, 2005). During the member check process, I asked the participants to both verify the transcripts and check the findings to ensure the accuracy of the report. To do this, I emailed the transcripts to the participants and verified the accuracy of what they had previously said and asked for 
comments or corrections. There were no additional comments or corrections offered from the participants.

Adler and Clark (1999) argued that in a qualitative study one of the validity concerns is to do with the interviewer him or herself. They explained that the way a researcher poses the questions may affect the way the participants answer questions. This is referred to as an "interviewer effect" which is "the change in a respondent's behavior or answers as a result of being interviewed by a specific interviewer" (p. 218). Bogdan and Biklen (2007) argue that each respondent needs to be approached differently with the goal of making them feel relaxed and express themselves in a meaningful way.

In this research, I did my best to acknowledge each participant's differences and made every effort to make them feel relaxed and answer questions freely. First of all, I gave them the freedom to meet at a place that felt most comfortable for them. Most participants chose to meet in their own offices. Two participants preferred to come to my office. I avoided interrupting them while they were talking. While I had not had a professional relationship with all but one participant prior to the interviews, they were all very receptive and welcoming when I entered their office. Those who came to my office did not show any signs of discomfort or anxiety.

\section{Summary}

This chapter discussed the methods used in this dissertation research that explored community college instructors' stories, perceptions, and experiences about how they approached teaching culturally diverse population, whether they adjusted their teaching practices according to the student body in their classes, and whether they promoted 
intercultural competence among their students. As stated in the Chapter one, the increased diversity in college classrooms and growing interaction between people with culturally diverse backgrounds in professional environments necessitates that faculty be equipped with cultural knowledge, skills and attitudes in order to understand and engage constructively with their students as well as prepare them to live productively in a multicultural society.

Using a narrative inquiry approach allowed the researcher to best explore the phenomenon and 'the 'essence' of the lived experiences if persons about that phenomenon" (Creswell, 2008, p. 93). In this study the quantitative data was collected through in-depth interviews in order to learn about participants' experiences in class as they relate to engaging diversity and promoting intercultural competence.

The next chapter will present the themes that emerged from the data. Chapter four will also present an examination of each participants' background to better contextualize their responses and provide a deeper understanding of the participants' perceptions related to the culturally relevant pedagogical approaches they employ in their community college classrooms. 


\section{CHAPTER IV}

\section{FINDINGS}

This chapter will present the profiles of the participants and report the findings of this study that aimed to explore the culturally relevant teaching practices of effective community college instructors and the motivation behind their choices. Ten participants were interviewed and given the Intercultural Development Inventory (IDI). The interview data were analyzed in order to better understand what specific culturally competent pedagogies they used and the reasons behind their choices. A narrative inquiry method was used to analyze the data.

The research questions were 1) What specific culturally competent pedagogies do effective community college instructors use? and 2) What motivates these effective community college instructors to use these culturally competent pedagogies? Common themes in the data were identified and grouped in response to the research questions.

All the instructors interviewed had a number of years of experience in teaching at the community college level ranging from five to twenty years. Recall from chapter three that each of the instructors were asked to participate in the study because they were all given either a Distinguished Teacher Award or Excellence in Teaching Award that indicated that their teaching practices were found to be highly effective by the students who participated in the selection process for the respective awards.

The findings highlighted the instructors' attitudes toward the growing diversity in their classes and the pedagogical choices that they made in order to accommodate that diversity. In addition, the findings indicated that some instructors made these 
pedagogical choices to expose their students to diverse ideas regardless of their students' backgrounds.

\section{Profiles of the Research Participants}

This section describes each participant's teaching background and their Intercultural Development Inventory (IDI) scores. While the IDI results were not used in analyzing the narrative data, the participants were given the test to better understand their intercultural sensitivity level. In the interest of protecting the participants' confidentiality, pseudonyms are used in the following sections.

The participants' demographic information and the IDI scores are summarized in Table 1 followed by a description of each participants' responses. Recall that the IDI scores represent a continuum ranging from denial to integration. A full explanation of all six stages was provided in the literature review on pages 15 through 21 .

Table 1 shows five participants are in the minimization stage reflecting a tendency to highlight commonalities across cultures. This implies that these participants may fail to recognize important cultural differences in values, perceptions and behaviors. Two participants are at the cusp of acceptance indicating an emerging orientation that recognizes and appreciates patterns of cultural difference in one's own and other cultures values, perceptions and behaviors. Two participants are in the polarization stage reflecting an "us and them" judgmental viewpoint toward cultural differences. Finally, one participant is in the adaptation stage reflecting a capability to understand, shift cultural perspective, and adapt behavior across cultural differences. 
Table 2.

Participants' Demographic Information and the IDI Scores

\begin{tabular}{|c|c|c|c|c|c|c|c|}
\hline Participant & $\begin{array}{l}\text { Age } \\
\text { Range }\end{array}$ & $\begin{array}{l}\text { Years taught } \\
\text { at college }\end{array}$ & Education level & Department & Employment status & Test score & IDI Stage \\
\hline Mark & $41-50$ & 20 & MA in English & Humanities & Full-time & 137.58 & Adaptation \\
\hline Amy & $41-50$ & 13 & MA in English & Humanities & Full-time & 109.75 & The cusp of Acceptance \\
\hline Liam & $30-41$ & 5 & MA in Literature & Humanities & Part-time & 109.07 & The cusp of Acceptance \\
\hline Heather & $41-50$ & 15 & MA in English & Humanities & Full-time & 105.92 & Minimization \\
\hline Jake & $41-50$ & 10 & MA in Digital Media & Integrated Media & Full-time & 101.0 & Minimization \\
\hline Alice & $31-40$ & 13 & MA in English & Humanities & Full-time & 95.56 & Minimization \\
\hline
\end{tabular}




$\begin{array}{lcclllll}\text { Sam } & 30-41 & 8 & \text { MA in Education } & \text { Adult Basic Skill } & \text { Full-time } & 91.08 & \text { Minimization } \\ \text { Barbara } & 51-60 & 15 & \text { MA in English } & \text { Humanities } & \text { Full-time } & 90.66 & \text { Minimization } \\ \text { Lawrence } & 61+ & 17 & \text { MA in Science } & \text { Biology } & \text { Full-time } & 81.66 & \text { Polarization (defense) } \\ \text { Rick } & 51-60 & 18 & \text { MA in Management of } & \text { Automotive } & \text { Full-time } & 75.75 & \text { Polarization (reversal) } \\ & & & & & & & \end{array}$


Participants. Again, ten community college instructors participated in this study. All of the participants were Caucasian Americans. The following provides a brief description of each of the participant's background. Recall that pseudonyms have been used to protect the identity of each participant.

Mark. Mark is the first participant in this study. He has been teaching in the Humanities Department at the college for 15 years; he possessed five more years of teaching experience prior to his current position. Mark shared that he first wanted to pursuit a law degree, but after an internship in a law firm he was not inspired to continue to pursue a career in the field. He thought the work they did was completely opposite of what his English professors were doing. Mark observed that people in the law firm appeared to be less passionate and inspirational compared to his English professors. He wanted to make a difference in the world and realized that a career in the legal field would not provide the types of opportunities he was interested in pursuing.

Mark shared that he liked teaching at a college level because he liked the freedom and creativity that a college setting provides him as an academic. He thought he could come up with his own ideas about what he liked to do in classroom and not be restricted as is likely to be the case in most high school settings.

Mark indicated that he did not like to describe himself as an expert in any area. He stated he considered himself a "true generalist" (personal communication, May, 2014). He said that he liked to be able to teach a variety of subjects. For example, he has taught literature, drama, film classes, and international studies and coordinated study 
abroad programs. He has taken students to Florence, Italy, and London. He also mentioned that he enjoyed exploring new areas of literature and film.

In terms of diversity in the classroom, at the time of the study, Mark shared that he had one or two African Americans, some Asian Americans and students who selfidentified as Hispanic enrolled in the courses he was teaching. He mentioned that he always had four or five non-native English speakers from a variety of linguistic backgrounds enrolled in his courses in any given term. Mark is in the adaptation stage of the IDI continuum.

Amy. The second participant is Amy. She has been teaching for 23 years, 13 years of which have been at the community college where she is currently working in the English Department. Amy owned and operated an agricultural company in her twenties, but she decided to pursue a Masters of Arts degree in English and switch to a career in teaching. Her area of expertise is in creative writing, American literature and linguistics.

Amy shared that she enjoys teaching at the community college level because she loves the content she teaches. She says she likes to talk about writing, linguistics, language acquisition and literature. Amy described the classes she was teaching at the time of this study as being comprised of predominantly White students with about $10 \%$ Hispanic, $8 \%$ Asian, and about 3\% percent African American students. She also has Eastern European students in some classes. Amy is on the cusp of acceptance on the IDI continuum.

Liam. The third participant is Liam. He is the only part-time instructor who took part in this study. Liam has been teaching for five years in the Humanities Department. 
Prior to teaching at the college level, he was a high school teacher. He describes his area of expertise as being in reading and teaching academic skills.

Liam reported that he did not like to teach at the high school level because he felt he had to be a disciplinarian and he had to "fill time in a way [he] didn't like" (personal communication, April, 2014). He shared that he likes to teach in a community college environment because he feels it is a more equal interaction. He stated "I like the model of I'm here in the classroom for whoever decides to show up and learn and if you decide to show up and learn that's great. And if we don't quite fill the whole hour, that's okay, and if we have to go five minutes over the hour you'll bear with me because we're meeting on more equal terms and I'm not responsible for what you do outside of class. I'm not responsible if you don't do your homework. There are no parents to talk to" (personal communication, April, 2014).

In terms of cultural diversity, Liam's classes were made up of predominantly Caucasian students; however, he said that he also had many immigrant students as well as some African Americans. Liam is on the cusp of acceptance on the IDI continuum.

Heather. Heather is the fourth participant. She is also a member of the Humanities Department and has been teaching for 15 years. She shared that she likes the community college atmosphere and especially the fact that community colleges enroll anybody who wants to go to college. She specializes in Composition and Rhetoric. She also teaches literature classes.

In terms of cultural diversity, she says some of her classes can be very homogenous, but others can be very culturally and racially diverse. She says she has 
noticed an increasing number of Hispanic and Eastern European students in her courses. She describes them as U.S. born bilingual students. Heather is in the minimization stage of the IDI continuum.

Jake. The fifth participant of the study is Jake from the Integrated Media Department. His expertise is in film sound, primarily in post-production stages. He started teaching at this community college in 1994 as a part-time member of the faculty. After several years of work at the school, he was hired full-time when a new grant program was established. Upon the end of the program, he left the school for seven years. When a new integrated media program was started at the college he was invited back to teach part-time as an adjunct instructor and later that year was hired full-time.

Jake related that he likes to teach college level classes because he thinks it is more satisfying in terms of seeing students engage in what they learn. He said that he especially liked to teach at this particular community college because compared to other places he taught, he felt that this school provided a better learning environment, which provided students more hands-on practice and less lectures.

In terms of cultural diversity, Jake mentioned a big difference between his classes when he first started teaching twenty years ago and the composition of his current classes. He said his classes in early 1990s were comprised entirely of young Caucasian students. Today, his students are a mixture of older and younger students as well as one or two African American and many non-native English speakers. Jake is in the minimization stage of the IDI continuum. 
Alice. Alice is the sixth participant in this study. She has been teaching at the community college level for 13 years with a total of 18 years of experience in teaching. She started as a part-time instructor and eventually received a full-time appointment at the college. She teaches in the English Department and she stated that her area of expertise is in the creative use of language, creative writing, and technical writing. Alice is interested in languages and speaks Spanish fluently. She mostly teaches technical writing and fiction classes.

Alice shared that she teaches at community college level because, "it is what it felt most natural to me. It feels like a good use of time for me and it feels like a good use of my capabilities" (Personal communication, May 2014). She thinks at this level she has the opportunity to "get work done, and feel like we are really engaging ideas."

Alice stated that in addition to her mainstream students, she typically has nonnative English speakers, mostly from Eastern European, Asian, and Spanish speaking countries. She also has two or three African American students in each class. Alice is in the minimization stage of the IDI continuum.

Sam. The seventh participant is Sam. He has been teaching for a total of eight years with five years at the community college level. Sam's area of expertise is in postsecondary reading and adult education. He teaches full-time General Education Development (GED) classes within the Adult Basic Skills Department.

After earning a Bachelor of Arts degree, Sam traveled to France where he took classes at the college level for two years. Upon his return to the U.S., he studied for his Masters in Teaching degree while working at the French-American International School 
as an extra-curricular assistant. Even though he hoped to work in K-12 setting, he found himself struggling to find work, stating "I didn't think that with the state of the economy that I was going to be able to get into the high school level." He decided to study for a reading endorsement and was hired as a last-minute reading instructor at this community college to teach a reading class. Several terms later, he moved on to teach GED classes. In time he was hired full-time in this department.

In terms of diversity, Sam's students hail from wide variety of countries of origin. A broad number of languages and regional dialects are spoken in his classes. Sam shared that there are increasing numbers of Hispanic, Russian, and African immigrants and refugees from a broad range of regions enrolled in his courses. Sam also spoke about his former employment situation in another community college where there were large populations of students from Southeast Asia and Russia. Sam is in the minimization stage of the IDI continuum.

Barbara. Barbara is the eighth participant in the study. She is a member of the Humanities Department and has been teaching for 15 years. She was a high school teacher for four years prior to her employment at the college. Barbara holds a Masters degree in English. She mostly teaches writing classes where at least a third of her students are non-native English speakers. She related that this number can be higher in courses with fewer sections.

Barbara thinks that the community college setting is the right fit for her because she has a diversity of students and she likes to help them in terms of writing skills and life skills, such as taking responsibility for their actions. The majority of her non-native 
English speakers list Spanish, Russian or Ukrainian as their mother tongue. She also has one or two African-American students each term. Barbara is in the minimization stage of the IDI continuum.

Lawrence. The ninth participant is Lawrence. He has been teaching biology classes at the college level for 17 years. He describes his expertise as being the disciplines of cell and molecular biology. He began his career at this particular community college as a science laboratory coordinator, and when a teaching position opened, he was hired as a full-time faculty member.

When asked about the typical make up of his classes in terms of diversity, Lawrence said he seemed to regularly have Hispanics and Asian students who are nonnative English speakers. He also reported having some Eastern European students. Lawrence is in the polarization stage of the IDI continuum.

Rick. The tenth and last participant is Rick. He has been teaching at the community college for 18 years. Prior to his current position, he was a high school teacher. Rick began teaching at a community college level with an unexpected job offer. He was invited to an interview to teach at the community college and was subsequently offer a position. He stated that his area of expertise is in automotive technology and vocational education and management.

Rick teaches automotive classes in two-year cohorts. He finds that teaching at the college level is "a lot more rigorous and academically challenging." He said the department cross-walked their curriculum to fit the requirements of National Institute for Automotive Service Excellence (ASE), National Automotive Technicians Education 
Foundation (NATEF), and Ford Service Technician Specialty Training (STST) program. Therefore, he selected his materials from the variety of materials provided on the ASE and Ford Motor Company websites.

Rick stated that his classes were lecture-based in the morning hours and in the afternoon, involved practical application practice in the laboratory. He described the laboratory as the area where students worked on vehicles and applied theoretical knowledge to real-life problems.

Throughout the interview, Rick maintained that he did not notice any differences between mainstream students and students from diverse backgrounds. Therefore, he did not see any need to make adjustments to cater to the needs of any specific student or students. Rick is in the polarization stage of the IDI continuum.

\section{Responses to Research Questions}

The findings of the narrative study were analyzed using the process described by Creswell (2005) by writing a narrative discussion to explain findings in response to the research questions. In order to retell each participant's story and to avoid introducing my own voice and biased perspective, I followed Creswell's suggestion of using "extensive participant quotes and the precise language of the participants and carefully constructing the time and the place of the story" (p. 484). I analyzed their story for themes that emerged in response to the research questions from the interview data. In addition, while I did not administer the IDI to correlate participants' teaching practices to their instructional activities, it was valuable information to see an assessment of their intercultural competence at an individual level. This information may, in fact, explain 
how intercultural competence manifests itself in the classroom in terms of instructional strategies. Therefore, while analyzing the data I did not disregard the participants' intercultural competence levels and used them wherever I could to be able to better understand the depth and breadth of the instructional choices they made. The following presents the emergent themes that inform each of the research questions.

\section{Responses to research question one: What specific culturally competent} pedagogies do effective community college instructors use? In response to the first research question, three themes clearly emerged. The first theme was materials selection that reflect diverse ways of knowing. The second theme was teacher's characteristics, and the third theme was teaching activities.

\section{Material selection that reflects diverse ways of knowing. Five participants} expressed that they intentionally selected instructional materials that reflected diverse experiences and values. It was clear from the data that the teachers who taught in the Humanities and Adult Basic Skills departments made a conscious effort in choosing diverse materials.

The first participant that mentioned that he intentionally designed courses to meet the needs of diverse students was Mark. He said he paid attention to who his students were and what their interests were in each course he taught. He emphasized that he constantly works to find accessible, interesting, challenging, and provocative course materials based on his desire to expose his students to different lived experiences. He explained: 
I'm doing an Intro. to Fiction class right now, so I'm trying to make sure that I have stories by men and stories by women, stories by more affluent people, stories that capture experience that's more marginalized. I'm trying to select stories that are from other traditions in translation not just sort of very traditional sort of white, Anglo-Saxon American experience, but also Asian experience, and some stories from African writers. ... It's a fiction class, but I try to make sure that there are several examples from different traditions. Similarly, in my film classes I try to make sure that we're drawing upon different types of stories so it's not all sort of Hollywood mainstream films. I want students to see people like them on screen as much as possible ...I definitely take into account who the students are...

Mark also drew upon links and resources that spoke to a variety of cultural backgrounds that help students understand the relevancy of education. He provided a specific example:

There is a film called Dark Girls and it's about skin tones and skin color and the the prejudice around mixed race, particularly women. And how all - lightening cream, and there's this sort of hierarchy and there's all - there's, you know, competition and judgment and it's very invisible to a larger mainstream culture that sees people, as okay you're black, or you're white, or you're - you're mixed race, right. I don't know what you are, right whereas there's a tremendous, subculture around these issues. 
Mark brought a variety of resources, including web link suggestions that reflected different cultural experiences around the topic they explored, but they were not assigned to every student. He told his students, "if this issue is interesting, or if you want to explore this issue about race in a - in a way that maybe you've never thought of before, here's a short trailer. Check it out. And if you're interested, here's the full - here's the full thing."

Similarly, Amy took into consideration her students' backgrounds when selecting materials. She usually selected readings written by people from all over the world. She wanted her students to think about different worldviews and reflect in their class work. Amy said:

There is a strong Ukrainian population and kind of Eastern, former Eastern block countries those students who are here [that] I get in classes. So I'll bring in readings that are written by a variety of writers from all over the globe to illustrate how we have a common human experience but we just voice it differently and also to just have them think about different areas of the world outside of Portland, Oregon, or Gresham, Oregon.

Another participant who also incorporated materials that reflected diversity in her classes was Alice. She said she liked to introduce different ways of thinking to her students and expose them to different social experiences. She thought the best way to do this was to use materials written by different authors from different parts of the world or bring videos reflecting others' experiences in different countries. She could easily do this in her fiction classes. She said that she brought a map to class to show the students where 
each author that they would read in class originated. Alice shared that she regularly facilitates classroom conversations focused on why they would read authors from different parts of the world and the value of this diversity of perspectives. Alice emphasized that she made it clear in her syllabus why each story was included in the course and that her express goal was that of cultural exposure to different ways of thinking.

In her technical writing classes, Alice related that she liked to bring videos to watch in class, and whenever possible she preferred to show non-western ways of doing things so that students could be exposed to different experiences and ways of thinking. She said:

We were watching a TED Talk to look at how well the presenter used the visuals in the screens. We were looking at specific technique, but I chose to give them a talk by a guy from Qatar and it was about how they've used desalinization as a process for their nation to prosper. So we could have watched a TED Talk about anything but I thought here's an opportunity to just show them, "Oh, yeah, remember the Middle East? And look, here it exists not in the context of war, not in the context of a tyrant, but in the context of this nation that's doing something wonderful." So mostly it's when I bring in supplementary materials, I'm always looking for not just something that will do the job but something that might also speak to diversity of experience.

Alice also carefully selected stories that had non-American characters in them such as people of color or people who were from outside of the English speaking world. 
She said instructors in the department would keep an eye on each other's reading list. She said, "we call somebody out on it when we see it. 'Wow, that's pretty white,' or 'that's pretty male.' We call each other out."

Another instructor who used materials reflecting diversity was Sam. He said that he tried to choose materials that reflect different cultural perspectives. He emphasized that he worked to include readings that are different from the dominant culture although he thought he did not bring in these materials as often as he should into class.

Sam mentioned that he thought he had a lot more room in social studies classes to choose materials. He said, "I bring in a wide variety of perspectives on American history so that the students will be interested in it rather than just hear about another president who did great things. They might hear about the Mexican- American War or the Trails of Tears." Sam also added that some specific course outcome goals, like understanding some key grammatical concepts, do not lend themselves to activities designed for appreciating other cultures or perspectives. In such courses, even though he recognized it was a very small concession, he made an effort to use non-western American names in grammar exercises.

Heather chose novels and short stories from diverse backgrounds with different kinds of characters, authors, time periods and some stories in translation. Some examples she gave were Tony Morrison, Khalid Hosseini, Gish Gen, and Junot Diaz. She created a list and gave the students the freedom to choose what they want to read. She often asked her students to respond to a story that has a personal connection to what they read so that 
they thought about how the story impacted their perception of their own lives and also reflected things that happen in their own lives.

Teacher characteristics. Another theme that emerged from the data was teacher characteristics. Almost all participants mentioned the certain practices that they used an enhanced learning environment strategies in class and supported all students as well as students from diverse backgrounds. These teacher characteristics were summarized in four sub-themes.

Creating a comfortable class environment. One sub-theme that clearly emerged from the data was creating a comfortable class environment. For example, Sam realized that in his classes, students may have had culturally different educational experiences. He stated that he worked to create a very relaxed, informal atmosphere in his classes wherein students were able to approach him and talk about issues in class. He tried to achieve this by being open and informal. Sam shared that he realized that some students may have had negative relationships with past instructors, which impacted their learning and achieving their educational goals. Therefore, he wanted his students to feel encouraged in his classes. He made sure that he was approachable and gave his students the feeling that they can talk to him about issues in class.

Alice was also very careful about making her students feel safe in her classes. She also mentioned situations wherein she has occasionally felt compelled to warn her students who have exhibited prejudices against students whose first language were not English. She said native speaker students did not like to read papers written by nonnative speakers because of the grammatical errors in their papers, which made them 
difficult to understand. She wanted these students to focus on the ideas related to the target topic rather grammar. She said, "I go so far as to say you're being racist without saying it." She said she sometimes told some students, "you're letting something affect your ability to do what you're supposed to do and you need to put it aside." She also added a lot of times she was not very nice about it because "I just don't think that there's room for it. I personally don't have room for it and may be because I'm sensitive to it because of my husband or just because I'm a human, but that has happened before in a class and it's happened more than once. It's happened a few times."

Mark also mentioned that he wanted his students to express themselves freely during group work. He wanted students to be exposed to different ideas or different ways of thinking. He thought that the key to motivate free expression of perceptions was to create a safe place in the classroom. He said

As much as possible the classroom environment has to be a place where we are all together working toward a better understanding of it. And I think that's a complicated thing. But I think that some of that can happen if you persuade students that their own lives are worth examining, then you empower them to share elements of who they are. I think that's also important to model that you know, I am not the expert. I do not have all the answers. I try to keep my classroom persona very fallible so that students don't feel like things are too high stakes. They're important but they're also relatively low stakes, especially in the classroom. So that you're not losing points or you're not a good or bad person, or you didn't have a bad idea because of the way that you saw this. 
Similarly, Amy expressed her desire that her students feel comfortable in a classroom environment, especially in front of each other. She said she achieved this by having them do group presentations.

...group presentations where the pairs will share with the group whatever their opinion is on the topic and speaking in front of the group, I try to do that so that everyone feels what it's like to be at the front of the classroom and facing their peers and speaking with this impromptu kind of language; I always try to do that to make everybody kind of comfortable with the whole classroom environment. So I take the focus off the teacher and put the focus on the student; that seems to keep them most engaged whether - no matter where they're from.

Rick also mentioned that he intentionally worked to create safe environment for his students. He related several situations where some students were picked on for being perceived as different. He said, "...it is usually the Oregonians or the Caucasians who are causing the problems." He said he would prevent it immediately. "Maybe they'll start teasing a Hispanic student about his background. Maybe involvement with cartels or something like that. I'll shut it off right away. We don't talk about it."

Lawrence also stated that he tried to be unbiased and made his classes free of racist comments. He said, "I make it instantly clear that is not appropriate, and that students making statements like that will be ejected." He also said that he would be very patient, especially with foreign-born students who struggled with English language. He tried to make them feel comfortable by waiting until "they get it out whatever they're 
trying to say, and not just jump in and fill in the words for them, but just sit back and have body language that says I'm here; I'm waiting. You're fine."

Liam shared that he also worked to create an environment where students felt comfortable. He said he tried to model being polite and demanded that his students be polite to one other. He added, "I am very open to different cultures, model respect for them... simply I show the respect that I would intend for everyone to have and let that be my teaching." He added that he models curiosity as a way of validating his non-native English speaking students' cultural backgrounds and showing respect. He explained that whenever the opportunity arose, he asked these students to compare a point discussed in class to their own language.

...I'll ask people with other language backgrounds how does your language handle this, this grammatical construction? How do verbs have to agree with each other in Russian, is it the same way as English? Or you notice that we don't have - Arabic doesn't differentiate between subject and object, can you show us an example of that or something like that. And so that engagement is something I model when the opportunity arises...

Self-reflection and awareness. The second sub-theme of the teacher characteristics theme was self-reflection and awareness. Barbara acknowledged that being self-aware was a key component in dealing successfully with diversity. She related that she had attended several diversity workshops where she learned about other cultures and had the chance to examine her own cultural beliefs. She said that she recognized that she grew up in a small town with very limited personal experience with cultural diversity 
and needed some training in that area. She shared that these workshops helped her understand why some of her students approach to some assignments differ from, as she put it, how a so-called mainstream stream student typically would approach assignments in her courses. Barbara explained:

One of the things that stood out for me was that as Americans, we're very direct. We - we cut right to the chase. Go right to the thesis. Verbally as well as in writing. But, apparently in other cultures, you tell the whole story. You can't get to the point until you've told the whole story. And that helped me understand why I got frustrated with the students who come in and they want to take minutes telling a whole story, instead of just getting to the point. So I think that makes me more patient with students who need to tell the whole story. It's not that they're wasting my time, it's that's the way they've learned to explain - to explain something. And maybe ask for help, or make a point, that's how they've learned to do it. So I think I'll be a little more patient with that, now that I know where it's coming from.

Alice commented on her learning style. She was very cognizant of her own learning style and described her learning style as "110\% auditory." She realized her learning style was significantly different from the majority of her students. She became aware that if she taught favoring the way she learned, she would put many of her students at a disadvantage. Therefore, she learned to vary the way she presented the content of her lessons in order to differentiate instruction for diverse learners. 
Alice also shared that she became aware over time that she was making assumptions about what students were already expected to know as students, especially those who came from different cultural backgrounds. She related that there have been many instances when a struggling student came to her for help and she found that the root of their confusion was based upon assumptions that she had made while giving the instructions for the assignment. She explained, "It's not something in the instructions. It's something behind the instructions. It's usually the assumption that's undergirding the assignment or a skill that I would have expected someone to have that maybe was just not part of their bringing up, or something like that." She also gave a specific example of a certain group of Latin American students who came to the college to take classes. She said that she reminded herself that she could not just assume that these students would already know about what format to follow when writing reports, as she would have with a so-called mainstream student. She stated:

For them, I completely have to deconstruct all of the assumptions that I can just normally make in a classroom about why we have alignment, why there's an invisible line that puts all of those together, and because this is larger, it's the most general and most important heading on the page, to explain all of those assumptions. And occasionally in a class, I will look around the room and realize you need to do that, not in a way that's saying, 'Hey, you. I bet you really need' but just in a way that says...As a Westerner, when I look at this page, I don't have to read that there's an invisible line here because we're supposed to know. And I'll go over why it is the way it is. 
Sam sympathized with his non-native students because of his experiences abroad. He observed that non-native students were reluctant to speak in class or ask questions. He expressed that he could understand where they were coming from because as a students in France, he often found himself in the same situation where he didn't want to speak up because of his lack of vocabulary and accent. He used quick writes to give these students a chance to be heard. He said "everyone has to write something for a certain amount of time then it forces everyone to think to express themselves and then even if they don't raise their hand to answer then they've still gone through the same process." Sam added that when he had classes wherein there is a mixture of young American students who are native English speakers and non-native English speakers, especially older students, he has inevitably experienced conflicts in terms of interpersonal communication styles. In that case, he said that he has tended to adapt his communication style to that of the non-native students, especially if they were in the majority. For example, he shared that in these situations, he has tried to make the tone of the courses more formal and regulated than he would if the class was comprised of just younger American students who all speak English as their native language.

As mentioned earlier, Sam strived to create a relaxed, informal environment for his students. However, he realized that creating an informal environment may not always work for students from diverse backgrounds. Sam spoke about some eye-opening experiences as he learned more about his students that helped him change his own behavior and perspective in class. He said: 
I remember I was teaching a night class. I don't think I had a native speaker in the classroom and it was just eye opening because I realized that the students behaved differently. So again I said that I try to be very informal and open and I would ask students to call me "Sam," because I don't want to be Mr. ... or Instructor or whatever it is. But the ESL students and particularly the older ESL students had a very difficult time with that. They wouldn't call me Sam, they would say, "Teacher," which was interesting. There was a student. He said something once that in his country and culture and I imagine in many others like similar ones, that education and educators are valued and respected. He was always surprised by how Americans didn't seem to value or appreciate educators. So that made me think that you know that maybe me being open and informal with certain students wasn't always the good thing, because they needed, maybe a little bit more distance in order to be, I don't know, true to their culture, but it just made them feel more comfortable if there was more of a distance between instructor and student.

Availability outside of the class. A third sub-theme that emerged from the data related to the teachers' characteristics theme was being available to support students outside of class time. Heather mentioned that she had quite a few students whom she saw outside of class, especially those who needed more support with their English. Also, she had students who needed help with a reading passage before class so that they could participate in class discussions. Heather shared that she thought if she made herself 
available outside of class for students to ask questions, students tended to feel more comfortable and less self-conscious.

Lawrence also believed in supporting students outside of class. He stated that he especially emphasizes in class that anyone who needs help should contact him. He also made it clear that he was always available during his office hours, and he also encouraged students to email him if they were struggling with concepts. Lawrence shared that he felt it was important that he always answered student emails within 24 hours.

Liam chose to help individual students outside of class whenever he felt in-class instruction was not adequate for certain students, especially those who came from another country. He explained, "I tend to deal with that on a one-to-one basis... So I work with that very individually through office hours and through email."

Sam noticed that his students do not use his office hours for extra help. He thought some did not come to office hours because of their cultural upbringing. Therefore, he decided to hold his office hours in the classroom instead of in his office. He went to class 30-minutes before the class time. This gave students a chance to talk to him and ask questions in a non-threatening, familiar environment. Sam related that this practice also provided the opportunity to get to know his students better and therefore, better prepared him to anticipate and adapt to their needs.

Learning about students. Amy stated that she used writing assignments to learn more about her students. She used a lot of narrative assignments wherein she asked students to explain something related to their upbringing or their parents' upbringing "to get a feel for where they're coming from, if they're [a] first generation college student, if 
they grew up in America or came here later in life, so a lot of those narratives will help me understand their background more. And I also, in every class, like to get some kind of initial feeling for how they learn to read and write because that will tell me a lot about their writing skills."

Jake was also greatly interested in learning about his students' backgrounds so that he could make his lessons culturally relevant to them. He said that because his students' backgrounds were different than his and he is the one who lectured them, he had to know who his students were. He did not want to assume that his classes were monocultural. He explained:

I try to do my best to know and understand everybody that's in my room and ... understand where everybody's coming from. So I think it's important for an instructor to understand the culture of the room that you're working in because if you just treat it that everyone's this black or white thing, you're going to lose people. I think the students appreciate that, especially when you're lecturing. You want to engage and ask questions, invite conversation, because it should be more than just somebody putting PowerPoint up and running through the slides and then giving a quiz. There has to be some level of engagement that's a little higher.

Similarly, Mark expressed the importance of knowing who his students were and something about their cultural backgrounds. He said that whenever the College Board produced a report on the current demographics of the student population, he made sure he looked at it and reflected on the implications of the shifting changes on his own teaching 
practice. He was interested in knowing about the high schools that feed into the college and difference between those high schools in terms of the racial and socioeconomic makeup of those schools and what issues they had that may potentially influence the students he would be teaching.

Barbara was another participant who shared that she paid attention to who her students were as individuals, including learning about their cultural backgrounds. Barbara said she paid attention to the diverse backgrounds of her students and always made sure to know whether they had linguistic or cultural diversity, or if they were the first to go to college in their family. She related that she took all these factors into account when she designed learning activities.

Liam also mentioned that he learned about his students through conversation and their writing assignments. He related that he loved to listen to them during breaks as they talked about themselves so that he could learn more about them as individuals.

Instructional Activities. The third major theme that emerged from the data was the specific instructional activities that the participants used. What follows is a presentation of each of the sub-themes that emerged from this major theme.

Allowing students to use their backgrounds. The first sub-theme related to instructional activities is allowing students to use their backgrounds in learning tasks or projects. Heather liked to allow students to bring their cultural background into the classwork rather than dictating the particular topics they research. For instance, she gave her students the freedom to choose what they wanted to research related to a particular topic that she outlined within a domain. She gave an example: 
We're working on a unit in Writing 121 about food. So food is definitely a very cultural thing. And students have, within that particular topic, the freedom to choose what they want to research, and so some students do choose particular sorts of ethnic foods. Like I had one student last term who wrote about pork in the black community, and why some people saw pork as sort of a foundation food and heritage foods, and others saw pork as unclean coming from the Black/Muslim background. Sometimes they'll do readings about like - they have one coming out next week about why people eat, and how people's eating habits change when they come to the U.S. But food is one of the last things that change within those populations...they really hang on to their cultural foods sometimes more than their languages, their religious habits.

Heather said allowing students to choose their topics maximized their learning as they created a personal connection to the material. She tried to give some room for them to say who they were, where they came from and what their families did both here and in the places they came from prior to moving to the U.S.

Jake is another participant who liked to give students freedom to bring their backgrounds into the creative projects they worked on rather than dictating to them what to do. Jake related that he felt that this instructional strategy made the learning more meaningful to diverse groups and created opportunities for students to learn from each other.

Jake shared that in one of the class projects students were required to present how to do something. He liked this activity because it not only allowed students to be media 
experts on a short piece but also gave them opportunities to learn from one other. For example, in one of his classes, a student from Eastern Europe made a piece on how to cook a certain dish from his country. It was a difficult dish to make; yet the whole team learned how to make it based on the fact that this student chose to use something reflecting his cultural background.

Amy also realized that when she allowed students to bring their backgrounds into assignments, their learning was positively impacted and they improved much faster than they did without familiar contextual elements present in assignments. She gave an example of a Spanish student whose writing exhibited tremendous improvement when she wrote about topics with which she was familiar. Amy said the student's writing became more descriptive and more personal. Amy said that this student "taught her a lot about letting people just discuss things they are familiar with but maybe they haven't reflected upon because she came here when she was maybe 10 years old but she had all these memories..."

Using students' backgrounds as a teaching tool. Amy utilized her students' backgrounds to stimulate discussions and help students see that there were two sides of an issue. She gave an example about perceptions of undocumented immigrants receiving drivers' licenses.

I'll have students whose parents maybe came here and they were born here and now they're arguing that people who immigrated as illegal immigrants should be able to get their driver's license, like that was some argument and then there's some kids in class who are like, "No, they shouldn't even be here," and so those 
arguments get going. But usually they're pretty friendly. I can't think of one time that it's become hostile but it's good to hear both sides. I'm glad they speak out against each other ... so no matter what their view is they have to keep thinking of the opposition and restate what somebody else would believe because then at least they have - it's called the art of concession.

Similarly, Mark was another participant who believed in the importance of letting students capitalize on their own experiences and perspectives. He referred to his practice as having a student-centered approach and said that many of his assignments require students to take what they learned and apply it to their own lives. He explained:

I don't want them to tell me what the textbook says about this particular issue, I want them to show me that they can apply this issue to some issue in their own life. So, whether it's an essay or my, you know, quiz questions, I'll often ask [students] to use an example from your own life that illustrates this concept. Or, I have students in my film class do presentations at the end where they bring something from their own experience and then also apply or bring in some of the concepts that we use.

Using group or pair-work activities. In order to encourage students to take part in learning activities and learn from each other, some instructors said that they used group or pair activities. For instance, Sam shared that he used many group work activities to encourage the participation of students from diverse backgrounds. $\mathrm{He}$ thought using group and pair work activities worked well, in particular for foreign-born students because they were very reluctant to speak or ask questions in class, especially if 
there were a lot of native English speakers in the class. He said, "I sympathize with them because I was a student in a French university and I didn't want to speak up because my accent was bad and I didn't have the vocabulary." Sam also added that when he grouped students, he mixed them and did not categorize them as the English as a Second Language group and native English speakers group because he did not want students to think that they are separate or different from others [based on their linguistic background]."

Similarly, Mark utilized small group discussions when he knew he had students who may be reluctant to participate in large class discussions because of their cultural background. In such classes, he avoided doing classroom activities that relied heavily upon large group discussions wherein students were expected to raise their hands and speak in front of large group of people. He said he observed that many Asian students in his classes were not very comfortable speaking in front of a large group. He was not sure whether this reluctance was based on perceived language barriers or other cultural reasons, but he decided to design activities that involved group discussions rather than whole class discussions in classes comprised predominantly of students from Asian cultures.

Amy also liked to use pair work activities rather than group work. She said this provides students with opportunities to hear and consider others' opinions. She explained:

Any kind of pairing, pairing share, is really effective more than three or four in a group but two in a group so that they have to communicate with their partner and 
not pairing - you know pairing maybe the traditional White student with somebody who is from a different culture, that works very well...

Amy also stated that when there is a controversial issue being discussed, she provided her students with some templates which helped them to keep considering the opposing views. It also helped them restate the opposing views before they expressed their own opinion. She explained that she thought that this practice helped students understand that there may be different views, and acknowledging this diversity gives them the ability to empathize with other points of views. She also shared that sometimes she required her students to take a different view from their own and defend it. "By the end of it they've lost track of their view, you know, because that's part of the goal, is you can't stick to your view; you just have to read what was written, pick up with it, restate it, and then counter it so it helps them detach from whatever their opinion is going into it. It's hard for them. It's hard to state the opposition."

Barbara was another participant who encouraged group work so students both learned from each other and learned to work with people from different backgrounds. She said that at the beginning of a term she allowed students to work with others sitting near them. She noticed that students gravitated toward sitting with people who were similar to themselves, such as sharing a common language or an ethnic background. Therefore, the groups were not very diverse in their perspectives. Barbara said that she had no problem with this because she always tried to build comfort at the beginning of the quarter. Later in the term she designed activities that required more shuffling of the groups and pairs which forced students to learn from the others in the room who were of 
different cultural backgrounds. She did this because she wanted students to leave their comfort zones and become accustomed to working effectively with diverse students.

Liam was another instructor who encouraged students to work in different groups through specific activities. He often used what he called punctuated lectures which allowed students to agree or disagree on a concept and explain it to someone else. He said, "I can get people to stand up and move around, go to a different place, regroup themselves, to conduct and activity, for instance in small groups."

Taking learning styles into account. Alice made a conscious effort to reinforce the information she was trying to convey in three or four different ways as she realized many of her students had different learning styles from her own. Recall that Alice shared that her personal learning style was primarily auditory. Therefore, she always made sure that her learning style did not affect the way she delivered the content in a way that may disadvantage her students. She explained:

I teach in a computer lab, so there's always a hands on component and there's always something for them to look at and I'm always delivering this way, too. I also tape my little tiny talks about my material and put them up on the portal so when they go home, they can replay. Because sometimes if I'm going too quickly over something or I'm, for example technical writing, there are some cultural concepts that when you look at a page and you say, "Oh, this is a first level heading, second level, third level," you look at the page and you make certain assumptions about what it's saying to you but students who aren't as versed in this 
particular culture, they need a slower, more deliberate explanation of why it is the way it is.

Alice related that she realized that demonstrating or letting students explain the material was much more effective way of teaching than merely explaining the material. She said:

What I've tried that doesn't work is talking, but what I've tried that works a lot of times is to just have the student describe to me the nature of what they're working on and write it down, kind of like my therapist does, and then read it back to them, like, "Oh, this is what you told me." And a lot of times, they're afraid to put it down on paper because it somehow becomes illegitimate. If they say it to me and I write it down, then all of a sudden I'm validating it for them, and so the talking usually doesn't work but doing something usually is useful.

Alice also mentioned that one of her students from India was amazed at the fact that Alice was so good at looking at things from a different perspective and finding a way to present concepts to her students in a way that they might relate to new ideas. She said, "his exact words were, 'It's interesting how you do that, how you consider that there might be another way to do it,' or something to that effect. I could be better at it for sure. I could be better at it."

Jake was another participant who claimed that it is important to him to deliver content in different ways to accommodate different learning styles. In their program, the same students took mostly the same classes in other areas of the program such as 
photography, video design, and broadcasting. Therefore, the program directors worked closely together in curricular design and had students share core projects.

Recently, the program faculty decided to use a service in lieu of requiring written materials or textbook. He described this service as an online tutorial that trains students in using software. He said, " it trains really, really well in the sense that there's both texts, there's video, there's how and do kind of things, things we used to have to do traditionally in our classrooms as a part of the bigger picture." His program contracted with the company and received a significant discount for their students for a full year. Jake shared that students were given full access to "absolutely everything", about 300,000 titles, which includes programs such as Photoshop and Microsoft Word. He explained:

We found that that's good for students that have different learning styles and different speeds at which they learn. We give them assignments and then they go home and they watch and they do them on their own time when they can do them, and if they miss something, they can go back. Whereas in the classroom, especially with computer-based instruction, sometimes if somebody doesn't get it you can miss a step. The whole class has to stop and then that person, pretty soon that person's always stopping the class, here's a lot of resentment that goes on in there, whereas now, I can keep the activities to, "Okay, if you're having an issue, here are some titles. Please watch those." And if somebody's having a really specific issue, we can rewind it back to fall quarter when we did this. "Here, rewatch these five lessons again because you're falling behind." 
Jake said using this program helped students with diverse backgrounds learn the material better. He explained, for example, if a student tended to learn more by listening, watching videos helped him/her. If someone needed to read what was being said, they could use the transcripts and read all the information. He added his non-native English speakers benefited from this program as well because the videos had subtitles in many different languages.

Allowing students to use their native language. Jake said that when it came to training for television and radio, he involved his students in performance-based activities and projects, such as giving traffic updates or reporting the news or directing a television show. Since everything was done live on a clock, the pressure was there to get things done fast and efficiently. He realized that activities such as delivering commands in a fast manner were very challenging for non-native English speakers to accomplish. His solution to this was to allow students to use their native language so they could experience the process in their own language, which he thought, also facilitated the learning process. He explained, "A non-native speaker, they have a harder time because where even a native speaker has a hard time delivering verbal commands to somebody, can you imagine having to take that in your native language, process it, and then actually speak to somebody in a very direct, short-clipped manner, in order to get a command across in a language that's not your own? That's a tough task. And so often times what I'll do, for example, we do traffic and news updates just as a mock radio show. We'll go through it and we'll do it all in English, for example, and then my English-speaking students, they'll struggle, everybody will struggle at it. But my non-native speakers, 
what's great is that if you let them do it, you say, okay, next time, I want you to do it in Spanish, and it's like everything just clicks in ... it becomes easier for them to read, easier for them to do all of it.

Jake provided another example of how letting students use their own language assists the learning process. He said he allowed a Japanese student to use his own language in a task of directing a television show because he was always struggling with the director position. He said, "it wasn't because he couldn't understand what was going on. It was just that he was slower to give the commands in English. When he did it in Japanese, it was funny, because everybody knew because we had done the shows so much. Everybody knew what he was saying, but it was so much easier for him to get the commands out and everybody else got to experience what it was like to be in that classroom."

Rick was another participant who thought his foreign-born students needed more support in the area of using and developing their command of technical language. Since he did not have any course books and used mostly online materials, he often referred students to the websites where he took the materials from and asked them to read the texts or watch the videos in their own language if translations were available. He said:

Students can go to the Ford website and choose their language if they're struggling with maybe doing the courses in English. They can study in their own language, usually Hispanic students do that. I ask them from time to time, "Hey, you seem like you were struggling with this information. Can we look at it in a different language?" And sometimes they do. 
Liam also said when he used group work activities, he did not necessarily group student in a way so that they would work with culturally different others. He, in fact, let students who spoke a common language group together so they would support each other.

\section{Response to the second research question: What motivates these effective community college instructors to use these culturally competent pedagogies?}

Three themes emerged in response to the second research question. The first theme was exposing students to different perspectives. The second theme was enhancing thinking processes, and the last theme was to facilitate the learning process through building self-confidence.

Exposing students to different perspectives. Some participants said they chose certain pedagogical practices such as group work and using materials reflecting diversity because they wanted students to learn about others' perspectives. For example, Mark made a conscious choice of selecting readings that captured lived experiences of some of his students because he wanted students "to be exposed to...readings that represent a very different experience and background so that students are challenged to look at reading not only in terms of written word but also the cultural context."

Heather also wanted all students in class to be exposed to variety of perspectives both from the materials and through their classmates. She thought that liberal arts education has many purposes and one of them is to learn to become better citizens. Heather said, "I don't think you can be better unless you can understand things from other people's points of view." She added it is often hard for her students to develop appreciation for diversity because "they've been in their box a lot of times, especially 
some of the sort of sheltered students, very religious students, you know very sort of isolated students who come in. It is really hard for them to learn how to understand each other."

Alice was another participant who selected materials reflecting different characters or cultures. She explained the reason behind her decision was to show her students that there were a lot of ways of doing something. She realized that many times her students thought there was only one way to do it, and her approach was to present them with the reality of having possibilities. She said:

Instead of valuing one cultural precept over another, can we look at the merits of both of them and see which one in which situation would be great or useful? So it's not so much a matter of this is the dominant culture we're in and let's acknowledge that these other ones exist and are useful. It's no, look at all these ideas we have and which one is most appropriate in the situation, or is there a marriage of these two cultural ideas, or basically what will be useful and practical, not what will reinforce what we already know and have.

Amy also wanted her students to understand there were different views and experiences from their own. She wanted them to think about these and reflect in their class work. She achieved this by selecting materials written by authors from other countries "to illustrate how we have a common human experience but we just voice it differently and also to just have them think about different areas of the world outside of Portland or Gresham, Oregon, to think about how fortunate we are really to live where we live." 
She had classroom discussions about issues around the world. She designed activities that required students do research on the topics of their choice or sometimes on specifically assigned topics.

I think it helps them really realize how many freedoms we have in America, how many people still struggle in America, and what it's like to move here from being outside of this country. We spend a lot of time discussing what it's like to immigrate to America and are people welcomed here really or do they struggle to integrate into the society? And then there's this horrible picture on the front of Time magazine of a girl who - in Afghanistan and her nose was cut off by the Taliban. Have you seen this picture? It's really horrifying. So the things like that where you're like, “All right, let's talk about human rights," and all of a sudden they realize that there's lots of violations of the things that we take for granted. And I just think it helps them appreciate what we have here and helps them realize why people would want to come here because I think we lose sight of that you know. It's people just want to come here to live off the system; no, not really. There's a lot of people who don't have any of these freedoms so that's a pretty important part of I think helping them think about that we are very fortunate in America.

Sam also explained the reason behind using group work was that it helped prepare students for real world. He said that in real world people do not always have a chance to choose with whom they will work. Therefore, everybody needs to learn how to function around people who are different from themselves or have different opinions. Sam 
explained that both students from different background and so-called mainstream students had an opportunity to work with people with different views in his classes. He said he would not tolerate disrespect among students and also tried to model how differences could be overcome in a respectful way.

Enhancing the thinking processes. The second theme that emerged from the data was related to helping students develop critical thinking skills. Mark used materials that spoke to cultural diversity because he thought it helped students feel like education was relevant to them and helped them to think for themselves. He said by bringing in a diversity of social issues like prejudice around races which might be invisible to people in the greater mainstream culture, he provided some students a place to identify with and some others an eye opening experience. Mark also shared that he also provided students with web links to resources where they can get more information about these topics in case they were interested in learning more. He explained:

I want them to think critically. I want them to see themselves as one voice in a rich culture that has a variety of other voices. I want them to understand areas where they experience privilege and areas where they don't. And I want them to be able to take some of the concepts and think about them going forward. I tell my Writing 122 students that in six months, I want you to remember these ten fallacies. I don't want you to ever have someone tell you that because everybody else is voting for this person you should vote for them too. Or, you know to use pathos as an effective argument strategy on you. And, my goal is that in six months that they will always remember these sort of higher level thinking skills. 
And see the relevance of them to their lives, not just as, okay, when I am in school I think this way. And then when I'm outside of school I don't have to do that. I want them to see the principles, the thought processes, the communication strategies that we do in class, as being about them. And being - and to see that these larger narratives in the society is happening. And it's either happening with them as participants, who have some idea about their - where they have control and where they don't. Or it's just happening to them. And if it's unexamined and it's not thought out, that they're missing out. Missing out on opportunities, making less good judgments and decisions than they otherwise would.

Mark added that his students from different cultural backgrounds tend to have greater awareness of issues like power and privilege or discrimination based on their personal experience; these students have seen how privilege and discrimination have worked while others may be blind to it. He wanted them to "recognize and make their own decisions and see how these structures and processes work." Mark further added the idea that he wanted his students to see themselves as belonging in college and in a world of ideas as they generally have not grown up seeing themselves as intellectuals or as college students. He clearly expressed that it would be a significant success to him if he could teach this to his students.

Similarly, Heather wanted her students to become better thinkers. She said, "it doesn't seem like a writing skill, but it is and to be able to replicate any task in another setting. So the idea with one of the core course like Writing 121 is that they run a good process for themselves, whatever it may be for conquering whatever task it is." 
Facilitating the learning process through building self-confidence. Finally, the third theme that emerged from the data that informs the second research question, what motivates these effective community college instructors to use these culturally competent pedagogies is facilitating the learning process through building selfconfidence. The instructors related a number of ways in which they worked to facilitate learning intended to aid in the development of students' self-confidence. The following presents three of the instructor participants' examples.

Sam used many group work activities in his courses. He expressed that one reason why he used group work was that he wanted students to feel comfortable and realize that other students are going through the same problems they were experiencing, such as expressing their opinions. Sam stated that he purposely designed such activities in a manner that helps students to realize that they were not the only ones who were having difficulties in the learning process. He, for example, had students explain concepts to each other rather than him lecturing about it. He thought this gave everybody a chance to be engaged in the material as well as interact with others.

Mark also stated that he was aware that many of his students were first generation college students or students who came from backgrounds where higher education may once not have been viewed as a choice for them. He also pointed out that some students simply did not think themselves as intellectuals. He made his pedagogical choices to support students to "get themselves as belonging here, belonging in college, belonging in world of ideas to talk about, think about and that would be a great success to me.” 
Barbara also mentioned that she designed some group work activities that would help boost students' self-confidence. She tried to build on each student's strong points and assign roles accordingly. For example, she observed that many foreign-born students had a stronger understanding of proper English grammar concepts than others do and almost always had the right answers to the questions to do with language structures. Therefore, she often included sentence level exercises that required knowledge of grammar rules. She said these activities helped build up non-native English speakers' confidence and that these activities assisted students who felt lost at times.

\section{Limitations}

Qualitative researchers identify possible limitations in their study addressing problems in data collection, unanswered questions, sampling strategies, or sites of the study and make recommendations for future studies (Creswell, 2005). The following presents limitations encountered in this study.

First, the sample size in this narrative study was small and the participants were all from one research site. With a limited number of participants, it is not possible to make broad generalizations about the culturally relevant teaching practices of community college instructors. In addition, this study investigated the teaching practices of instructors in a particular community college the Pacific Northwest; therefore, it is not possible to generalize the findings to instructors in other community colleges. However, the purpose of this study is not to generalize findings, rather it is to contribute towards the development of a detailed, complex understanding of the issue and to see how the participants address the issue in a particular setting (Creswell, 2008). 
Another limitation to the study was the way the participants were selected. I selected the participants from a pool of instructors who received either the Distinguished Teacher Award or Excellence in Teaching Award. These are awards created by the college to honor instructors who were recognized as being highly effective instructors in their fields. There is no scientific method used in selection of the instructors who receive these awards. Students and employees nominate who they feel deserve these awards. To my knowledge, there is always one person in the department who leads these efforts and encourages employees and students in that department to vote for the nominee. Although the departments show every effort to increase participation, it is possible that there are always students and employees who choose not to participate in this process. Therefore, it is highly possible that the effectiveness of instructors is determined by a small number of people and these characterizations may not reflect the opinions of the majority.

Another limitation of this study is that the participants do not reflect all of the programs in the college. Six of the participants come from the Humanities Department, which means more than half of the participants teach within the same discipline. Therefore, the findings of the study do not necessarily represent the instructional practices of instructors in other disciplines.

Finally, the participants in this study are all white, North American instructors. Not having participants of color or participants who come from culturally diverse backgrounds limits the findings to the experiences of a homogenous group of faculty. 


\section{Threats to Validity}

Qualitative research is interpretative research and recognizes the researcher as an interpreter of the data and an individual who represents information (Creswell, 2005). The data in this research came from a single one-on-one interview conducted with each participant. However, I read the data many times and created codes and themes to make sure that the participants' stories were reflected accurately. I also used member checking process to check the accuracy of their accounts.

As a community college instructor myself and coming from a different cultural background, I may have biases towards certain classroom practices and may favor others. For example, as a language teacher, I may favor pair and group activities in particular teaching and learning context over other pedagogical strategies. I may be more empathetic towards second language speakers and favor instruction that takes into account students' linguistics backgrounds. Furthermore, I may have a different understanding of cultural differences and dynamics in a language class as opposed to a college course in a different discipline. However, I showed every effort to be selfreflective about the way I interpreted the data and worked to stay as neutral as possible in

order not to interweave my worldview and biases into my interpretation of data. I did my best to keep my own perspectives and assumptions to myself so the responses of the participants were identified as the most significant data.

\section{Summary}

The results of the findings revealed several themes that serve to inform the research questions. In examining what culturally competent pedagogical approaches the 
participants used, three themes emerged from the data: material selection that reflects diverse ways of knowing, teacher characteristics, and teaching activities. In response to the second research question, that asked what motivated these instructors to use these culturally competent pedagogies, three themes emerged: exposing students to different perspectives, enhancing the thinking processes, and facilitating the learning process through building self-confidence. Tables 2 and 3 summarize the participants and the themes that emerged.

Findings indicate that the participants are cognizant of the growing diversity in their classes and that they make conscious choices to cater to their students' needs in what they consider to be an effective manner. However, regarding the IDI scores, it was clear from the data that instructors who taught Humanities and Adult Basic Skills classes fell into minimization, acceptance and adaptation stages as described by the IDI, which show a transitional orientation toward cultural differences and commonalities. These are orientations that recognize and appreciate patterns of cultural difference and a capability to deeply understand and shift cultural perspective, respectively. Interestingly, the data also showed that the participants who were in these stages according to the results of the IDI also chose materials that reflected diverse ways of knowing. It was evident from the interviews that in many cases, the instructors' academic discipline influenced the instructional choices they made. For example, the instructors who taught in humanities were more comfortable and free in adjusting their pedagogies compared to their counterparts who taught primarily in the sciences or vocational fields. The former used group activities so that student could share their ideas, used materials that reflected 
diversity, had more interest in knowing who their students' were, and provided opportunities for their students to explicitly draw upon their cultural background in the class work whenever applicable. On the other hand, the science and vocational instructors, who were in the defense stage, expressed that they did not have much choice in selecting materials or adapting their instruction in a reflexive manner and use culturally relevant pedagogies. They attributed this lack of flexibility to the perception that they were required to follow a comparatively stricter curriculum or had to align themselves with a certificate program, which required certain materials to be covered, than that of the Humanities and Adult Basic Skills and that this strictness allowed them fewer choices to modify their lessons.

It was also was evident from the data that many instructors shared common teacher characteristics, such as being available through office hours and email in order to support students and create a safe classroom environment. Several instructors made a conscious effort in learning more about whom their students were as individuals and as groups of students with shared backgrounds. The third theme was instructional activities. It was almost all Humanities and Adult Basic Skills instructors who used instructional activities that emerged in the findings, such as group and pair work, allowing students to use their backgrounds as well as their native languages. The only instructor outside this group who fell within this theme was Rick. He said he allowed his students to use their native language.

The second research question asked what motivates these effective community college instructors to use these culturally competent pedagogies. The themes that 
emerged in response to this question indicated that instructors wanted their students to learn about different ideas and develop higher thinking skill. They also wanted to increase their students' confidence in themselves. Interestingly, all of the participants who expressed these ideas were Humanities and Adult Basic Skills instructors.

The next chapter presents the significance of the findings and discusses how the findings support the existing literature and adds to it. Chapter five also offers recommendations for further research.

Table 3. Themes that emerged in response to first research question

\begin{tabular}{ll}
\hline Themes & Participants \\
\hline Materials selection that reflects diverse ways & Mark, Amy, Alice, Sam, Heather \\
of knowing & \\
Teacher Characteristics &
\end{tabular}

$\begin{array}{ll}\text { Sub theme1: Comfortable class } & \text { Sam, Alice, Mark, Amy, Rick, } \\ \text { environment } & \text { Lawrence, Samuel } \\ \text { Sub theme 2: Self-reflection and } & \text { Barbara, Alice, Sam }\end{array}$

awareness

Sub theme 3: Availability outside of the Heather, Lawrence, Liam, Sam, class

Sub theme 4: Learning about students $\quad$ Amy, Jake, Mark, Barbara, Liam Instructional Activities

Sub theme 1: Allowing students to use Heather, Jake, Amy 
their backgrounds

Sub theme 2: Using students'

Amy, Mark,

backgrounds as a teaching tool

Sub theme 3: Using groups or pair work

Sam, Mark, Amy, Barbara, Liam

activities

Sub theme 4: Taking learning styles

Alice, Jake

into account

Sub theme 5: Allowing students to use

Jake, Rick, Liam

their native language

Table 4. Themes that emerged in response to second research question

Themes Participants

Exposing students to different perspectives Mark, Heather, Alice, Amy, Sam

Enhancing thinking process Mark, Heather

Facilitating the learning process through Sam, Mark, Barbara,

building self-confidence 


\section{CHAPTER V DISCUSSION}

This narrative study set out to answer two research questions: 1) What specific culturally competent pedagogies do effective community college instructors use? and 2) What motivates these effective community college instructors to use these culturally competent pedagogies? In order to address these questions, this study employed a qualitative research method. A narrative inquiry was specifically chosen in order to gain a rich understanding of participants' experiences. Data was collected through individual semi-structured interviews with ten community college instructors at a community college in the Pacific Northwest.

The first part of this chapter discusses the major findings of the study in the context of existing research. The second part of the chapter addresses the implications for practice, and the final part includes recommendations for future research.

In this section I will discuss the findings to the first research question with references to the literature review. Recall that the first research question was what culturally competent pedagogies do effective community college instructors use?

\section{Material Selection That Reflects Diverse Ways of Knowing}

As mentioned in chapter two, the curricula and classroom practices of higher education faculty that introduce students to issues of diversity positively affect student learning in a myriad of ways such as engaging learners intellectually, maximizing students' cognitive skills and supporting social development (Astin, 1993a, 1993b; 
Chang, Astin, \& Kim, 2004; Gurin, Dey, Hurtado, \& Gurin, 2002; Hu \& Kuh, 2003). In fact research (e.g. Villanpando, 2002) has demonstrated that including content that approaches racial and ethnic issues positively affects all students regardless their cultural background.

The participants, specifically the ones who work in social science departments, chose materials that reflected different ways of knowing and cultural perspectives. Some of these materials included literature written by foreign authors, films that represented topics being discussed through different lenses, or videos that showed different ways of doing things in different cultures.

This finding is concurent with the current literature. For example, Light (2001) reported that students learned better when they studied academic content that reflected diverse perspective. Similarly, Mayhew and DeLuca Fernandez (2007) asserted that students who engaged in course materials that reflected different perspectives and analyzed them in the context of societal issues developed a better understanding of themselves and the issues about diversity.

Both Alice and Heather included a curated list of the materials in their syllabus. Alice explained to her students the reasons why they would be reading assigned materials while Heather allowed her students to choose what they wanted to read from a list and respond to the readings by making personal connections. Lee et al. (2012) explained that while it was beneficial to include a list of assigned readings, it is equally important to explain to students the reasons behind these selections. Mark also introduced his students to a list of reading materials found online and hoped that the topics that they explored in 
class would spark further curiosity in students and they would read more on this topic.

He made sure that students were aware of the resources he posted online. He also ensured that students knew why they had these resources available to them. He explained to his students these resources would help them explore issues that they might be interested in and would like to explore further. He also told them that these resources might allow them to look at issues from a different perspective.

It is notable that all three of these participants taught social studies and as such, they were given considerable freedom to choose their own instructional materials. This is concurrent with Hurtado's (2001) findings that indicated that faculty teaching social studies tend to involve more diversity related content in their courses than their counterparts teaching in other fields of study.

\section{Teacher characteristics}

Creating a Comfortable Class Environment. The findings in this study support the importance of creating a comfortable, safe classroom atmosphere. Seven participants mentioned that they strived to create a safe learning environment for students. Two of the participants promoted a safe environment by encouraging students to share information about themselves, their beliefs and worldview in order to foster a relationship among students, and in turn, create a safe learning environment. The literature supports that designing such activities facilitates the learning process and develops relationships over time (Fallon and Brown, 2010b; Ortiz, 2000) and promotes intrinsic motivation (Ginsberg and Wlodkowski, 2006). 
Community building through activities that are designed to give students opportunities to learn about each other's stories and worldviews is considered a practice that works well in diverse classrooms (Tatum, 2000; Ortiz, 2000). Amy described instructional strategies that use this strategy as part of a student-centered approach designed to encourage students to learn from each other while exploring new cultures and worldviews as a class. For example, she designed group presentation activities wherein students shared their perspectives in smaller groups before presenting their ideas before the entire class, a strategy that helped create a safe environment.

Alice, for example, during peer review activities made sure that the students who reviewed the papers of non-native students' papers focused on the ideas rather than the grammatical errors. She wanted her students to see beyond the conventions of grammar and deeply consider the ideas being conveyed. However, it was apparent from the discussion that she did not provide her students with clear guidance as to how to move beyond focusing on mechanical issues in the writings and respond strictly to content. Lee, Poch, Shaw, and Williams (2012) cautioned that peer reviews without specific guidance may reinforce the discomfort between reviewers.

Lee et al. (2012) argued that modeling the behaviors that are expected of students helps to establish a safe environment for students. Similarly, one of the participants exhibited respect and politeness to everyone's ideas and demanded the same for the students. Another participant, Mark, mentioned that he lowered the filters by presenting an image of himself as someone who was not perfect and who didn't have all the answers. 
He believed this behavior helped reduce students' social anxiety and even out their sense of social capital within the group.

Two of the participants, Rick and Lawrence, explained that creating a safe environment for their students by disallowing racist remarks in their presence. This practice is partially supported by the literature. While the literature states that it is important to prevent apathetic attitudes or a sense of tolerance towards such remarks, it is equally important to address the remarks to prevent defensiveness that might be caused by them (Weinstein and Obear, 1992).

There was little evidence in the data as to how these study participants managed the classroom environment after halting racist remarks made by their students in class. For instance, Rick explained that he quickly intervened and stopped the parties making the offensive remarks and said they did not talk about such things in his class. He did not however, elaborate on how the tension in the room may have influenced the class discussion that followed or how he did or did not capitalize on the teachable moment to address how word choice deeply affects communication and understanding. Given the fact that Rick was at the polarization stage of the IDI, it is possible that he may not have knowledge of how to handle such remarks other than disallowing them. According to Bennett (2004), people in the reversal stage of polarization may become strong proponents of racial issues and see people in the dominant culture as all bad. He may have thought by silencing racist remarks he was supporting the minority groups. People in this stage can move to the next stage, minimization, when they understand the common humanity of people of other cultures (Bennett, 2004). 
Self-Reflection and awareness. The major models of intercultural competence all include self- awareness as one of the necessary components of intercultural sensitivity (Paige, 1993; Deardorf, 2006; Byram, 1997, 2009; Bennett, 2009). Self-awareness is a cognitive skill, which requires knowledge of one's own cultural values and beliefs. Selfawareness was one of the areas of findings in this study.

Lee et al. (2012) stated that curiosity towards difference, an affective quality of intercultural competence, could help develop skills such as being willing to listen and learn about others' cultural position that are different from ours. Barbara's experience fit this observation. She described that over time, she realized that her own cultural beliefs were different from that of her students'. Having been curious about this, she has educated herself about different ways of knowing over the years. She stated that the knowledge she gained helped her make sense of why some of her students approached the course assignments in the ways that they did and how to adapt to their patterns. For example, she used to be frustrated with students who used a more circular communication style, which meant they told stories and build the context around the assigned topic, rather than explicitly making their point. After having been to several workshops, she developed sympathy and patience towards these students, as she could understand where they were coming from. It is significant to mention that Barbara's curiosity and desire to move from her comfort zone and learn about other cultures led her to develop some listening, observation, and evaluation skills. Furthermore, she developed flexibility with her diverse students' approaches to the assignments. This process is, in fact, exactly what Deardorff's (2006) process model of intercultural competence framework presented. The 
model described the key elements of intercultural competence and its developmental process. The model started from attitudes (respect, openness, curiosity and discovery), which was considered as fundamental to intercultural competence and moved to the knowledge and comprehension level (cultural self-awareness and skills such as listening, observing and evaluating).

Alice was also cognizant of her learning style. Knowing that many of her students have different learning styles than her own, she tried to differentiate her instruction whenever possible. Alice realized that she made assumptions about her students regarding their educational backgrounds, especially of those who came from different countries. She had assumed that they would possess the skills that mainstream students had, such as formatting an academic paper.

It is interesting to note that both Barbara and Alice are in the Minimization stage on the IDI continuum. Bennett (2004) stated that cultural self-awareness is one of the pieces that need to be resolved before moving into ethnorelative stages. It is possible that these participants, as they encounter growing number of students from different cultural backgrounds will experience development of cultural identity and a greater awareness of what and how to adapt their course designs to teach to diversity.

Availability outside of the class. Findings also revealed that most participants made themselves available for students outside the class time in order to support them better. Many made themselves available through office hours and electronic mail. One participant even held his office hours in the classrooms to encourage students to receive extra help. Developing a relationship with students both in and outside of the class is 
recognized as one of the ways to include culturally responsive pedagogy in higher education settings (Han et al., 2014). Mayo, Murguia, and Padilla (1995) reported that being available outside the class hours was a major factor that helped students in a positive way. In the same vein, Figueroa (2014) argued that connecting with students outside class time enables them to reach their true potential while helping instructors build relationships with their students.

Learning about student. Having a clear understanding of who their students are will help faculty design culturally relevant activities and help facilitate intercultural development in students. In this study, five participants clearly paid attention to who their students were and made conscious efforts to learn about them. They said having information about their students' backgrounds helped them to adaptively design instructional activities.

Similarly, Lee et al. (2012) argued that paying attention to the cultural difference that students have can help instructors to improve their instruction and maximize the students learning. Alfred (2009) also emphasized the importance of having knowledge of demographic profiles, educational histories and values of students is an important factor in creating culturally competent pedagogy. Brookfield (2006) also emphasized the importance of learning about students. However, he also added that it was equally important to learn about students' reactions to certain activities by using different tools. It is notable that none of the participants mentioned how they determined the success of activities that they designed or their students' reactions to them. 


\section{Instructional Activities.}

Allowing students to use their backgrounds. Three participants stated that they allowed their students to use their backgrounds in learning tasks and projects. They believed that this practice maximized students' learning and engaged them more in the content. This response fit with Harper and Quaye's (2009) findings that faculty who value students' lived experiences assume what students bring to class deepen understanding of course concepts. Similarly, Magolda (2001) stated that students did not think they needed education if it did not "acknowledge, respect and connect to their experience and perspectives" (p. 234).

Using students' backgrounds as a teaching tool. Two of the participants capitalized on their students' wealth of knowledge and life experiences to enrich their classroom activities. This pedagogical strategy aligns with that of Alfred (2009) who argued that utilizing what students bring to class may promote cross-cultural understanding and increase the relevance of the school program while increasing the equal opportunities and access for students. Considering this practice as one of the principles of intercultural pedagogy, Lee et al. (2012) argued that valuing the assets that the students bring to class allows students to enrich their academic knowledge and connect their affective experiences to cognitive knowledge by engaging in multiple ways of knowing. Importantly, the study participants also explained that this practice shifts the spotlight off of the instructors and thus tends to remove the uneasiness that some faculty may feel when they think they need to be intercultural experts. 
Using group or pair- work activities. Some of the participants used pair and group work activities to give their students a chance to work with people from different backgrounds. This practice is widely supported in the literature. Working with diverse others in carefully designed and facilitated activities has been shown to promote students intellectual and intercultural development (DeTurk, 2001; Lee et al, 2012; King, 2002; Smith and Associates, 1997). The practice has also been demonstrated to foster community building among students (Ortiz, 2002; Tatum, 2000). Brookfield (1997) described working with others as a critical means for students to deepen their understanding by being exposed to different views and challenged by unfamiliar perspectives.

Lee and Sheared (2002) indicated that instructors should be cognizant of how students' cultural background may affect their learning behaviors. Alfred (2009) also mentioned that group activities benefit both native and non-native students in terms of building community. For example, mindful of the importance of thoughtfully organizing student collaborations in a culturally sensitive manner, one participant said that he tended to choose smaller break-out group discussions over large class discussion when he had classes heavily made up of Asian population in order to increase class participation.

Taking learning styles into account. Paying attention to students' learning styles is also considered culturally relevant pedagogy (Barrington, 2004; Gardner, 1993; Fallon and Brown, 2010a). Instructional delivery can be differentiated to appeal to different learning styles, which may be defined by one's cultural upbringing. In this study, two participants also mentioned that they were cognizant of the fact that there may be 
students with different styles of learning, and therefore, they strived to deliver course content in different ways. They both ensured that they provided rich learning environments where students had opportunities to engage in materials in different ways, such as using videos or recorded lectures for auditory and visual learners or hand-on projects for kinesthetic learners.

Allowing students to use their native language. Three participants mentioned that they supported their students by letting them use their native language in or outside of class activities. Two participants offered their students videos with subtitles in students' native language or allowed them to help each other in class using their own language among themselves. While there is a body of literature on non-native speakers in the higher education settings (Alfred, 2009; Guy, 2002; Lee and Sheared, 2002), interestingly, utilizing students' native language was not present as a culturally competent pedagogy in the higher education settings. On the other hand, studies in K-12 settings provide ample evidence of advantages of using students' native language in class, including increased cognitive function and attention (Bialystok, 2001; Diaz \& Klinger, 1991), improved self-confidence and motivation in school (Lee, 2008), and increased academic achievement compared to other students (Umansky and Reardon, 2014)

Thus concludes the discussion related to the first research question, what culturally competent pedagogies do effective community college instructors use? Building upon the relationship of the findings to the literature, in the following section I will discuss the data that informed the second research question, What motivates these effective community college instructors to use these culturally competent pedagogies? 
Exposing Students to Different Perspectives. Brookfield (2009) argued that students who work with diverse others were better prepared for the outside world because they would have a chance to increase their knowledge about other view points. In the same vein, Hurtado (2005) posited frequent interaction with diverse others not only allows students to learn about social differences but also helps them be equipped to work in diverse workplaces. In response to the second research question and in keeping with Brookfield and Hurtado's perspective, five participants explained that they wanted to expose their students to different perspectives. They achieved this by utilizing instructional strategies that involved interpersonal interactions between pairs or group work activities. One participant explained the importance of being exposed to different perspectives because such experiences prepare students for the outside world where they would have little to no control over who they will work with on a regular basis.

Other participants mentioned they wanted their students to develop appreciation for other viewpoints and become aware that there was more than one way of doing things. Being open to other ideas and tolerating ambiguity when encountered with new perspectives are the attitudes in the first level of Deardorff's (2006) process model of intercultural competence. Similarly, Bennett (2009) also argued that one of the characteristics of intercultural competence was having affective skills, which include open-mindedness. Lee et al. (2012) argued that increased interaction among students through carefully designed class activities gives students a chance to engage in different points of view. Such interactions facilitates use and development of intercultural attitudes and skills, such as appreciating other opinions and managing one's own anxiety 
as learning about other ways of thinking and engaging in meaningful conversations require affective, cognitive and behavioral adjustments, some of which may be unsettling. They asserted that intercultural development could not take place if students state of mind remains static and they do not productively challenge their own way of thinking. In keeping with Lee and his colleagues assertions, the study participants' specifically emphasized the use of activities designed to facilitate student interactions and expose them to different ways of thinking is a step towards facilitating students' intercultural competence development.

Enhancing the thinking process. Two of the participants expressed that they wanted to enhance their students' critical thinking abilities, and therefore, they used materials reflecting different perspectives. Quaye and Harper (2007) argued that discussions about diverse issues, no matter how uncomfortable they were, enabled students to "think critically about issues they have not been aware of before" (p.34). In keeping with this perspective, another reason why the participants said they used culturally competent pedagogy was to help students develop critical thinking skills. One participant, Mark, explained that using culturally diverse materials provided opportunities for students to think critically about issues such as privilege and prejudice, something many of his students had never done. He also mentioned that many of his mainstream Caucasian students came to class with a feeling of entitlement to success because they were in college and would end up with a well-paying job, unaware of power and privilege relationships, a concept that his students from diverse background understood better. Therefore, he designed instructional activities for his students that helped them 
understand power dynamics in the society because "they have a personal stake in recognizing the structures in society that and how those work in a way that benefits some and that harm others." Whenever they talked about a social issue, Mark also asked his students to find a connection to their own lives and how this specific issue affected them personally. Mark's motives in encouraging his students to engage in different thinking process resonates with King (2002) who argued that activities that required students interact with each other facilitated high-level cognitive thinking skills since their thought process was challenged, which prompts them to think further in order to resolve the cognitive conflict.

Similarly, Heather wanted her students to think critically about the diverse issues and perspectives on the issues they explored in her courses, and in doing so, expand their worldviews. She wanted her students to be "better citizens" who could understand other people's points of views. She thought that some of her students were "sheltered" in a way that they were only exposed to one way of thinking. For example, some of her students came from a in a strict religious environments, and it was hard for them to be able to understand other worldviews. Heather's perspective resonates for that of Bennett (2004) who observed that people coming from monocultural perspectives have hard time construing differences between their own culture and others', therefore, not being able to engage in more sophisticated meaning making processes.

Facilitating the learning process through building self-confidence. The third and the last reason why some of the participants included culturally competent pedagogy was facilitating the learning process through building self-confidence. One of the 
participants explained that he wanted boost students' self-confidence by helping people to see that education was relevant to them and see themselves being part of the college environment. Another participant explained he wanted his students to see that they are not the only ones experiencing problems in college.

Many community college students are first-generation students. According to Falcon (2015) first generation students may not feel comfortable in a college environment, come from a different cultural and socio-economic background and may not be adequately prepared for college work. Therefore, they may lack self-confidence in their abilities to be successful (Falcon, 2015). Leveraging individual competencies was described by participants as beneficial to strengthening students' sense of selfconfidence. For instance, Barbara shared that one of her strategies for increasing nonnative speakers' self-confidence was exploiting English Language Learners' deep knowledge of English grammar and treating them as expert resources in the classroom. Increased social capital tends to enhance students' sense of belongingness and selfconfidence as college students.

Nauman, Bandalos and Gutkin (2003) argued that students who believed that they could be successful in college performed better in college. While possessing selfconfidence is accepted as one of the key components to any student's success and persistence, interestingly, I have not encountered this factor described as a culturally relevant practice in the literature I read on culturally competent pedagogies. 


\section{New Insights}

Several new findings emerged from this study. One interesting finding was regarding the needs of the increasing numbers of non-native speakers in college classes. Instructors responded to the needs of these students by allowing them to use their first language to support their learning. In the field of second language acquisition, allowing students to use their first language has been widely accepted as an effective practice. Auerbach (1993) argued that students' first language "provides a sense of security and validates the learners' lived experiences, allowing them to express themselves" (p. 19). However, there seems to be a lack of literature that strongly examines the support of nonnative speakers in mainstream college classes when it comes to using their native language in the classroom, especially in the context of using culturally relevant pedagogies. Such instructional practices also contribute to creating safe learning environments for non-native speakers where filter levels may be lower and risk taking behaviors more likely to occur. Therefore, I suggest that allowing students to use their first language should also be considered a part of culturally relevant pedagogy.

Another interesting finding that emerged from this study was that boosting selfconfidence was explicitly cited as one of the reason why some faculty used group/pair work formats, which is considered culturally relevant practice. Increasing diversity on community college campuses may also go hand-in-hand with the increasing population of first-generation college students. Being cognizant of their students' backgrounds should provide faculty with the advantage of being better able to recognize some of the challenges students may experience, and therefore, be better prepared to anticipate 
adaptations that support student success. Ultimately, the greatest selling point for providing professional development is providing instructors with support in developing sensitivities to student thinking, and on a very practical level, having reflective support in using culturally competent strategies intended to increase students' self-efficacy and help students persistence.

Finally, another new finding was regarding instructors' disciplines and use of culturally competent pedagogies. While it was not unexpected that the participants who taught Humanities and Adult Basic Skills classes were able to make curriculum more accessible to their students and promote student interaction, the participants who taught in the science and vocational fields did not just turn a blind eye to their diverse students with the assumption that their fields would not lend themselves to culturally competent pedagogies. In this study, while these participants had to follow a strict curriculum, they supported their students by exhibiting teacher characteristics, such as being available outside of the class, creating a safe environment, or using some instructional activities like allowing students to use their native language.

\section{Recommendations}

In this section I offer some recommendations based on the findings. The following recommendations are intended for community college faculty and higher education institutions.

As it was stated in Chapter one, student demographics have dramatically shifted in the higher education settings in recent decades. Consequently, the student population is more diverse than ever in American colleges and universities. Students in community 
colleges, in particular, hail from a wide variety of backgrounds and educational experiences. Many speak English as a second language because they come from different countries.

Educators. In light of the shifting dynamics in community college settings, educators need to be cognizant of who their students are and use culturally competent pedagogies in order foster inclusion and meet the needs of a diverse population. Perhaps unsurprisingly, the participants in this study who taught Humanities and Adult Basic Skills classes expressed that they had more flexibility and freedom to design instructional activities that engage diversity in class in comparison to those who taught in the sciences or vocational arts. Those who taught in the Humanities and Adult Basic Skills classes were easily able to include materials that reflected diversity and intentionally designed activities to foster dissonance in student thinking and encourage people to think beyond their familiar social and cultural environments.

To meet the needs of diverse students, I recommend that community college educators receive support to design instructional activities that leverage the diversity of skills students bring to class to foster intercultural competence in all students. In this study, only four of ten participants expressed that they were interested in learning who their students were so that they could adapt their instruction and materials accordingly. Sixty percent of the instructors experienced disincentives to strategize in this manner as they indicated that they lacked the freedom to alter their curricular materials. Richards, Brown, \& Forde (2006) argued, "if instruction reflects the cultural and linguistic practices of one group of students, then the other students are denied equal opportunity to learn." 
Instructors who strive to engage diversity effectively cannot ignore the fact that each student comes to class with a different cultural and educational background and expectations (Lee et al, 2012). Therefore, I recommend that regardless of the discipline, instructors pay attention to who their students are and make deliberate instructional choices to accommodate diverse learners. Instructors have powerful potential for working to promote intercultural competence in all students and that this can be done in a myriad of ways, even ones that do not involve adapting the course content. Participants in this study described providing students with structured opportunities to share their perspectives, think critically in pairs and group discussions and opportunities to build their self-confidence by recognizing the unique skills they bring to the learning environment through moderated class discussions and interactive media.

The majority of participants in this study stated that they created a comfortable, safe learning environment for their students as a way to include diversity in their classes. While creating a safe environment is very important to engage diversity in class, it is not enough alone. In fact, one of these participants, during the interview, expressed that he didn't know what else to do in terms of diversity in his classes. All instructors have the responsibility to learn methods for how to go beyond creating a safe environment and learn to effectively engage diversity regardless of their specific fields. Instructional activities can take different forms in different fields; however, all instructors have the power to make the material relevant to their students and design activities that maximize interaction among learners. As Lee et al. (2012) put it, "... classrooms can be designed so as to serve as wonderfully dynamic places where intellectual and social energy emerges 
from respectful intercultural interactions united in a quest to understand the nuances of an academic discipline or field" (p. 104).

Educators can take it upon themselves to expand their professional development choices from field specific trainings to other opportunities on teaching diversity in class and addressing the needs of all learners. According to Lee et al. (2012), teaching diversity effectively and promoting intercultural competence "are processes that rely on acquiring knowledge, experiencing interactions in a "live" dynamic context, and engaging in reflective practice that facilitates the ability to adapt to shifting and particular conditions ... such as student demographics,[and the] level of course..." (p. 59). The process of moving towards intercultural acceptance is incremental and requires testing and refining effective culturally competent pedagogy within a structured reflective process. In fact, the literature strongly recommends that instructors should engage in critical reflection of themselves and their teaching practices in order to understand their own identity and recognize their biases that might inform their teaching practices (Alfred, 2009; Brookfield, 2003; Harper and Quaye, 2007; Villegas and Lucas, 2002).

It is also interesting to note that only the instructors in Humanities designed culturally competent instructional activities in order to instill cultural competence in their students. One participant in this field explained she collaborated with other faculty in the department to choose readings. She also explained that they monitored each other's reading lists to ensure that the list did not excessively reflect the dominant culture. It is possible that the collaboration among the instructors in Humanities Department helped them to incorporate and expand more culturally competent teaching strategies in their 
teaching. This may be a very promising practice in other departments as faculty will encourage and inspire each other while providing support.

Aside from collaboration within faculty's own department, I recommend that educational leaders actively encourage faculty members to work across-disciplines, as this practice would provide opportunities to benefit from each other's expertise and, on a very practical level, learn instructional strategies and the reasons for using them to increase culturally competency levels in the classroom.

Ellingboe (1998) argued that graduate schools were crucial to development of intercultural competence in faculty. Almost all participants expressed that they never received training relevant to how to teach diversity in their graduate school years. This finding corroborates Harper and Quaye's (2007) point that many faculty teach in what they perceive as being culturally neutral ways because they were never taught to strive to include diverse readings and instructional practices into their course.

In addition, the majority of college level faculty never had professors as role models who would exhibit appreciation of diversity and use culturally relevant pedagogies. Therefore, it is highly important that graduate schools require their students to take courses that are designed to appreciate cultural diversity and prepare them to teach effectively in multicultural classes as well as provide opportunities for those in leadership positions and those they serve to continuously improve their practices in this area.

Institutions. While it is important instructors have an interest to learn more about and teach from a more culturally competent perspective, it is equally important that the higher education institution they work for emphasizes the importance of culturally 
competent pedagogy and consistently encourages their instructors to employ best practices. In fact, given that institutions of higher education are expected to produce graduates who possess intercultural skills and can function well in diverse work environments, it is incumbent upon them to prioritize training their faculty who will teach these graduates. Instructors are busy with their teaching responsibilities, and many are also involved in administrative responsibilities that their jobs may require. Left alone, it is easy for too many of them to stagnate in their existing practices and lose interest in understanding and adapting their practices to involve culturally competent pedagogies. Therefore, it is essential for higher institutions to continuously provide direction and ongoing professional development support for their instructors such that faculty are wellprepared to teach a diverse student body and prepare all students to live and work in a diverse society.

Various pieces of research have strongly indicated that teachers who have had experiences abroad exhibit increased levels of intercultural competence (e.g. Bu, 1995; Emert, 2008; Roberts, 2003). It is very interesting to note that one of the participants, Mark, was the only instructor who utilized most of the culturally competent pedagogies that emerged in the findings. Recall that Mark considered himself a "true generalist" and did not want to categorize himself as an expert in any subject (personal communication, May 2014). He wanted to be open to all ideas and wanted his students to understand that there were many other ideas in life. Interestingly, Mark was the only participant who took his students abroad for a four to seven week study-abroad course. It is possible that Mark, who was in the Acceptance stage in IDI, experienced a significant cognitive shift 
over time and developed a higher level cross-cultural competence in part, due to his experiences abroad.

On the other hand, another participant, Sam, who worked in the Adult Basic Skills Department, spent two years in France as a student during his undergraduate years. While Sam, who was in the Minimization stage of the IDI, did not include culturally competent pedagogy to the same degree as Mark did in his teaching practice, it is notable that he did incorporate a number of culturally relevant activities into his classes such as selecting reading materials that approach subjects related to cultural and ethnic diversity, making himself available to students outside of class time, striving to create a comfortable classroom environment and building students' self-confidence.

Ellingboe (1998) stated that having international experiences did not automatically translate to using culturally relevant pedagogies, as faculty may have to change their thinking. Intercultural sensitivity is learned and developed overtime; people who are in the Minimization stage still need to develop a cultural self-awareness and recognize how the culture they are raised in influence their beliefs and values (Bennett, 2004). Considering Sam has only been teaching for eight years, he may still be struggling with reflecting his international experiences in his teaching more effectively. It is important for institutions to constantly offer travelling and teaching abroad opportunities to their faculty and encourage them to take advantage of them plus, provide faculty with structured opportunities to reflect on the implications of their observations on teaching and learning in highly practical ways such as peer mentoring or faculty group work. 


\section{Suggestions for Future Research}

This study investigated what culturally competent pedagogies effective community college instructors use and what motivates them to use these pedagogies. A qualitative research design was chosen to conduct this study. Semi-structured interviews were used to collect data. The study involved interviews with ten faculty members of a large community college in the Pacific Northwest. Due to the limited sample size and single data collection site, this study is limited to the experiences of the participants in this specific community college. Building on what is to be learned from this and similar studies, a research study conducted at multiple community colleges may effectively reflect the experiences of instructors in using culturally competent practices, thus providing highly practical, immediately useful ideas for how to adapt practices to better meet the needs of diverse learners.

While this research measured the participants' intercultural sensitivity level, the results were not used in analyzing the data. Nonetheless, it is interesting to note that the data indicated that instructors who taught Humanities ranked higher on the IDI continuum than those who were in other fields. This finding suggests that it may prove to be useful to correlate instructors' intercultural sensitivity levels to their classroom practices in order to better understand if a relationship exists.

Furthermore, research that would investigate student learning outcomes and intercultural competence development is also suggested. Quantitative research could be utilized to measure both instructors' and students' intercultural competence levels and compared with students' success rates in these instructor's classes. With a large enough 
sample size, it is possible that a researcher may be able to detect patterns between how particular instructional strategies work for specific groups of students, thus providing evidence upon which instructors may develop a well-reasoned rationale for why and how to employ particular instructional strategies out of a wide range of choices.

In addition, research shows that teachers are not specifically trained in using culturally competent pedagogies in many graduate programs. Therefore, it is highly likely that teachers entering this profession are not cognizant of specific pedagogies and lack core components of intercultural competence (cognitive, affective and behavioral). It would be useful to conduct a study that investigates the importance of community college instructors using culturally competent pedagogies and what they do to improve their practices overtime.

Based on the findings in this research, it was clear that Humanities and Adult Basic Skills instructors were able to incorporate more culturally relevant pedagogies in their classes. For example, almost all of instructors were able to select their own materials, use group or pair work activities, and allow students to use their own background in course work. In science and vocational field instructors' narration of what they do in their classes, these practices were almost non-existent. These instructors expressed that they were bound by a strict curriculum that they had to follow, and therefore, were not able to select their own materials. Both instructors were in the Polarization stage of the IDI, which meant they had an ethnocentric orientation. On the other hand, five out of eight instructors who taught in the Humanities were in the Minimization stage. According to the IDI results these instructors had ethnocentric 
orientations, as well. The fact that all of these instructors were voted as effective instructors in their area and received distinguished teacher awards is very interesting. Therefore, another narrative study that would closely look into classroom practices of science instructors in the community college setting would be useful to better understand how they respond to increasing diversity in their classes.

There is a body of research (Ellingboe, 1998; Johnson and Inoue, 2003; Helms, 2003; Schuerholz-Lehr, 2007) that indicates that there is not a clear link between intercultural sensitivity and culturally relevant classroom practices. On the other hand, there is literature that says in order to promote student success, faculty should be culturally competent (Cushner, McClelland, and Stafford, 2009; Lee et al., 2011; Locke, 1988; Scisney-Matlock \& Matlock, 2001; Wallace, 2000). Further research is necessary to better understand classroom practices of instructors who are not necessarily measured as culturally competent yet still may be using culturally relevant pedagogies. Such research efforts are quite likely to help expand the definition of culturally relevant teaching thus increasingly the sense of relevance to instructors who otherwise may not think that learning culturally relevant pedagogies is part of their job descriptions.

My final recommendation for research is also found in the domain of intercultural sensitivity of faculty. Half of the participants in this study were in the Minimization stages of the IDI and two were in the Polarization stage. In fact, only three of ten participants were measured in the ethnorelative stages of acceptance. In light of the fact that all of these instructors are pressured by rapidly changing diverse classrooms yet they are each at different levels of awareness, an interesting question emerges: can instructors 
who are not culturally competent move students passed the stage of the IDI that they are in?

\section{Conclusion}

Community college student population has become more diverse than ever. It is community college's responsibility to respond to this change by serving these diverse students effectively and prepare all students to live and work in a multicultural society. This study was conducted to explore what culturally competent pedagogies effective community college instructors use and what motivates them to use these pedagogies. While there were number of limitations, findings revealed that the participants used a number of culturally relevant pedagogies. These included using materials that reflected diverse ways of knowing, teacher characteristics, and teacher activities. The findings revealed the three reasons behind these choices: exposing students to different perspectives, enhancing the thinking process, and facilitating the learning process through building self-confidence. This study provides insights into what community college instructors can do in terms of diversity in their classrooms. Although the findings indicate that all participants in this study were cognizant of the changing demographics in their classrooms, it was evident in the findings that Humanities and Adult Basic Skills instructors had more latitude in engaging diversity. It is crucial that all community instructors practice culturally relevant pedagogies and prepare students for the global world. Faculty should possess knowledge, skills, and attitudes so that they can promote inclusive learning environments and promote cultural sensitivity. This is a demanding and ongoing process; however, it is not impossible. Educators and institutions should 
continue their efforts to best serve all students in an equitable and inclusive way and prepare everyone for the demands of increasingly globalized world. 


\section{REFERENCES}

Adler, E. S., \& Clark, R. (1999). How it's done: An invitation to social research. Belmont, CA: Wadsworth.

American Council of Education (1995). Educating Americans for a world in flux: Ten ground rules for internationalizing higher education. Washington, DC: Author. American Association of Community Colleges (2012). Students at community colleges. Retrieved from http://www.aacc.nche.edu/Pages/default.aspx.

Alfred, M.V. (2009). Nonwestern immigrants in continuing higher education: A sociocultural approach to culturally responsive pedagogy. The Journal of Continuing Higher Education, 57, 137-148.

Anderson, J. A. (2008). Driving change through diversity and globalization. Sterling, Virginia: Stylus Publishing, LLC.

Armstrong, M. A. (2011). Small world: Crafting an inclusive classroom (no matter what you teach). Thought and Action, 27, 51-61.

Association of American Colleges and Universities (2007). College learning for the new global century. Washington, DC: Association of American Colleges and Universities.

Astin, A. W. (1993a). Diversity and multiculturalism on the campus: How are students affected? Change, 25(2), 44-49.

Astin, A. W. (1993b). What matters in college? Liberal education, 79(4), 4-16.

Astin, A. W. (1993c). What matters in college?: Four critical years revisited. San Francisco: Jossey-Bass. 
Ayers, J. F., Wheeler, E. A., Fracasso, M. P., Galupo, P. M., Rabin, J. S., \& Slater, B. R. (1999). Reinventing the university through the teaching of diversity. Journal of Adult Development, 6(3), 163-173.

Babbie, E. (2001). The practice of social research ( $9^{\text {th }}$ ed.). Belmont, CA: Wadsworth.

Banks, J. (2004). Diversity and citizenship education: Global perspectives. San Fransisco: Jossey-Bass.

Banks, J. A. (2001). Citizenship education and diversity: Implications for teacher education. Journal of Teacher Education, 52(1), 5-16.

Barnett, P. E. (2011). Discussions across difference: Addressing the affective dimensions of teaching diverse students about diversity. Teaching in Higher Education, 16(6), 669-679.

Barrington, E. (2004). Teaching to student diversity in higher education: How Multiple Intelligence Theory can help. Teaching in Higher Education, 9(4), 421-434.

Bennett, C. I. (2001). Research on racial issues in American higher education. In J. A. Banks \& C. A. M. Banks (Eds.), Handbook of research on multicultural education (pp. 663-682). San Fransisco: Jossey-Bass.

Bennett, J. M. (1986). Modes of cross-cultural training: Conceptualizing cross-cultural training as education. International Journal of International Relations, 10(2), $117-134$.

Bennett, J. M. (2009). Transformative training:Desigining programs for culture learning. In M.A. Moodian (Ed.), Contemporary leadership and intercultural competence (pp. 95-110). Thousand Oaks, CA: SAGE Publications, Inc. 
Bennett, J. M., \& Salonen, R. (2007). Intercultural communication and the new American campus. Change, 39(2), 46-50.

Bennett, M. J. (1986). Towards ethnorelativism: A development model of intercultural sensitivity. In R. M. Paige (Ed.), Cross-cultural orientation: New conceptualizations and applications (pp. 27-70). New York, NY: University Press of America.

Bennett, M. J. (1993). Towards ethnorelativism: A development model of intercultural sensitivity. In M. R. Paige (Ed.), Education for the intercultural experience (pp. 21-71). Yarmouth, ME: Intercultural Press.

Bennett, M. J. (1998). Intercultural communication: A current perspective. In M. J. Bennett (Ed.), Basic concepts of intercultural communication (pp. 1-34). Boston, MA: Intercultural Press.

Bennett, M. J. (2004). Becoming interculturally competent. In J. S. Wurzel (Ed.), Towards multiculturalism: A reader in multicultural education (2nd Ed.) (pp. 6277). Newton, MA: Intercultural Resource Corporation.

Bennett, M. J., \& Bennett, J. M. (2004). Developing intercultural sensitivity: An integrative approach to global and domestic diversity. In D. Landis, J. M. Bennett \& M. J. Bennett (Eds.), Handbook of intercultural training (3rd ed.). Thousand Oaks, CA: SAGE Publications.

Bialystok, E. (2001). Bilingualism in development: Language, literacy, and cognition. New York: Cambridge University Press.

Bikson, T. K., \& Law, S. A. (1994). Global preparedness and human resources: College 
and corporate perspectives. Retrieved from

https://www.rand.org/content/dam/rand/pubs/monograph_reports/2005/RAND_M R326.pdf

Bochner, A. P. (2001). Narrative's virtues. Qualitative Inquiry, 7(2), 131-157.

Bogdan, R. C., \& Biklen, S. K. (2007). Qualitative research for education: An introduction to theories and methods ( $5^{\text {th }}$ ed.). Boston, MA: Pearson Education.

Boggs, G. R., \& Irwin, J. (2007). What every community college leaders needs to know: Building leadership for international education. New Directions for Community Colleges, 2007 (138), 25-30.

Bok, D. (2006). Our underachieving colleges. New Jersey: Princeton University Press.

Bowman, N. A. (2010). College diversity experiences and cognitive development: A meta-analysis. Review of Educational Research, 80(1), 4-33.

Brislin, R. W. (1981). Cross-cultural encounters: Face-to-face interaction. New York: Pergamon Press.

Brookfield, S. (2006). The skillful teacher. San Fransisco, CA: Jossey-Bass.

Brookfield, S., \& Preskill, S. (2005). Discussion as a way of teaching: Tools and techniques for democratic classrooms. San Fransisco: Jossey-Bass.

Brooks, N. (1997). Teaching culture on the foreign language classroom. In P. R. Heusinkveld (Ed.), Pathways to culture: Readings on teaching culture in the foreign language class (pp. 11-37). Yarmouth: Intercultural Press.

Bu, K. (1995). Exploring the meaning of culture shock through the affective 
experiences of American teachers teaching in China (Doctoral dissertation). Retrieved from Dissertations and Theses Database. (UMI No. 9615191).

Byram, M. (1997). Teaching and assessing intercultural communicative competence. Clevedon, UK: Multilingual Matters.

Byram, M. (2000). Assessing intercultural competence in language teaching. Sprogforum, 18(6), 8-13.

Byram, M. (2009). Intercultural competence in foreign languages. In D. K. Deardoff (Ed.), The SAGE handbook of intercultural competence (pp. 321-332). Thousand Oaks, CA: SAGE Publications.

Chang, M. J., Astin, A. W., \& Kim, D. (2004). Cross-racial interaction among undergraduates: Some consequences, causes, and patterns. Research in Higher Education, 45(5), 529-553.

Clandinin, D. J., \& Connelly, F. M. (1989). Narrative and story in practice and research. (ERIC Document and Reproduction Service No. ED309681).

Clandinin, D. J., \& Connelly, F. M. (2000). Narrative inquiry: Experience and story in qualitative research. San Fransisco: Jossey-Bass.

Clayton-Pederson, A. R., Parker, S., Smith, D. G., \& Teraguchi, D. H. (2007). Making a real difference with diversity. Washington, DC: Association of American Colleges and Universities.

Cohen, A. M., \& Brawer, F. B. (2003). The American community college (4th ed.). San Fransisco: Jossey-Bass. 
Cohen, A. M., \& Brawer, F. B. (2008). The American community college (5th ed.). San Francisco: Jossey-Bass.

Cohn, E. R., \& Mullennix, J. W. (2007). Diversity as an integral component of college curricula. In J. Branche, J. W. Mullennix \& E. R. Cohn (Eds.), Diversity across the curriculum: A guide for faculty in higher education. Bolton, MA: Anker Publishing Company.

Colby, S. L. \& Ortman, J. M. (2015). Projections of the size and composition of the U.S. population: 2014 to 2060 . Retrived from http://www.census.gov/content/dam/Census/library/publications/2015/demo/p251143.pdf?

Coley, R. J. (2000). The American community college turns 100: A look at its students, programs, and prospects. Princeton, NJ.:Educational Testing Services. (ERIC Reproduction Service No. ED 441553).

Condon, J. (1986). The ethnocentric classroom. New directions for teaching and learning, 26, 11-20.

Creswell, J. W.(2007). Qualitative inquiry and research design: Choosing among five approaches ( $2^{\text {nd }}$ ed.). Thousand Oaks: SAGE Publications.

Creswell, J. W. (2005). Educational research: Planning, conducting, and evaluating qualitative and quantitative research ( $2^{\text {nd }}$ ed.). Upper Saddle River, NJ: Pearson Education, Inc.

Cushner, K., \& Brislin, R. (1996). Intercultural interactions: A practical guide (Vol. 9). Thousand Oaks: SAGE Publications. 
Cushner, K., McClelland, A., \& Safford, P. (2009). Human diversity in education: An integrative approach (6th ed.). Boston: McGraw Hill.

Deardorff, D. K. (2004). The identification and assessment of intercultural competence as a student outcome of internationalization at institutions of higher education in the United States. Unpublished doctoral dissertation, North Carolina State University, Raleigh.

Deardorff, D. K. (2006). Identification and assessment of intercultural competence as a student outcome of internationalization. Journal of Studies in International Education, 10(3), 241-266.

Deardorff, D. K. (2009a). Exploring interculturally competent teaching in social sciences classrooms. ELiSS, 2(1), 1-18.

Deardorff, D. K. (2009b). Implementing intercultural competence assessment. In D. K. Deardorff (Ed.), The SAGE Handbook of Intercultural Competence (pp. 477-491). Los Angeles: SAGE Publications.

Denzin, N. K., \& Lincoln, Y. S. (2005). Introduction: The discipline and practice of qualitative research. In N.K. Denzin \& Y.S. Lincoln (Eds.), The SAGE handbook of qualitative research ( 2 nd ed.). Thousand Oaks, CA: SAGE.

DeTurk, S. (2001). Intercultural empathy: Myth, competency, or possibilty for alliance building? Communication Education, 50(4), 374-385.

Diaz, R. M., \& Klinger, C. (1991). Towards an explanatory model of the interaction between bilingualism and cognitive development. In E. Bialystok (Ed.), Language 
processing in bilingual children (pp. 140-185). New York: Cambridge University Press.

Dinges, N. (1983). Intercultural competence. In D. Landis \& R.W.Brislin (Eds.), Handbook of intercultural training: Issues in theory and design (Volume 1, pp. 176-202). New York, NY: Pergamon Press.

Dorjee, T. (2002). Multiple Americas: Redeveloping a scale to measure mainstream United States culture. Long Beach, CA.: California State University.

Eddy, P. L. (2007). Faculty development in rural community colleges. New Directions for Community Colleges, 137, 65-76.

Emert, H.A. (2008). Developing intercultural competence through teaching abroad with Fulbright: Personal experience and professional impact (Doctoral dissertation). Retrieved from Dissertations and Theses database. (UMI No. 3308089)

Emert, H. A., \& Pearson, D. L. (2007). Expanding the vision of international education: Collaboration, assessment and intercultural development. In V. Edward \& R. L. Raby (Eds.), New Directions for Community Colleges, no.138. San Fransisco: Jossey-Bass.

Ellingboe, B. J. (1998). Divisional strategies to internationalize a campus portrait: results, resistance, and recommendations from a case study at a U.S. university. In J. A. Mestenhauser \& B. J. Ellingboe (Eds.) Reforming the higher education curriculum: Internationalizing the campus (pp. 198-228). Phoenix, AZ: Oryx Press. 
Fallon, M. A., \& Brown, S. C. (2010a). A student-centered approach to college classrooms. In M. A. Fallon \& S. C. Brown (Eds.), Teaching inclusively in higher education (pp. 3-16). Charlotte, NC: Information Age Publishing.

Fallon, M. A., \& Brown, S. C. (Eds.). (2010b). Teaching inclusively in higher education. Charlotte, NC: Information Age Publishing.

Fantini, A. E. (2000). A central concern: Developing intercultural competence. Report of the Intercultural Communicative Competence Task Force. Brattleboro: VT: World Learning.

Fantini, A. E. (2009). Assessing intercultural competence. In D. Deardoff(Ed.), The SAGE handbook of intercultural competence (pp. 456-476). Thousand Oaks, CA: SAGE Publications, Inc.

Figueroa, I. (2014). The value of connectedness in inclusive teaching. New Directions for Teaching and Learning, 140, 45-49.

Friedman, T. L. (2007). The world is flat: A Brief history of the twenty-first century (3rd ed.). New York, NY: Picador.

Fueyo, V. (1999). Those who can, teach: Reflections on teaching diverse populations. Teacher Education Quarterly, 26(3), 25-35.

Gacel-Avila, F. (2005). The internationalization of higher education: A paradigm for global citizenry. Journal of studies in international education, 9(2), 121-136.

Garcia, M., \& Smith, D. G. (1996). Reflecting college inclusiveness in the college curriculum. In L. I. Rendon \& R. O. Hope (Eds.), Educating a new majority: 
Transforming America's educational system for diversity (pp. 265-288). San Fransisco: Jossey-Bass.

Gardner, H. (1993). Multiple intelligences: The theory in practice. New York, NY: Basic Books.

Gay, G. (2000). Culturally responsive teaching: Theory, research, and practice. New York: Teachers College Press.

Gay, G. (2002). Preparing for culturally responsive teaching. Journal of teacher education, 53(2), 106-116.

Ginsberg, M. B., \& Wlodkowski, R. J. (2006). Diversity and Motivation: Culturally responsive teaching in college (2nd ed.). San Fransisco, CA: Jossey-Bass.

Gollnick, D. M., \& Chinn, P. C. (2002). Multicultural education in a pluralistic society (6th ed.). Upper Saddle River, NJ: Merrill Prentice Hall.

Grant, A. G., \& Sleeter, C. E. (1985). Who determines teacher work? The debate continues. Teaching and Teacher Education, 3(1), 61-64.

Green, M. F. (2000). Toward comprehensive internationalization: An ACE initiative for undergraduate education. Washington, DC: American Council on Education.

Green, M. F. (2007). Internationalizing Community Colleges: Barriers and strategies. New Directions for Community Colleges, 2007(138), 15-24.

Greene, M. (1988). Qualitative research and the use of literature. In R. R. Sherman \& R. B. Webb (Eds.), Qualitative research in education: Focus and methods (pp. 175189). London, UK: Falmer Press. 
Grove, C., \& Torbiörn, I. (1993). A new conception of intercultural adjustment and the goals of training. In Paige M. (Ed.). Education for the Intercultural Experience. Yarmouth, ME: Intercultural Press, pp. 73-108.

Grubb, N. W., \& Associates (1999). Honored but invisible: An inside look at teaching at community colleges. New York, NY: Routledge.

Gudykunst, W. B. (2002). Intercultural communication (2nd ed.). Thousand Oaks, CA: SAGE Publications.

Gudykunst, W. B. (2005). Anxiety/uncertainty management (AUM) theory of effective communication: Making the mesh of the net finer. In W. B. Gudykunst (Ed.). Theorizing about intercultural communication (pp. 281-349). Thousand Oaks, CA: SAGE Publications.

Gudykunst, W. B., \& Kim, Y. Y. (Eds.). (1992). Communicating effectively with strangers. New York: McGraw-Hill, Inc.

Guerin, S. H. (2009). Internationalizing the curriculum: Improving learning through international education: Preparing students for success in a global society. Community College Journal of Research and Practice, 33, 611-614.

Gurin, P. (1999). Expert report of Patricia Gurin. In Gratz, et al. v. Bollinger, et al., The compelling need for diversity in higher education, No. 97-75231 (E.D. Mich.), and Grutter, et al. v. Bollinger, et al. No. 97-75928 (E.D. Mich.). Ann Arbor: University of Michigan. Retrieved from http://diversity.umich.edu/admissions/legal/expert/gurintoc.html 
Gurin, P., Day, E., Hurtado, S., \& Gurin, G. (2002). Diversity in higher education: Theory and impact on student outcomes. Harvard Educational Review, 72(3), $330-366$.

Guy, T.C. (2002). Black Immigrants of the Caribbean: An invisible and foreign community. Adult Learning, 12(4), 18-21.

Hall, E. T. (1959). The silent language. Greenwich, Conn.: Fawcett Publications, Inc.

Hammer, M. R. (1998). A measure of intercultural sensitivity. The Intercultural Sourcebook, 2, 61-72

Hammer, M. R. (2009). The intercultural development inventory (IDI): An aproach for assessing and building intercultural competence. In M. A. Moodian (Ed.), Contemporary leadership and intercultural competence (pp. 203-218). Thousand Oaks, CA: SAGE Publications.

Hammer, M. R. (2011). Additional cross-cultural validity testing of the Intercultural Development Inventory. International Journal of Intercultural Relations, 34(4), 474-487.

Hammer, M. R., \& Bennett, M. J. (2001). Intercultural Development Inventory. Portland, OR: Intercultural Communication Institute:

Hammer, M. R., Bennett, M. J., \& Wiseman, R. (2003). A measure of intercultural sensitivity: The intercultural development inventory. International Journal of Intercultural Relations, 27, 421-443. 
Hammer, M. R., Gudykunst, W. B., \& Wiseman, R. L. (1978). Dimensions of intercultural effectiveness: An exploratory study. International Journal of Intercultural Relations, 2, 382-393.

Han, H. S., Vomvoridi-Ivanovic, E, Jacobs, J., Karanxha Z., Lypka, A., Topdemir, C., \& Feldman, A. (2014). Culturally responsive pedagogy in higher education: collaborative self-study. Studying Teacher Education, 10(3), 290-312.

Hannigan, T. P. (1990). Traits, attitudes, and skills that are related to intercultural effectiveness and their implication for cross-cultural training: A review of the literature. International Journal of Intercultural Relations, 14(1), 89-111.

Harbour, C. P., \& Ebie, G. (2011). Deweyan democratic learning communities and student marginalization. New Directions for Community Colleges, 155, 5-14.

Hartley, C. C., \& Petrucci C. J. (2004). Practicing culturally competent therapeutic jurisprudence: A collaboration between social work and law. Journal of Law \& Policy, 14, 133-182.

Helms, S. M. (2003). The examination of cultural sensitivity and exhibition of cultural competence for faculty at liberal arts institutions within higher education (Doctoral dissertation). Retrieved from Dissertations and Theses database. (UMI No. 3107769).

Hofstede, G. (2012). Dimensionalizing cultures: The Hofstede model in context. In L. A. Samovar, R. E. Porter \& E. R. McDaniel (Eds.), Intercultural communication: A reader (13th ed., pp. 19-33). Boston, MA: Cengage Learning. 
Hogan, M. (2008). A tale of two Noras: How a Yup'ik middle schooler was differently constructed as a math learner. Diaspora, Indigenous, and Minority Education, 2(2), 1-25.

Howard-Hamilton, M. F. (2000). Creating culturally responsive learning environment for African American students. New Directions for Teaching and Learning, 82, 4553.

Hu, S., \& Kuh, G. D. (2003). Diversity experiences and college student learning and personal development. Journal of College Student Development, 44(3), 320-334.

Hurtado, S. (2001). Linking diversity and educational purpose: How diversity affects the classrom environment and student development. In G. Orfield (Ed.), Diversity challenged. Evidence on the impact of affirmative action (pp. 187-203).

Cambridge, MA: Harvard Education Publishing Group.

Hurtado, S. (2005). The next generation of diversity and intergroup relations of research. The Society for the Psychological Study of Social Issues, 61(3), 595-610.

Hurtado, S. (2007). Linking diversity with the educational and civic missions of higher education. The Review of Higher Education, 30(2), 185-196.

Ignash, J. M. (2000). Linguistic diversity, immigration, and today’s undergraduates: Demographics. In J. W. Rosenthal (Ed.), Handbook of undergraduate second language education (pp. 3-28). Mahwah, NJ: Lawrence Erlbaum.

Johnson, D. M. (1992). Approaches to research in second language learning. New York, NY: Longman,. 
Johnson, K., \& Inoue, Y. (2003). Diversity and multicultural pedagogy. Journal of Research in International Education, 2(3), 251-276.

Kanu, Y. (2007). Increasing school success among Aboriginal students: Culturally responsive curriculum or macrostructural variables affecting schooling? Diaspora, Indigenous, and Minority Education, 1(1), 21-41.

Kim, Y.Y. (1988). Communication and cross cultural adaptation: An interdisciplinary approach. Clevendon, Avon, England: Multilingual Matters.

Kim, Y. Y. (1992). Intercultural communication competence:A systems-theoretic view. In W. B. Gudykunst \& Y. Y. Kim (Eds.), Readings on communicating with strangers (pp. 371- 381). New York: McGraw Hill, Inc.

Kim, Y. Y., \& Gudykunst, W. B. (1988). Cross cultural adaptation: Current approaches. Newbury Park, CA: SAGE Publications.

Kim, Y. Y., \& Ruben, B. (1992). Intercultural transformation. In W. B. Gudykunst \& Y. Y. Kim (Eds.), Readings on communicating with strangers (pp. 401-414). New York: McGraw Hill, Inc.

King, A. (2002). Structuring peer interaction to promote high-level cognitive processing. Theory into Practice, 41(1), 33-39.

Kitano, M. K. (1997). What a course will look like after multicultural change. In A. I. Morey \& M. K. Kitano (Eds.), Multicultural course transformation in higher education: A broader truth (pp. 18-34). Needham Heights, MA: Allyn \& Bacon.

Knight, J. (2007). Internationalization brings important benefits as well as risks. International Educator, 16(6), 59-62. 
Koltai, L. (1993). Community colleges: Making winners out of ordinary people. In A. Levine (Ed.), Higher learning in America, 1980-2000 (pp. 100-113). Baltimore: Johns Hopkins.

Kramp, M. K. (2004). Exploring life and experience through narrative inquiry. In K. deMarais \& S. D. Lapan (Eds.), Foundations of research (pp. 03-11). Mahvah, NJ: Lawrence Erlbaum Associates.

Kroeber, A. L., \& Kluckhohn, C. (1952). Culture: A critical review of concepts and definitions. Cambridge, MA: The Museum of American Archaeology and Ethnology, Harvard University.

Kupka, B., Everett, A., \& Wildermuth, S. (2007). The rainbow model of intercultural communication competence: A review and extension of existing research. Intercultural Communication Studies, 6(2), 18-36.

Laird, T. F. N., Engberg, M. E., \& Hurtado, S. (2005). Modeling accentuation effects: Enrolling in a diversity course and the importance of social action engagement. The Journal of Higher Education, 76(4), 448-476.

Lavin, D. E. (2000). Policy change and access to 2- and 4- year colleges: The case of City University of New York. The American Behavioral Scientist, 43(7), 1139-1158.

Lee, A., Poch, R., Shaw, M., \& Williams, R. D. (2012). The need for intercultural competency development in classrooms. ASHE Higher Education Report, 38(2), 1-132. DOI: $10.1002 /$ aehe. 20002

Lee, L. (2008). The effect of ethnic identity and bilingual confidence on Chinese youth's self-esteem. Alberta Journal of Educational Research, 54, 83-96. 
Lee, M., \& Sheared, V. (2002). Socialization and immigrant students' learning in adult education programs. New Directions for Adult and Continuing Education, 96, 2736.

Legrain, P. (2004). Open world: The truth about globalization. Chicago, IL: Ivan R Dee. Levin, J. S. (2002). Global culture and community college. Community College Journal of Research and Practice, 26(2), 121-145.

Light, R. (2001). Making the most of college: Students speak their minds. Cambridge, MA: Harvard University Press.

Linder C., Harris, J.C., Allen, E. L., \& Hubain, B. (2015). Building inclusive pedagogy: Recommendations from a national study of students of color in higher education and students affair graduate programs. Equity and Excellence in Education, 48(2), 178-194.

Locke, D. C. (1988). Teaching culturally-different students. Growing pine trees or bonsai trees? Contemporary Education, 59(3), 130-133.

Lustig, M. W., \& Koester, J. (2003). Intercultural competence: Interpersonal communication across cultures (4th ed.). Boston, MA: Pearson.

Marshall, P.L. (1996). Multicultural teaching concerns: New dimensions in the area of teacher concerns research. The Journal of Educational Research, 89(6), 371-379.

Marin, P. L. (2000). The educational possibility of multi-racial/multi-ethnic college classrooms. Washington, DC: AAUP.

Martin, J. N., \& Nakayama, T. K. (2009). Intercultural communication in contexts (5th ed.). New York, NY: McGraw Hill. 
Mayhew, M. J., \& DeLuca Fernandez, S. D. (2007). Pedagogical practices that contribute social justice outcomes. Review of Higher Education, 31(1), 55-80.

Mayo, J. R., Murguia, E., \& Padilla, R. V. (1995). Social integration and academic performance among minority university students. Journal of College Student Development, 36(6), 542-551.

Maxwell, J. A. (2005). Qualitative research design: An interactive approach ( $2^{\text {nd }}$ ed.). Thousand Oaks, CA: SAGE Publications.

McDaniel, E. R., Samovar, L. A., \& Porter, R. E. (2012). Using intercultural communication: The building blocks. In L. A. Samovar, R. E. Porter \& E. R. McDaniel (Eds.), Intercultural communication: A reader (13th ed., pp. 4-19). Boston, MA: Cengage Learning.

Mendoza, P., Basham, M. J., Campbell, D. F., O'Daniels, T. M., Malcolm, Z., \& Felton, S., (2009). Mission, values, and "flying monkeys": Critical issues for community colleges today and in 2019. Community College Journal of Research and Practice, 33, 866-882.

Merriam, S. B. (1998). Qualitative research and case study applications in education. San Fransisco: Jossey-Bass.

Moore, W. (2006). Behind the open door: Racism and other contradictions in the community college. Victoria, BC, Canada: Trafford Publishing.

Murray, J. P. (2001). Professional development in publicly supported two-year colleges. Community College Journal of Research and Practice, 25, 487-502. 
National Center for Education Statistics (2008). Community colleges. Retrieved from http://nces.ed.gov/programs/coe/analysis/2008-index.asp

Nevarez, C., \& Wood, L. J. (2010). Community college leadership and administration. New York, NY: Peter Lang Publishing, Inc.

Noddings, N. (1986). Fidelity in teaching, teacher education, and research for teaching. Harvard Educational Review, 56(4), 496-510.

Oliver, D. G., Serovich, J. M., \& Mason, T. L. (2005). Constraints and opportunities with interview transcription: Towards reflection in qualitative research. Social Forces, 84(2), 1273-1289.

Ortiz, A. M. (2000). Expressing cultural identity in the learning community: Opportunities and challenges. New Directions for Teaching and Learning, 82, 6779.

Paige, M. R. (1993). Education for the intercultural experience. Yarmouth, ME: Intercultural Press.

Pascerella, E., \& Terenzini, P. (2005). How college affects students, Volume 2: A third decade of research (2nd ed.). San Francisco, CA: Jossey-Bass

Patton, M.Q. (2002). Qualitative research and evaluation methods ( $3^{\text {rd }}$ ed.). Thousand Oaks, CA: SAGE Publications.

Quaye, S. J., \& Harper, S. R. (2007). Faculty accountability for culturally inclusive curricula. Liberal Education, 93(3), 32-29.

Raby, R. L. (2007). Internationalizing the curriculum: On-and-off-campus strategies. New Directions for Community Colleges, 138, 57-66. 
Rankin, S. R., \& Reason, R. D. (2005). Differering perceptions: How students of color and white students perceive campus climate for underrepresented groups. Journal of College Student Development, 46(1), 44-61.

Rendon, L. I., \& Valadez, J. R. (1993). Qualitative indicators of Hispanic student transfer. Community College Review, 20(4), 27-37.

Rhoads, R. A., \& Valadez, J. R. (1997). Democracy, multiculturalism, and the community college: A critical perspective. New York, NY: Garland.

Richards, H.V., Brown, A., \& Forde, T.B (2006). Addressing diversity in schools: Culturally responsive pedagogy. Tempe, Az: Arizona State University, National Center for Culturally Responsive Educational Systems.

Roberts, A. (2003). Proposing a broadened view of citizenship: North American teachers' service in rural Costa Rican schools. Journal of Studies in International Education, 7(3), 253-276.

Roper, L. D. (2004). Do students support diversity programs. Change, 36(6), 48-51.

Sanchez, I. M. (2000). Motivating and maximizing learning for minority students. In S. R. Aragon (Ed.), Beyond access: Methods and models for increasing retention and learning among minority students, 112, (pp. 35-44). San Francisco, CA: Jossey-Bass.

Sanderson, G. (2011). Internationalisation and teaching in higher education. Higher Education Research \& Development, 30(5), 661-676. 
Schuerholz-Lehr, S. (2007). Teaching for global literacy in higher education: How prepared are the educators? Journal of Studies in International Education, 11(2), 180-204.

Scisney-Matlock, M., \& Matlock, J. (2001). Promoting understanding of diversity through mentoring undergraduate students. New Directions for Teaching and Learning, 85, 75-84.

Singer, M. R. (1987). Intercultural communication: A perceptual approach. Englewood, NJ: Prentice-Hall.

Six, F. (2005). The trouble with trust: The dynamics of interpersonal trust building. Northhampton, MA: Edward Elgar Publishing.

Sleeter, C. (2001). Preparing teachers for culturally diverse schools: The overwhelming presence of Whiteness. Journal of Teacher Education, 52(2), 94-106.

Smith, D. G., \& Associates (1997). Diversity works: The emerging picture of how students benefits. Washington, D.C.: Association of American Colleges and Universities.

Spanier, G. B. (2001). The transformation of teaching. New Directions for Teaching and Learning, 85, 109-115.

Spaulding, S., Mauch, J., \& Lin, L. (2001). The internationalization of higher education. In P. O'Meara, H. D. Mehlinger \& R. M. Newman (Eds.), Changing perspectives on international education (pp. 190-211). Bloomington, IN: Indiana University Press. 
Spitzberg (2000). A model of intercultural communication competence. In L. Samovar \& R. Porter (Eds.), Intercultural Communication: A reader (9th ed., pp. 375-387). Belmont, CA: Wadsworth.

Spitzberg, B. H., \& Changnon, G. (2009). Conceptualizing intercultural competence. In D. K. Deardorff (Ed.), The SAGE Handbook of Intercultural Competence (pp. 252). Thousand Oaks, CA: SAGE Publications.

Spitzberg, B. H., \& Cupach, W. R. (1984). Interpersonal communication competence. Beverly Hills, CA: SAGE Publications.

Stearns, P. N. (2009). Educating global citizens in colleges and universities: Challenges and opportunities. New York, NY: Routledge.

Stewart, V. (2007). Becoming citizens of the world. Educational Leadership, 64(7), 8-14.

Stoll, M. (1995). What is multicultural education? Community College Journal, 65(3), pp. 11-15.

Tatum, B. (2000). The ABC approach to creating climates of engagement on diverse campuses. Liberal Education, 86(4), 22-32.

Thrilling, B., \& Fadel, C. (2009). 21st Century skills: Learning for life in our times. San Fransisco, CA: Jossey-Bass.

Timpson, W. M., Yang, R., Borrayo, E., \& Canetto, S. S. (2005). Practical tips for teaching diversity. Madison, WI: Atwood Publishing.

Ting-Toomey, S. (1993). Communicative resourcefulnes: An identity negotiation theory. In R. L. Wiseman \& J. Koester (Eds.), Theories in intercultural communication (pp. 72-111). Newbury Park, CA: SAGE. 
Ting-Toomey, S. (1999). Communicating across cultures. New York, NY: The Guilford Press.

Ting-Toomey, S., \& Chung, L. C. (2005). Understanding Intercultural Communication. New York, NY: Oxford University Press.

Townsend, B. K. (Ed.). (2000). Integrating nonminority faculty into the minority environment. San Fransisco, CA: Jossey Bass.

Twombly, S., \& Townsend, B. K. (2008). Community college faculty: What we know and what we need to know. Community College Review 36(1), 5-24.

Umansky, I., \& Reardon, S. (2014). Reclassification patterns among Latino English learner students in bilingual, dual immersion, and English immersion classrooms. American Educational Research Journal, 51, 871-912.

United States Census 2010 (2010). 2010 census data. Retrieved from http://2010.census.gov/2010census/data/

University of Michigan (2000). Fortune 500 corporations file brief in support of diversity in higher education (Press release). Retrieved from http://www.vpcomm.umich.edu/admissions/releases/fortune.html Villalpando, O. (2002). The impact of diversity and multiculturalism on all students: Findings from a national study. NASPA Journal, 40(1), 124-144.

Villegas, A. M., \& Lucas, T. (2002). Preparing culturally responsive teachers. Rethinking the curriculum. Journal of Teacher Education, 53(1), 20-32. 
Wallace, B. (2000). A call for change in multicultural training at graduate schools of education: Educating to end oppression and for social justice. Teachers College Record, 102(6), 1086-1011.

Weinstein, G., \& Obear K. (1992). Bias issues in the classroom: Encounters with the teaching self. New Directions for Teaching and Learning, 52, 39-50.

Wilson, R.A. (2007). Combining historical research and narrative inquiry to create chronicles and narratives. The Qualitative Report, 12(1), 20-39.

Wiseman, R. L. (2002). Intercultural communication competence. In W. B. Gudykunst \& B. Mody (Eds.), Handbook of international and intercultural communication. Thousand Oaks, CA: SAGE Publications.

Wong, M. S. (2006). Supporting diversity and internationalization through transformative learning experiences. Urbana, IL: Forum on Public Policy.

Zeszotarski, P. (2001). ERIC Review: Issues in global education initiatives in the community college context. Community College Review 29(1), 65-78. 


\section{APPENDIX A}

Participant:

\section{Interview Protocol}

Date:

Introduction:

The researcher will introduce herself and thanks the participant for accepting to be interviewed. She will remind the participant the purpose of the research and will reassure that all their responses will be kept strictly confidential and their identities will be kept confidential by using pseudonyms. She will also remind them that they will have an opportunity to read their comments once they are transcribed and make any changes if they feel any information is incorrect or misrepresented. She will ask permission to record the interview.

Questions

1. How long have you been teaching?

- How long have you been teaching at MHCC?

2. What led you to become a teacher? Please explain.

- Why did you choose to teach at the college level?

3. What is the area of your expertise?

4. Can you describe the typical make up of your class in terms of cultural diversity?

- When you design a syllabus for a particular course, how, if any, do you take into consideration your students' backgrounds? Can you give specific examples?

5. How do you select curriculum materials? 
- Does the potential make up of you students play any role in those selections?

- If yes, how do your students cultural backgrounds affect the decisions you make in terms of selecting curriculum, materials? Can you give specific examples?

- If no, can you explain why not?

6. Do your students' backgrounds affect how you deliver course content?

- If yes, how do your students backgrounds matter in your teaching?

- Can you give any examples of any specific activity or activities you use in your class that you think work well with culturally diverse students?

- If not, why not?

7. When students finish your class, what skills and abilities do you want your students to have?

8. In your teaching, is it important for your students to develop an understanding and appreciation for people from other cultures?

- If yes, can you tell me why it is important?

- How does your class facilitate this process?

- If no, can you explain why not?

The researcher will thank the participant and remind him/her that they will be emailed the IDI link soon and it should take about 20 minutes to complete. Remind the participant that he/she can take it at his/her own convenience. 


\section{APPENDIX B}

\section{Statement of Informed Consent}

\section{An Exploration of Effective Community College Instructors' Use of Culturally Competent Pedagogies}

You are invited to participate in a research study conducted by Aylin Bunk, a doctoral candidate at Portland State University, Graduate School of Education. The researcher hopes to learn what specific culturally competent pedagogies that effective community college instructors use and the reasons behind choosing these pedagogies. This study is being conducted in partial fulfillment of the requirements for a doctoral degree under the supervision of Dr. Becky Boesch, Assistant Professor, Educational Leadership and Policy, at PSU. You were selected as a possible participant in this study because you received either Distinguished Teaching Award or Faculty Award for Excellence in Teaching in your workplace.

If you decide to participate, you will be asked to 1) take an online Intercultural Development Inventory (IDI) which takes approximately 20 minutes to complete; and 2) be interviewed for 45-60 minutes. In the interview you will be asked to verbally answer the questions asked by the researcher. The entire interview will be recorded. While participating in this study, if you may choose not to answer any questions you are not comfortable with or withdraw any time. Audiotapes of interviews will be fully transcribed by the researcher. You will have an opportunity to review the transcripts and suggest any necessary revisions, changes, or clarifications to the transcript in order to insure that the transcripts accurately reflect your responses. All data and records will be kept on file in a secure place by the researcher for three years, and then will be destroyed after the study is completed.

Your participation in this study will inconvenience you by taking up a small amount of your time, but it does not involve any potential dangers or risks. You may not receive any direct benefit from taking part in this study, but the study may help to increase knowledge which may help others in the future.

Any information that is obtained in connection with this study and that can be linked to you or identify you will be kept confidential. Your name and identity will be kept completely confidential. This information will be kept confidential by using pseudonyms in the dissertation report. The audio taped recording of your voice will be erased following the completion of the study.

Your participation is voluntary. You do not have to take part in this study, and it will not affect your relationship as an instructor with Mt. Hood Community College. You may also withdraw from this study at any time without affecting your relationship with MHCC. 
If you have questions or concerns about your participation in this study, contact Aylin Bunk . If you have concerns about your rights as a research subject, please contact Research and Strategic Partnerships, Market Center Building $6^{\text {th }}$ floor, Portland State University, (503) 725-4288.

Your signature indicates that you have read and understand the above information and agree to take part in this study. Please understand that you may withdraw your consent at any time without penalty, and that by signing, you are not waiving any legal claims, rights, or remedies. The researcher will provide you with a copy of this form for your own records.

Signature Date

\section{Print name}

